University of Louisville

ThinkIR: The University of Louisville's Institutional Repository

Electronic Theses and Dissertations

$5-2010$

\title{
The effect of student attributes and program characteristics on doctoral degree completion.
}

\author{
Glenn Allen Gittings \\ University of Louisville
}

Follow this and additional works at: https://ir.library.louisville.edu/etd

\section{Recommended Citation}

Gittings, Glenn Allen, "The effect of student attributes and program characteristics on doctoral degree completion." (2010). Electronic Theses and Dissertations. Paper 502.

https://doi.org/10.18297/etd/502

This Doctoral Dissertation is brought to you for free and open access by ThinkIR: The University of Louisville's Institutional Repository. It has been accepted for inclusion in Electronic Theses and Dissertations by an authorized administrator of ThinkIR: The University of Louisville's Institutional Repository. This title appears here courtesy of the author, who has retained all other copyrights. For more information, please contact thinkir@louisville.edu. 
THE EFFECT OF STUDENT ATTRIBUTES AND PROGRAM CHARACTERISTICS

ON DOCTORAL DEGREE COMPLETION

\author{
By \\ Glenn Allen Gittings \\ B.A., University of Louisville, 2000 \\ M.A.E., Western Kentucky University, 2002
}

\author{
A Dissertation \\ Submitted to the Faculty of the \\ Graduate School of the University of Louisville \\ and \\ Graduate Studies and Research at Western Kentucky University \\ In Partial Fulfillment of the Requirements \\ for the Degree of
}

\begin{abstract}
Doctor of Philosophy
Department of Leadership, Foundations, and Human Resource Education University of Louisville and

College of Education and Behavioral Sciences

Western Kentucky University
\end{abstract}

May 2010 

THE EFFECT OF STUDENT ATTRIBUTES AND PROGRAM CHARACTERISTICS

ON DOCTORAL DEGREE COMPLETION

By

Glenn Allen Gittings

B.A., University of Louisville, 2000

M.A.E., Western Kentucky University, 2002

A Dissertation Approved on

March 11, 2010

by the following Dissertation Committee:

Dissertation Chair, Dr. Jay Fiene

Dr. Ric Keaster

Dr. Aaron Hughey

Dr. Kathleen Rudasill

Dr. Amy Hirschy 


\section{DEDICATION}

I wanted to take the opportunity in this small space to acknowledge the support of some very important people in my life. Both my parents and my wife stood by me through this entire process and deserve the appropriate recognition. From their humble beginnings, my parents agreed to devote all their efforts to allow their children to achieve beyond what they themselves could only imagine. They wanted us to reach for a level of achievement that would open up a lifetime of opportunities for ourselves and the generations to follow. My brother and I knew from an early age that going to college was not only a possibility, but a foregone conclusion. Education, in their belief was our path to opportunity. My parents worked multiple jobs and sacrificed many creature comforts in life in order to finance a private catholic education for both of their children. They continued this tireless support and work to not only get us through our undergraduate degrees, but to instill the belief, the dream, the opportunity, and the desire to reach the highest levels of educational attainment.

They never made it feel like a burden, or something that was forced. My brother and I ultimately fulfilled their dreams, by his completion of a Doctor of Chiropractic and my completion of a Ph.D. But they did not limit their support only to their sons. My parents also became ardent supporters of both of their daughter-in-laws. They, without hesitation or reservation, did whatever was needed to stand behind both Tara and Jen and see them through to the completion of their undergraduate degrees. 
When I look back on the entire duration of this degree, I realize that I have been a doctoral student for over five years and that my wife and I will celebrate our 5-year anniversary on October 1, 2010. Throughout our engagement and entire marriage I have been in the pursuit of this doctoral degree. With that acknowledgment, comes a realization that this was not a singular sacrifice and achievement. My wife Jennifer was there with me in the beginning when I interviewed in Elizabethtown to be admitted to the program, when I had assigned reading during our honeymoon, through the semesters of lonely evenings while I was at class, and the weekends consumed with studying. She tolerated the many late nights I spent writing my dissertation with our dogs Topper and Marley at my feet. She may not have always been happy with the sacrifices, and at times I know she was fed up with the circumstances, but she stayed by my side and saw me through to the end of this degree. These are the intangible things that are not described in the wedding vows, but embody a strong and dedicated spouse. Jen, you mean the world to me, and thank you for travelling down this journey with me and following it through to completion.

Therefore it is with years of hard work, endless late nights of reading, researching, and writing that I dedicate my dissertation to my wife Jen and to my parents Larry and Jennie. To my wife Jen, I look forward to building a long and happy life and finally having the time to just be together without having to put ourselves on the back burner. Congratulations Mom and Dad, now both of your sons, Dr. Scott Gittings and Dr. Glenn Gittings, achieved the dreams you set forth early in our lives. 


\section{ACKNOWLEDGEMENTS}

Although the achievement of this doctoral degree took individual dedication and continued effort, there are others that supported me along the way and in fact carried me through the completion of my Ph.D. To my committee, Dr. Jay Fiene, Dr. Aaron Hughey, Dr. Ric Keaster, Dr. Kathleen Rudasill, and Dr. Amy Hirschy, thank you for the guidance and wisdom throughout this entire process. Dr. Fiene, you are a champion for your students and your level of dedication and support to bringing a doctoral student through the process and to completion is unmatched. Dr. Hughey, you have been there for my entire graduate career and I wanted to thank you for your guidance, camaraderie, and friendship. Without the individual contributions of my dissertation committee and their dedication as a whole, this dissertation could not have become something for me to be proud to call my own.

To Dr. Jerry Wilder, thank you for your guidance and encouragement to start my doctoral degree. You have quietly but consistently followed and supported my path throughout graduate school and you will leave an indelible mark on my career in higher education.

To Beth Knight and her entire staff in the WKU library, including Selina Langford, thank you for your tireless service to me and all WKU doctoral students. You and your staff were always there to assist me with my research. The dedication, positive and professional service, and willing attitudes cannot be measured simply in words. You 
and your staff are a very important piece of the puzzle in WKU doctoral student degree completion.

To Dr. Doug Smith, thank you for the inordinate amount of time you committed to helping me understand the process of data analysis and devoting multiple evenings, weekends, and time over holiday breaks to running the data analysis for my research. I was not even one of your doctoral students, yet you never once hesitated in assisting me, and time never seemed to be a factor while we worked on the analysis. If only an ounce of your spirit and student devotion could be given to any new professor, then they could at least begin with a strong foundation that may allow them to grow into a professor that can go beyond teaching and actually make a lasting impact on their students.

To the two sets of doctoral cohorts that I belonged to throughout this process, thank you for your continued support and understanding. Dr. James McCaslin, Dr. Winnie Cohron, Dr. Dana Simmons, Dr. Gary Houchens, and my fellow May 2010 graduate soon-to-be Dr. Ashley Chance were all passengers with me in this doctoral odyssey. Also to Pat Jordan, keep up the hard work, you are almost to the finish line. Whether it was multiple trips back and forth from Louisville or dinners once a month at Dr. Fiene's hoping for an "atta boy" this group made the lonely and daunting process something we could all share together. 


\section{ABSTRACT \\ The Effect of Student Attributes and Program Characteristics \\ on Doctoral Degree Completion \\ Glenn Allen Gittings}

May 8, 2010

More than a decade after the state of Kentucky enacted higher education reform that provided specific direction to the University of Kentucky and the University of Louisville, this research study sought to examine the effect of student characteristics and program characteristics on doctoral degree completion. This study attempted to address the following research questions: (1) Do certain student variables (age, ethnicity, gender, financial support, employment, marital status, dependents, distance from campus, debt load, employment status change after comprehensive exams, and enrollment status) affect doctoral student degree completion? and (2) Do program characteristics (graduate orientation programs, departmental assistance, social involvement, dissertation preparation courses, dissertation preparation seminars, clarity and understanding of academic program procedures/requirements, dissertation chair contact, academic involvement, support groups, and mentoring) affect doctoral student degree completion?

Study participants consisted of doctoral students that entered the University of Kentucky and the University of Louisville spanning the academic years of 1997-2003. Participants completed a survey administered online that was based primarily on the previous work of Vincent Tinto and his survey designed for the National Science Foundation (NSF) called the Doctoral Studies Questionnaire along with a nationally 
vetted instrument called the Survey of Earned Doctorates. Participants provided demographic data and responded to survey questions about their experiences with doctoral education through a series of Likert questions.

The results of the data were analyzed using logistic regression to determine if individual student characteristics and program characteristics influenced doctoral degree completion. The researcher also utilized Pearson Correlations and produced descriptive statistics. Based on the logistic regression results, a statistically significant relationship existed between the dependent variable doctoral degree completion and the independent variables of age, full-time employment, employment change after comprehensive exams, enrollment status, satisfaction with dissertation chair, and satisfaction with academic involvement.

Analysis found that enrollment status of the student and the increase of age of the respondent may have a positive influence on doctoral degree completion. Conversely employment status change after comprehensive exams and increased satisfaction with academic involvement indicated a negative relationship with doctoral degree completion. Finally, the variables of increased satisfaction with the dissertation chair and full-time employment of the respondents produced significant positive relationships with doctoral degree completion. 


\section{TABLE OF CONTENTS}

PAGE

DEDICATION ..................................................................................................... ii

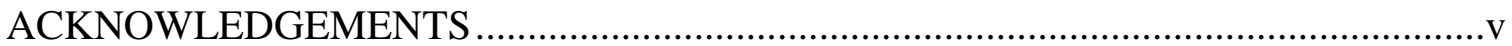

ABSTRACT ..................................................................................................... vii

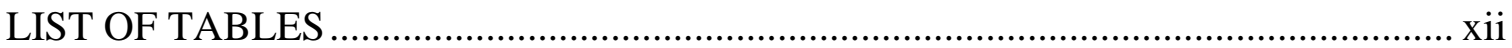

\section{CHAPTER}

\section{INTRODUCTION}

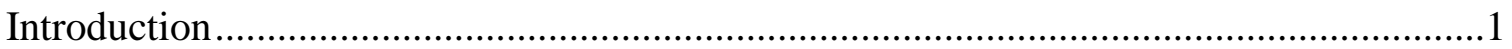

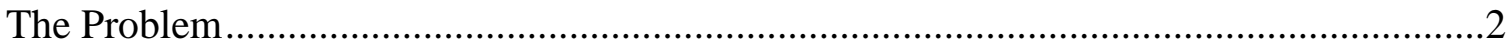

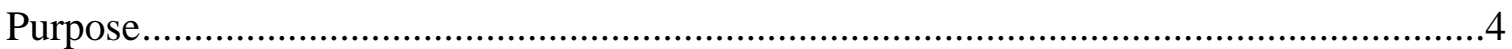

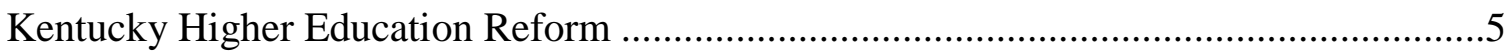

Doctoral Student Attrition Case Study …………….....................................................

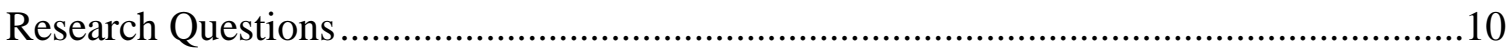

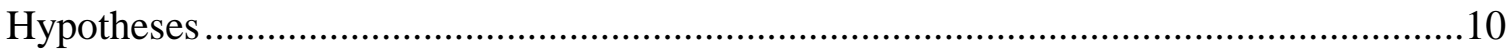

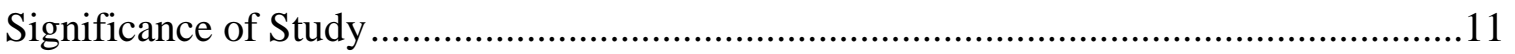

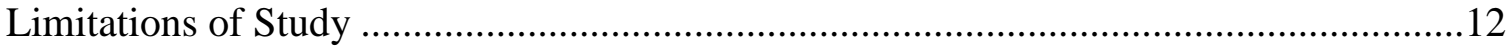

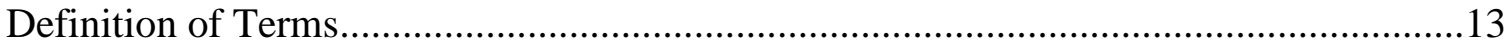

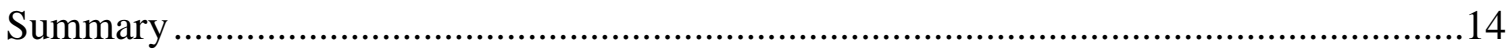

II. REVIEW OF THE LITERATURE

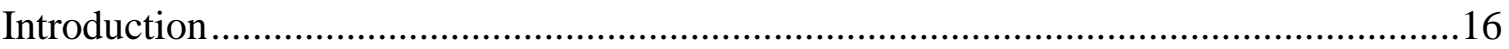


Theoretical Framework

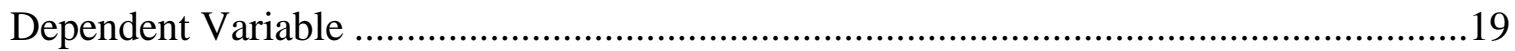

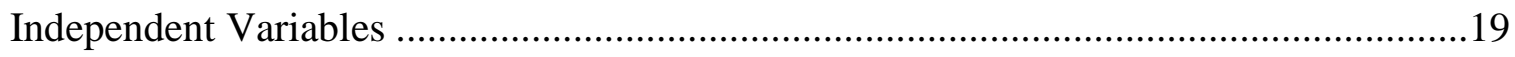

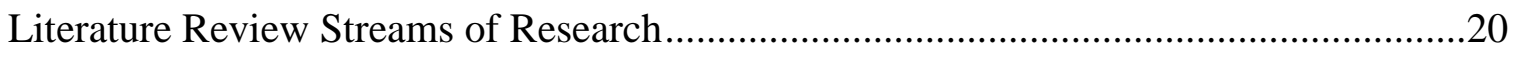

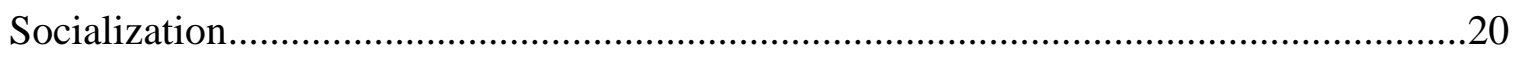

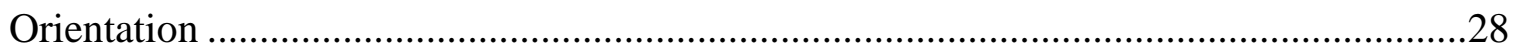

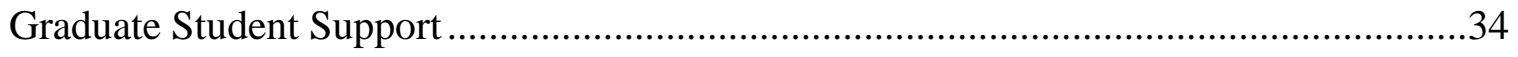

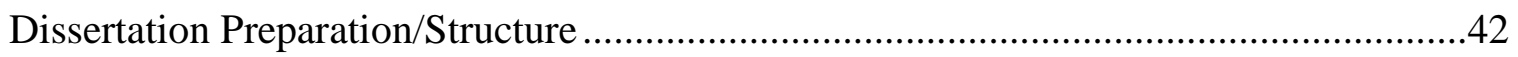

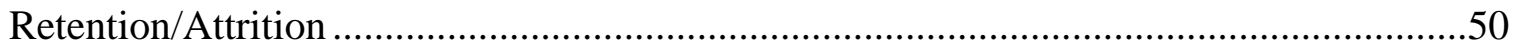

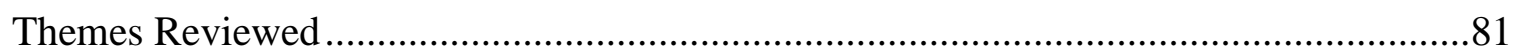

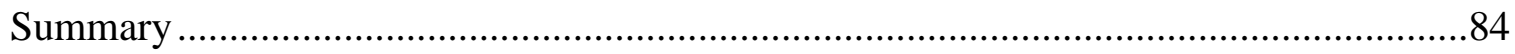

\section{METHODOLOGY}

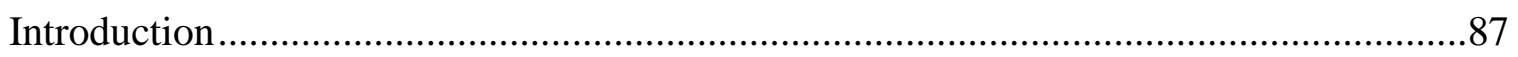

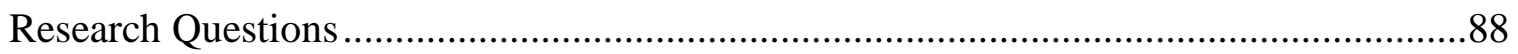

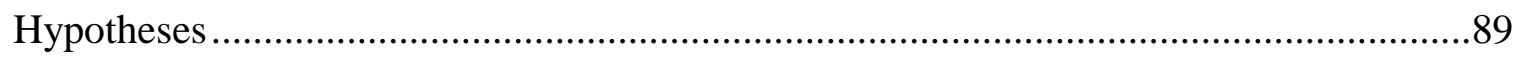

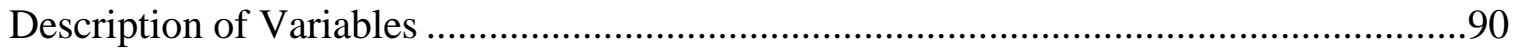

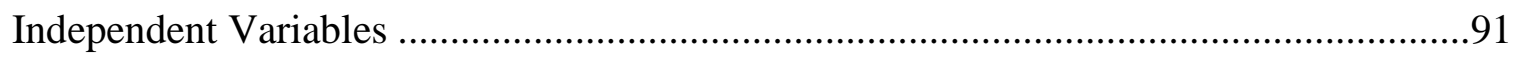

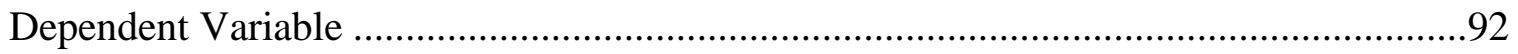

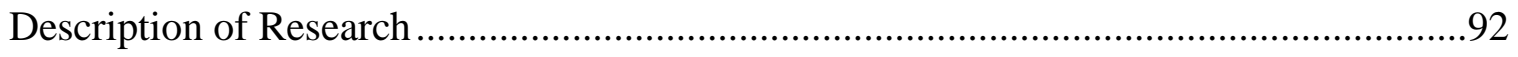

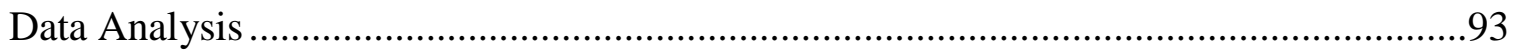

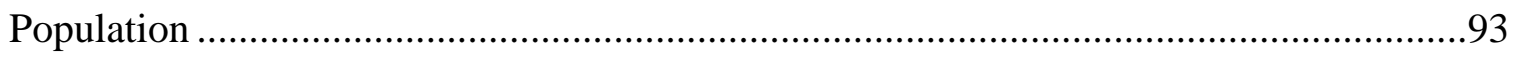

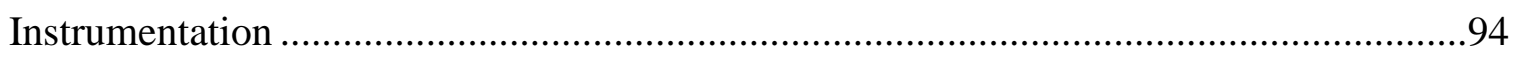

Validity and Reliability ..........................................................................................96

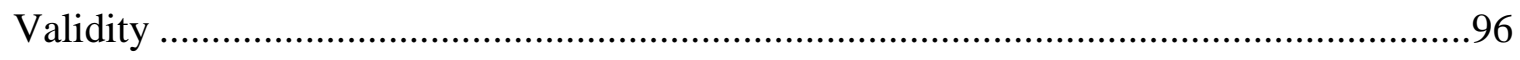


Content Validity

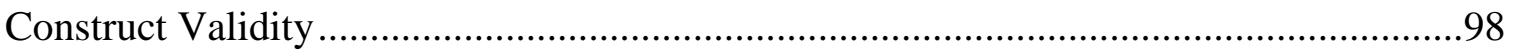

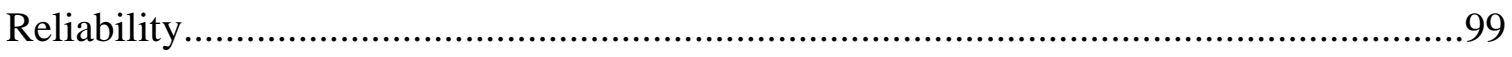

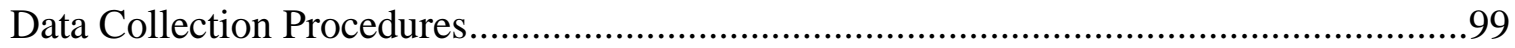

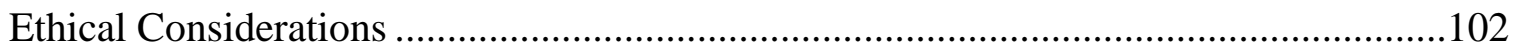

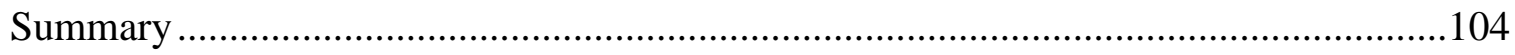

IV. RESULTS

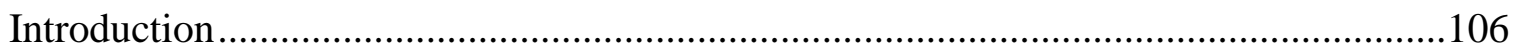

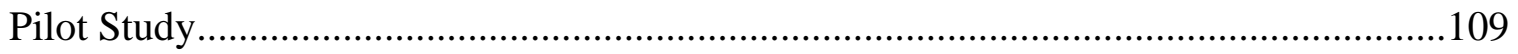

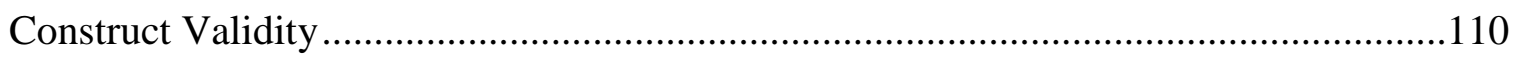

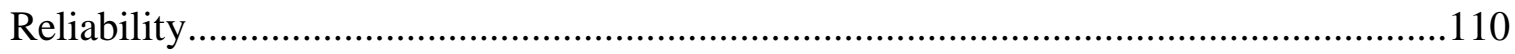

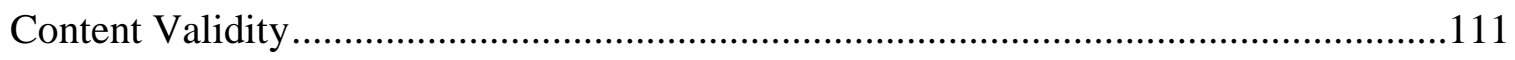

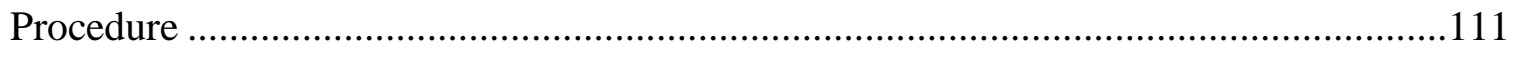

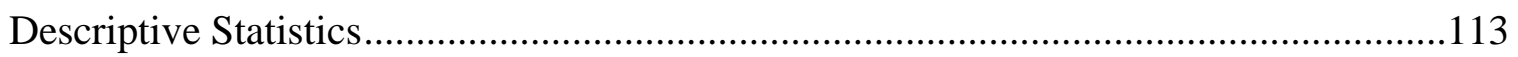

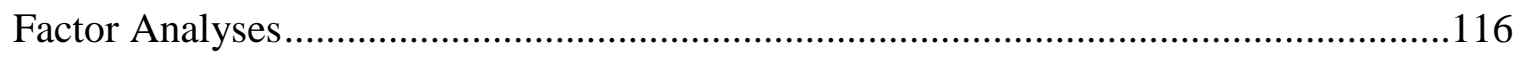

Research Questions ..............................................................................................122

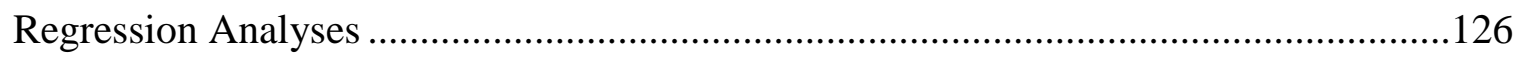

Initial Logistic Regression for Research Questions.......................................................127

Logistic Regression for Only Significant Variables ......................................................131

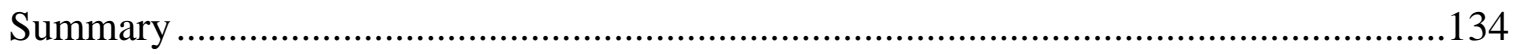

\section{DISCUSSIONS AND CONCLUSIONS}

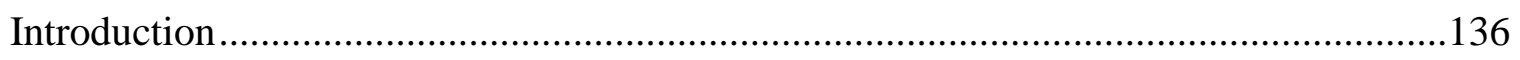

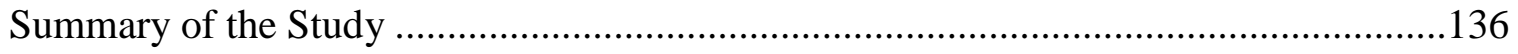

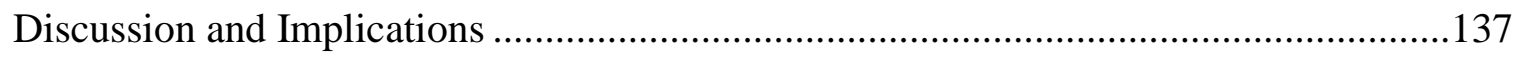


Research Question One

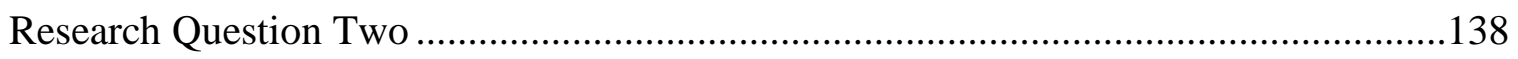

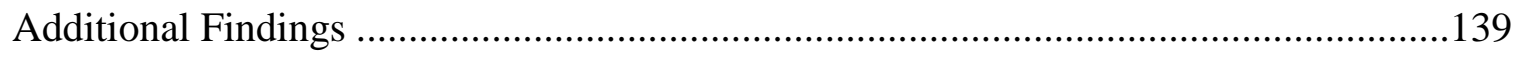

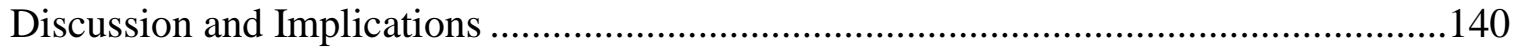

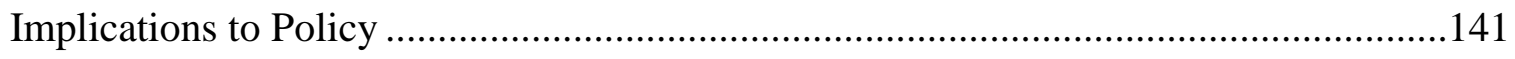

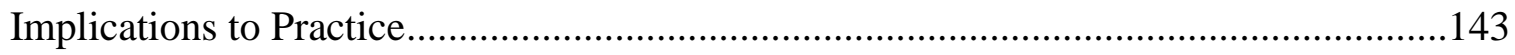

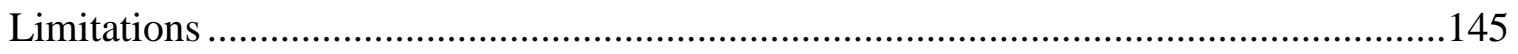

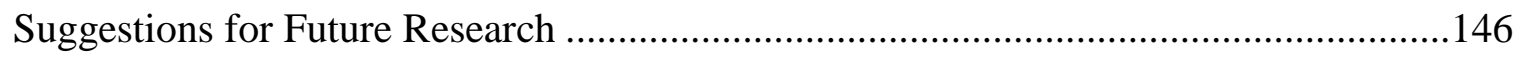

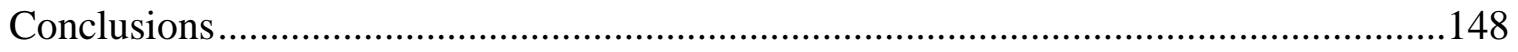

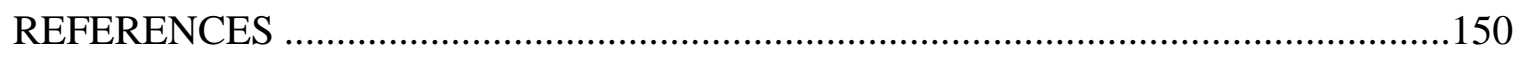

APPENDICES

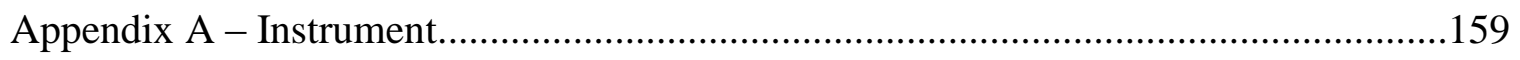

Appendix B - Data Usage Approval from University of Kentucky .............................179

Appendix C - Data Usage Approval from University of Louisville ...........................180

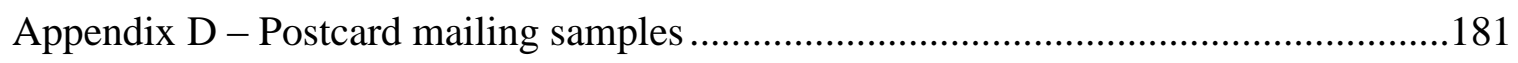

Appendix E - WKU Human Subjects Approval ..................................................183

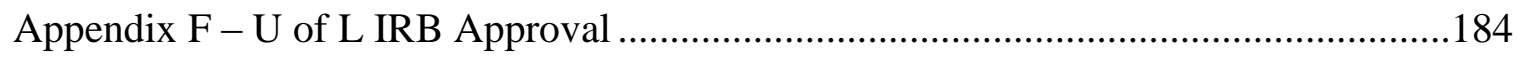

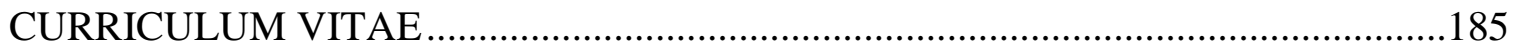




\section{LIST OF TABLES}

PAGE

\section{TABLE}

Table 1 - Participation Information: Institutions

Table 2 - Demographic Information: Gender, Ethnicity, and Ethnicity: White or Non-

White 114

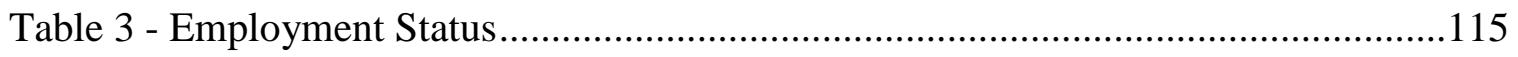

Table 4 - Enrollment Status ……………………………..........................................116

Table 5 - Pattern Matrix for Satisfaction with Departmental Assistance Scale................118

Table 6 - Pattern Matrix of Social Involvement …………........................................119

Table 7 - Factor Correlation Matrix for Social Involvement............................................119

Table 8 - Factor Matrix for Satisfaction of Program .....................................................120

Table 9 - Factor Matrix for Satisfaction of Chair …………........................................121

Table 10 - Factor Matrix of Satisfaction of Academic Involvement ..............................122

Table 11 - Correlations with Doctoral Degree Completion for All Variables Addressed in Research Question One for All Respondents ...................................................124

Table 12 - Correlations for Doctoral Degree Completion with all Variables Addressed in Research Question Two for All Respondents ....................................................126

Table 13 - Summary of Model Variables from Logistic Regression for Research Question One .129

Table 14 - Summary of Model Variables from Logistic Regression for Research Question Two .131

Table 15 - Overall Logistic Regression Model Fit for All Significant Variables 132 
Table 16 - Classification Table of Logistic Regression for All Significant Variables ....132

Table 17 - Summary of Model Variables from Logistic Regression for All Significant

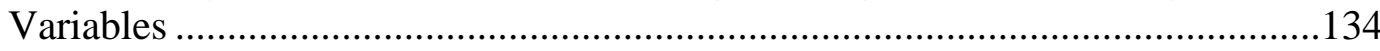




\section{CHAPTER I}

\section{INTRODUCTION}

Lovitts and Nelson (2000) surmised, "Forty years of studies suggest the long-term doctoral attrition rate nationwide is about 50\%" (p. 45). Doctoral students represent a highly educated and typically motivated group of students that have demonstrated the academic aptitude and personal characteristics to successfully complete multiple degrees, yet a large number are not completing the doctoral degree. Golde (1994) explained that, "Doctoral students are people who have generally succeeded at school. For some, choosing to leave graduate school can feel like the ultimate defeat by a system in which a student has always been successful" (p. 23). A misconception perpetuated by institutions is that doctoral students have navigated the educational waters of receiving a bachelor's degree and a master's degree and therefore should not need and do not want much guidance or assistance throughout the doctoral program.

Pontius and Harper (2006) asserted that institutions typically focus on undergraduate students and expend less effort engaging graduate and professional students. Doctoral education remains an evolving research setting that can be explored to further the knowledge base of understanding, not only concerning individual and institutional characteristics that contribute to doctoral attrition, but also with programmatic interventions that affect doctoral student completion rates. de Valero (2001) stated the following: 
Given the high costs associated with graduate education, the current national climate of diminishing resources for higher education, and an increased competition for these resources between undergraduate and graduate programs, understanding and examining the factors that affect the students' ability to complete their degree requirements in a timely manner and considering the implications of these factors becomes crucial. (p. 341)

According to Lampley (2001), "Factors such as decreased funding, slow enrollment growth, rising cost, increased competition, an increasing need for accountability, and a stronger sense of student consumerism, may force institutions of higher education to take a closer look at how they operate" (p. 13). Kluever and Green (1998) concluded the doctoral dissertation consists of independent activity that encompasses multiple hurdles to overcome and a variety of decisions to be made in order to complete the degree. Golde (1994) summarized that "Attrition cannot be seen as a discrete event, but rather, it is clearly a dynamic process, with antecedents, for some can be traced to expectations and goals formulated before enrolling" (p. 23).

\section{The Problem}

The National Science Foundation (1998, p. 1) stated, "The doctoral student is a precious resource in providing the new discoveries and expert knowledge essential to the nation's future.” Lipschutz (1993) suggested as faculty and graduate deans seek financial resources from government, foundations, and private sources, they need to justify their completion rates. Jacks, Chubin, Porter, and Connolly (1983) clarified graduate students that do not complete their education have always been around, yet little is known about them, their perceptions of the graduate education experience, and their assessment of their failure to complete and subsequent career choices. Golde (1994) stated, “One aspect of doctoral education that is often deplored but little studied is the high level of student 
attrition" (p. 1). Hatley and Fiene (1995) lamented that a significant number of talented doctoral students do not successfully complete the degree.

Jacks et al. (1983) stated the subject of doctoral students that never complete the dissertation has not been a topic for systematic study. Golde (1994) surmised that graduate and doctoral attrition is rarely published and most doctoral attrition research is only focused on individual doctoral student characteristics. Gillingham, Seneca, and Taussig (1991) explained that due to the years committed to completion of the doctoral degree and the sacrifice, measured by potential contributions to both doctoral students and society, is costly. Hatley and Fiene (1995) indicated ABD students "Pleaded for more structure, opportunity, encouragement, and mentoring” (p. 2). Kluever, Green, and Katz (1997) postulated at the doctoral level that attrition is damaging and costly for the student, faculty advisers, and the institution. Given the essential impact doctoral study has on research, education, leadership, policy, and professional practice, consistently high drop out rates remain inappropriate (Bair \& Haworth, 1999).

Malmberg (2000) suggested future research to determine the extent of interaction and influence of the factors affecting the degree progress of doctoral students and research into the value of doctoral student workshops and seminars designed to obtain and exchange information prior to completing coursework and prior to entering doctoral candidacy. Pauley (1998) indicated a need to examine the length of time to degree for the program and whether or not this variable affected attrition. Emerson (1998) encouraged research on the value of institutional support or programs designed to offer structure and/or guidance during the dissertation stage. Huguley (1988) recommended the need for institutions to develop departmental courses built into the program that structure the 
dissertation process for students. Lee (2003) suggested further research on the relationship with faculty mentors and the significance these relationships had on doctoral completion. Campbell (1992) also encouraged further research on the mentor-mentee relationship and the significance on doctoral completion.

Girves and Wemmerus (1988) concluded more research was needed concerning the type of graduate student financial support along with a further examination of the relationship between students and faculty at the graduate level. Gardner and Barnes (2007) assert more research concerning how various graduate disciplines encourage student involvement must occur. Globetti, Globetti, and Smith (1991) stated further study was needed to assess the graduate student population. Finally, Golde (1996) explained that it is time for candid discussions within departments and disciplines concerning the role of doctoral attrition and what are acceptable levels of doctoral attrition. Just as important a need is to discuss ways to remove potential barriers to doctoral student completion in order to help remedy some more common reasons for doctoral attrition.

\section{Purpose}

Researchers acknowledge and even lament that it is of considerable concern that such a small proportion of doctoral students stay the course and complete the degree (Berg \& Ferber, 1983). The investigator grounded the current study on two key thoughts of inquiry: (a) how to begin to diagnose, up front, individual characteristics that lead to success in doctoral study and completion of the doctoral degree, and (b) a desire to identify critical doctoral program components that lead to success in doctoral study and completion of the doctoral degree. The population for the study consisted of doctoral students across various departments that entered the University of Kentucky and the 
University of Louisville spanning the academic years of 1997-2003. Under the guidelines of survey construction and Web-based survey administration techniques provided by Dillman (2000) and Dillman, Smyth, \& Christian (2009), the researcher constructed and administered the instrument via the Internet utilizing the online survey design and administration company SurveyMonkey. The researcher based the study on suggested further research from other authors in the field (Campbell, 1992; Emerson, 1998; Gardner \& Barnes, 2007; Girves \& Wemmerus, 1988; Huguley, 1988; Lee, 2003; Malmberg, 2000). The purpose of this research was to predict and identify both individual doctoral student characteristics and doctoral program components that affected doctoral student degree completion.

\section{Kentucky Higher Education Reform}

The Kentucky General Assembly completely revamped higher education in the Commonwealth with the passage of the Postsecondary Education Improvement Act of 1997, commonly referred to as House Bill One (HB1). Since the inception of higher education reform in Kentucky in 1997 with HB1, both the University of Kentucky and the University of Louisville have been mandated to overhaul all aspects of their individual systems of postsecondary education. The plan cited the University of Kentucky and the University of Louisville, along with the regional universities and the newly created centralized community college system, as key tools in raising the educational level of the state of Kentucky in order to provide the opportunity for growth in a knowledge based economy.

A report from then governor of Kentucky Paul Patton in 1997 to the Task Force on Postsecondary Education identified dismal educational statistics, specifically doctoral 
student-related points. The Postsecondary Education report (State of Kentucky Task Force on Postsecondary Education, 1997) revealed in 1993 that Kentucky ranked in the bottom 20 of states for production of doctoral scientists and the bottom 12 of states for the production of doctoral engineers. This report also stated that "In 1996, the estimated doctoral degree production required for Kentucky to reach national averages needed to increase by $69 \%$ from the current 1996 level of 397 to the current 1996 national level of 672" (p. 24). According to this report, 1995-1996 figures indicated that 33\% of doctoral programs in the state of Kentucky were low performing programs that graduated fewer than three degrees per year. At the time of this investigation by the Task Force on Kentucky Postsecondary Education in 1996, Kentucky lacked any nationally recognized doctoral degree granting institutions and neither the University of Kentucky nor the University of Louisville had doctoral programs ranked in the top levels nationally. The report pointed out that at the time, the state appropriations for higher education in Kentucky did not provide incentive funding for national competiveness of research and graduate programs. The dismal statistics produced by this report led the Kentucky General Assembly to craft higher education reform goals. Specifically related to graduate education, the state believed that nationally prominent graduate and research programs could spur economic growth for Kentucky.

Based on the statistics and suggestions from the Postsecondary Education Assessment report in 1997, an agenda from then governor of Kentucky Paul Patton in 1997 to the Task Force on Postsecondary Education mapped out the entire plan of postsecondary education reform. Among the many other reforms, changes, and suggestions this report (Patton, 1997) mandated the University of Louisville and the 
University of Kentucky implement broad changes based on the reform that included the following:

University of Louisville will:

1. Become a metropolitan university with selected nationally-competitive research and graduate programs designed to enhance the regional economy.

2. Develop partnerships with the local community colleges and technical schools that are responsive to the needs of the region.

3. Provide the same services the regional universities provided to its assigned service area.

University of Kentucky will:

1. Perform as the state's flagship university.

2. Develop as a nationally-recognized center of excellence of academic study and research.

3. Be responsible, as the primary land-grant university, for statewide technology transfer for business and agriculture.

4. Attract the brightest students from Kentucky and across the world (p. 13).

HB1 mandated that the University of Kentucky become a Top 20 Public Research University by the year 2020. It also charged the University of Louisville to become a preeminent metropolitan research university over the same time frame (Patton, 1997). When HB1 mandated that the two institutions achieve national prominence, it included programs at all levels including doctoral. One specific metric of measurement of the state's achievement of these goals is graduate enrollments in the state of Kentucky and degrees and credentials earned. Among the many alterations that occurred due to the passage of this higher education reform, one focus centered on degree program and departmental systems and practices that could not only allow the University of Kentucky and the University of Louisville to become nationally recognized but also enroll, retain, and graduate more students at both the undergraduate and graduate levels. McGuiness (2002) explained that HB1 provided incentive funding linked to action agenda items focused on enrollment, retention, and graduation at all levels of education. By recruiting, 
retaining, and graduating more graduate and doctoral students, the two institutions will rise in the national rankings for specific programs and overall institutions (State of Kentucky Task Force on Postsecondary Education, 1997).

\section{Doctoral Student Attrition Case Study}

Attrition research is rich with examples from the realm of the undergraduate level. At the undergraduate level the students entering the institution of higher education bring a limited set of academic experiences and levels of preparation. Colleges and universities maintain highly divergent standards for admission that allow for all levels of students into the institution. With this in mind, there is a natural amount of attrition that will occur due academic inexperience, poor institutional acclimation, immaturity of the student due to age, and even poor pre-college preparation or pre-college academic ability. Tinto (1993) stated, "In most countries, the more selective the level of education, the higher the rate of completion, yet in the United States, the reverse is true" (p. 230).

At the graduate and even more specific, the doctoral level, of higher education, the admitted students have previously achieved at a level academically that allowed them to complete at least a bachelor's degree and more often than not a master's degree. Institutions select doctoral students that demonstrated the academic preparation to not only succeed previously in their academic endeavors, but that exude the skills and intelligence necessary to complete the academic requirements of a doctoral program.

Even with the academic credentials and preparation that students possess coming into a doctoral program, they are still not completing doctoral degrees at acceptable rates. Very little doctoral attrition research has focused on the individual student experiences and explanations for not completing a doctoral degree. The study below by Golde (1994) 
provided a detailed account of three doctoral students' experiences of dropping out of their doctoral programs at various points in his or her academic pursuits.

Golde (1994) conducted a qualitative study, drawn from a larger project on doctoral student attrition, that highlighted the educational experiences of doctoral students who did not complete their doctoral degrees. The participants in the study were doctoral students $(N=3)$ who left their doctoral studies at differing stages of the doctoral degree including after the first year, after 4 years of study, and a student completing all requirements but the dissertation. The respondents completed a 1-hour interview that consisted of chronicling the students' descriptions of the graduate school career and gaining the students' experiences of their doctoral careers.

Golde analyzed the data in search of emergent themes with a particular focus on the role of the departmental context. Four major themes emerged from the interview sessions concerning non-persisting doctoral student experiences: (a) opposing a common view that attrition serves a sorting purpose, the interviews indicated that the students demonstrated academic aptitude but could have continued their education with departmental intervention; (b) students inherently expected caring advisers and a social community and felt isolated when no community was found; (c) students reached out to someone in their departments about leaving; and (d) students all attempted diligently to navigate the structure of their departments and their own motives.

The Golde research sought to tell the story of attrition and explained that even the most capable of academically prepared doctoral students can and do fail to persist. Even though these students have succeeded at every academic level, they still inherently 
needed departmental assistance, faculty connection, student interaction, and clear and logical departmental structure to succeed.

\section{Research Questions}

The researcher sought to find influence of individual characteristics of doctoral students on doctoral degree completion, but also the influence of doctoral program characteristics on doctoral degree completion. Specific research questions were as follows:

1. Do certain doctoral student demographic variables (age, ethnicity, gender, financial support, employment, marital status, dependents, distance from campus, debt load, employment status change after comprehensive exams, and enrollment status) affect doctoral student degree completion?

2. Do doctoral program characteristics (graduate student orientation programs, departmental assistance, social involvement, dissertation preparation courses, dissertation preparation seminars, clarity and understanding of academic program procedures/requirements, dissertation chair contact, academic involvement, support groups, and mentoring) affect doctoral student degree completion?

\section{Hypotheses}

The following directional hypotheses were tested at the .05 level of significance:

$\mathrm{H} 1_{\mathrm{a}}$ : Students who are employed full-time will be less likely to complete the doctoral degree.

$\mathrm{H} 2_{\mathrm{a}}$ : Students who experience an employment status change after comprehensive exams will be less likely to complete the doctoral degree.

$\mathrm{H} 3_{\mathrm{a}}$ : Students who are enrolled part-time will be less likely to complete the doctoral degree.

$\mathrm{H} 4_{\mathrm{a}}$ : Students who are satisfied with the departmental assistance available will be more likely to complete the doctoral degree.

H5a: Students who are satisfied with the opportunity for social involvement during their doctoral degree will be more likely to complete the doctoral degree. 
H6 ${ }_{\mathrm{a}}$ : Students who are satisfied with the clarity and understanding of academic procedures/requirements within their program will be more likely to complete the doctoral degree.

H7 $7_{\mathrm{a}}$ : Students who are satisfied with the dissertation chair contact will be more likely to complete the doctoral degree.

$\mathrm{H} 8_{\mathrm{a}}$ : Students who are satisfied with the opportunities for academic involvement within their program will be more likely to complete the doctoral degree.

\section{Significance of Study}

Research on doctoral student degree completion continues to be an important focus for institutions of higher education. Researchers have consistently reported national doctoral completion rates at just barely at or above 50\% (Astin, 1997; Bair \& Haworth, 1999; Bauer, 2004; Cook \& Swanson, 1978; de Valero, 2001; Dorn \& Papalewis, 1997; Ehrenberg \& Mavros, 1995; Golde, 2001; Green \& Kluever, 1997; Kluever, 1997; Lee, 2003; Lovitts, 2004; Lovitts \& Nelson, 2000; Malmberg, 2000; Nerad \& Miller, 1996; Wynn, 2003). Polson (2003) suggested that investment in opportunities that help graduate students transition into their new roles were more likely to retain graduate students through degree completion. Researchers suggested departments invest resources in coursework and student programs centered on training for the dissertation process, career roles, and addressing student concerns (Golde \& Dore, 2001; Hatley \& Fiene, 1995; Kluever et al., 1997; Lampley, 2001).

The current study attempted to build upon and add to the research literature by determining individual and doctoral program characteristics that may contribute to or impede doctoral student degree completion. The researcher narrowed the focus of the study to the University of Kentucky and the University of Louisville since these institutions are the dominant doctoral degree granting institutions in the state of Kentucky 
and due the higher education reform legislation that sought an overhaul in the entire educational structure and culture at these two institutions.

This information could be significant to institutions of higher education, specific academic departments within the institutions, graduate faculty, doctoral degree program designers, and doctoral students. The information gained in this study could also benefit the programmatic and departmental practices at both the University of Kentucky and the University of Louisville. If specific individual characteristics or departmental programmatic interventions/coursework contribute to, or detract from doctoral student degree completion, the previously mentioned groups would benefit from the knowledge in order to implement structure or behaviors that would contribute to doctoral student degree completion. Doctoral degree completion will likely never get to $100 \%$, but characteristics, structures, and programming that contribute to higher degree attainment could assist in raising the overall percentage of doctoral degree completion.

\section{Limitations of Study}

This study only addressed doctoral students at two institutions (University of Kentucky \& University of Louisville) of higher education in the state of Kentucky. Limiting the sample to only two institutions within the state of Kentucky, may not allow results to be generalized to other institutions across the state of Kentucky and in fact across the United States. The sample of this study was limited to students who entered doctoral study between the years of 1997-2003 at the University of Kentucky and the University of Louisville. Limiting the sample to only a specified 6-year time period did not encompass the entire population of doctoral students that have enrolled at any time period in the history of the institutions. The use of non-experimental research methods 
did not allow the researcher to manipulate or control the independent variables and can therefore only provide correlations based on observations and measurements (Vogt, 2005). The participants completed the survey online. The online environment provides for greater access to a population at a lower cost but reduces the ability of the researcher to control the conditions in which the survey is administered.

\section{Definition of Terms}

Terms that were used throughout this study will have operational definitions listed in this section.

$A B D$ : All But Dissertation (ABD) refers to a student who has completed all coursework, comprehensive exams, residency requirements, and other requirements but has not completed the dissertation.

Attrition: The voluntary or involuntary discontinuance of a student's participation in the degree program prior to degree completion (Malmberg, 2000, p. 14).

Comprehensive exams: Examination taken upon completion of all doctoral coursework, designed to allow the student to demonstrate the understanding of relevant knowledge within a specific academic discipline. Completion of the comprehensive exam allows the student to begin the final step of the Ph.D., the dissertation.

Dissertation committee: A committee of graduate faculty that provide expertise and guidance on both the dissertation topic and the overall structure and composition of the dissertation. Typically the dissertation committee consists of multiple graduate faculty members and is led by the dissertation chair who provides overall guidance and responsibility for the dissertation. 
Dissertation preparation course: Any seminar or academic program course designed to assist doctoral students in the conceptualization, design, layout, and writing of the dissertation.

Doctoral student degree completion: Successful completion of all coursework, comprehensive examinations, and requirements and thereby graduation from the doctoral program.

Mentor: A guide or counselor who provides personal support.

Persistence: A student continuing progress toward doctoral degree completion.

\section{Summary}

Decades of research have focused on all the variables and components that factor into undergraduate students and their attrition/persistence behavior, yet only a minor amount of research has focused beyond the undergraduate level to the graduate and even the doctoral level. With a national economy that has bottomed out and a country trying to dig out of a recession, higher education funding has experienced prolonged and sometimes severe annual reductions. With federal, state, and private funding sources continuing to dwindle, institutions must further depend on revenue streams provided by tuition from all graduate and doctoral students. In the state of Kentucky, Higher Education reform has mandated among other things that the University of Kentucky and the University of Louisville become nationally prominent in a multitude of areas, including doctoral education. The state pinned its hopes on the need for a better educated citizenship in order to embrace a knowledge based economy. It is imperative that doctoral degree completion remain a topic for investigation and institutional intervention in the state of Kentucky, at least until higher rates of completion become the norm. 
The current study attempted to understand individual and departmental characteristics and actions that may affect doctoral student degree completion. Chapter Two reviews research studies of the topic of student attrition/persistence and more specifically doctoral student attrition/persistence. To address the research questions the researcher developed a survey instrument based on the work of Vincent Tinto and his survey designed for the National Science Foundation (NSF) called the Doctoral Studies Questionnaire along with a nationally vetted instrument called the Survey of Earned Doctorates to assess student perceptions of their personal and departmental level experiences with their doctoral education. Through the use of logistic regression, the researcher explored the relationship between individual doctoral student characteristics and departmental characteristics unique to each doctoral student as they relate to doctoral degree completion. The investigator then explored the relationship of various demographic variables as they relate to doctoral degree completion. Chapter Three outlines the overall methodologies employed in the current study. Chapter Four consists of the reporting of the data gathered and analysis of the results. Finally, the implications of the results concerning policy and practice along with suggestions for further research are discussed in Chapter Five. 


\title{
CHAPTER II
}

\section{REVIEW OF THE LITERATURE}

\author{
Introduction
}

The research in this study attempted to diagnose and identify both individual student characteristics and program components that affect doctoral student completion rates. Research on doctoral attrition/persistence has highlighted many areas of concern into the causes and solutions why doctoral students succeed and fail. Cusworth (2001) noted that the graduate experience is a great, unaddressed academic issue within higher education. The researcher sought to find any influence of student attributes, program attributes, and institutional attributes on doctoral student completion rates. The investigator included the theoretical framework which guided and structured the research. This chapter includes the independent variables utilized in the study and indentified previous use of those variables in research. The literature reviewed in this chapter is categorized by the following subsections: (a) socialization, (b) graduate student

orientation programs, (c) graduate student support, (d) dissertation preparation programming, and (e) retention/attrition.

\section{Theoretical Framework}

In 1975, Vincent Tinto addressed a need to further develop the literature on student persistence and withdrawal behavior at the undergraduate level. As Pascarella (1986) stated, "Tinto presented a major theoretical conceptualization of the student 
persistence or withdrawal process that has been the focus of substantial research" (p.

100). Tinto's undergraduate model sought to explain that various characteristics influence undergraduate student persistence. These concepts included background characteristics, initial commitments to the goal of college graduation, social and academic integration of student within the college, and subsequent commitments to the goal of college graduation. The model that Tinto developed, substantially contributed to the theoretical understanding of undergraduate student persistence and withdrawal behavior (Pascarella, 1986).

After decades of continued and substantial contribution to the topic of undergraduate persistence, Tinto offered the beginnings of a theory on doctoral student attrition in his 1993 influential book on undergraduate attrition. Tinto (1993) suggested that, "Graduate persistence is shaped by the personal and intellectual interactions that occur within and between students and faculty and the various communities that make up the academic and social systems of the institution" (p. 231). Tinto explained doctoral persistence, stating:

The process of doctoral persistence should be visualized as reflecting an interactive series of nested and intersecting communities not only within the university, but beyond it to the broader intellectual and social communities of students and faculty that define the norms of the field of study at a national level. The process of doctoral persistence seems to be marked by at least three distinct stages, namely that of transition and adjustment, that of attaining candidacy or what might be referred to as the development of competence, and that of completing the research project leading to the awarding of the doctoral degree. (pp. 234-235).

Within this influential book published in 1993, Tinto further attempted to develop a longitudinal model of graduate persistence (See Figure 1), but quickly cautioned that the process of graduate persistence cannot be easily described by one simple model. 


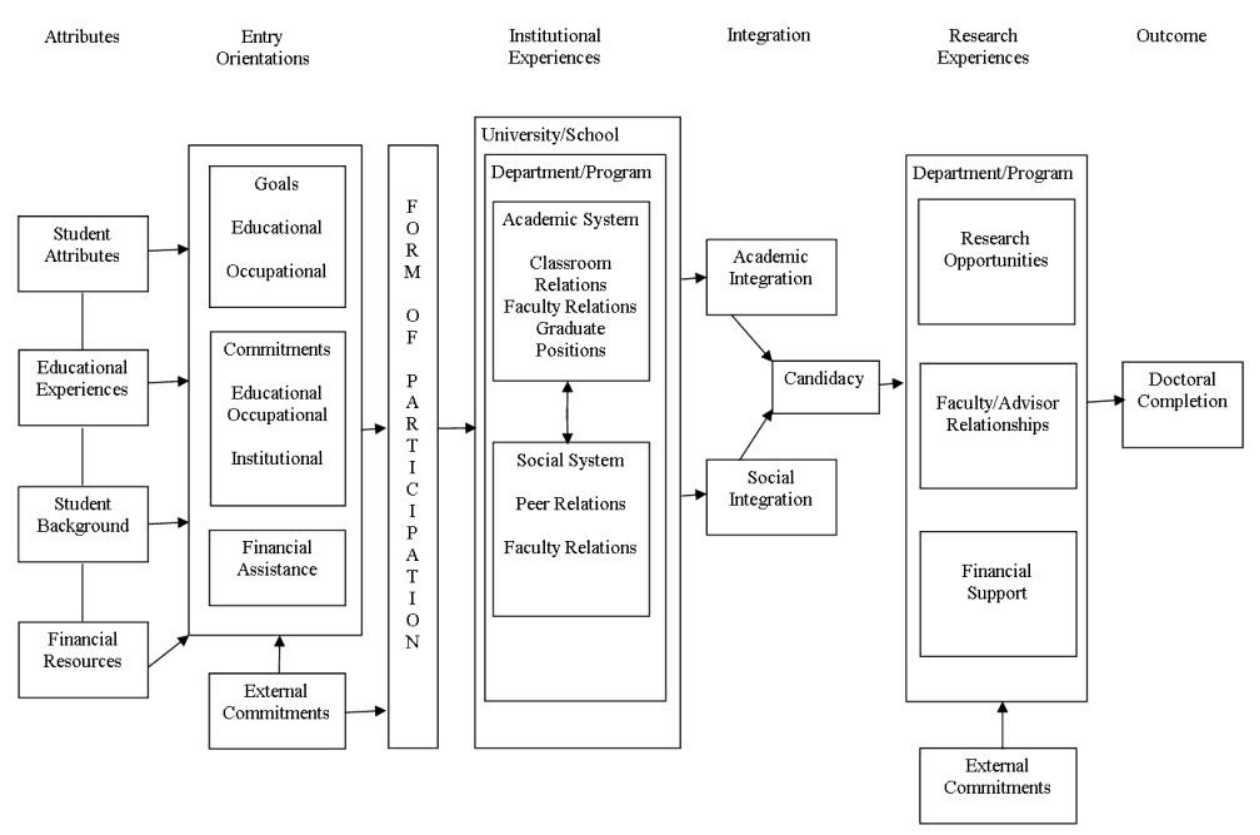

Tinto postulated that factors of importance to attrition included: student attributes, entry goals and orientation, institutional and program experiences, academic and social integration into a program, and research experiences (Kluever, Green, \& Katz, 1997). Tinto, notably defined several components of the model, including (a) student attributes (gender, age, race, ability, individual educational experiences, and social class); (b) external commitments (work and family responsibilities); (c) individual goals (educational and career); (d) commitments (goal and institutional); (e) financial resources (type and amount of financial aid); and (f) participation in graduate school (full- or parttime attendance and on- or off-campus residence). The model and theory of doctoral persistence posited by Tinto, is in no way offered as a rigid formula that serves as the 
only method in which to study doctoral student retention/attrition. Tinto's work on doctoral persistence, rather, offers the opportunity to guide research with tools that help provide a frame of reference and allow for evaluation. Therefore, based on this theoretical framework, the researcher sought to address the variables that may serve to assist or detract a doctoral student with degree completion.

\section{Dependent Variable}

Based on prior research utilization, the researcher used doctoral degree completion as a single defined method of measuring doctoral student progress (Bauer, 2004; Campbell, 1992; Dorn \& Papalewis, 1995; Dorn \& Papalewis, 1997; Emerson, 1998; Hatley \& Fiene, 1995; King \& Chepyator-Thompson, 1996; Leadabrand, 1985; Lovitts, 2004; Malmberg, 2000; Pauley, 1998; Stallone, 2003, Tinto, 1993)

\section{Independent Variables}

When designing the instrument for the NSF, Tinto utilized his theory on doctoral persistence as well as incorporated research that built upon his initial doctoral persistence theory in 1993. The independent variables used were either included in the Tinto (1993) model or the Tinto designed NSF instrument, utilized in prior research, suggested in various research to have influence in the overall experience of the pursuit and experience of attaining a doctoral degree, or designed based on research findings on variables that effect doctoral degree completion. The independent variables in this study were grouped in two key factors, and within each factor the variables are further defined as more specific measurable attributes.

Individual doctoral student characteristic variables:

1. Age (Abedi \& Benkin, 1987; Bair \& Haworth, 1999; Campbell, 1992; Huguley, 1988; Lee, 2003; Malmberg, 2004; Pauley, 1998; Tinto, 1993). 
2. Ethnicity (Abedi \& Benkin, 1987; Bair \& Haworth, 1999; Huguley, 1988; Lee, 2003; Malmberg, 2004; Tinto, 1993).

3. Gender (Abedi \& Benkin, 1987; Bair \& Haworth, 1999; Huguley, 1988; Lee, 2003; Malmberg, 2004; Pauley, 1998; Tinto, 1993).

4. Financial Support (Abedi \& Benkin, 1987; Ethington \& Smart, 1999; Lee, 2003; Pauley, 1998; Tinto, 1993).

5. Employment (Lee, 2003; Tinto, 1993).

6. Marital Status (Abedi \& Benkin, 1987; Huguley, 1988; Lee, 2003; Malmberg, 2004; Pauley, 1998; Tinto, 1993).

7. Dependents (Abedi \& Benkin, 1987; Bair \& Haworth, 1999; Lee, 2003; Pauley, 1998; Tinto, 1993).

8. Distance From Campus (Hatley \& Fiene, 1995; Kluever, Green, \& Katz, 1997; Wagner, 1986; Wright, 1991).

9. Debt Load (Gillingham, Seneca, \& Taussig, 1991).

10. Employment Status Change After Comprehensive Exams (Hatley \& Fiene, 1995).

11. Enrollment Status (Bair \& Haworth, 1999; Lee, 2003; Seagram, Gould, \& Pyke, 1998; Tinto, 1993).

Doctoral Program Characteristic variables:

1. Orientation (de Valero, 2001; Kluever Green, \& Katz, 1997).

2. Departmental Assistance (Lee, 2003; Lovitts, 2004; Pauley, 1998; Tinto, 1993).

3. Social Involvement (Dorn \& Papalewis, 1995; Ethington \& Smart, 1986; Golde, 2005; Leadabrand, 1985; Lee, 2003; Pauley, 1998; Tinto, 1993).

4. Dissertation Preparation Courses (Hahs, 1998; Kluever, Green, \& Katz, 1997).

5. Dissertation Preparation Seminars (de Valero, 2001; Hahs, 1998; Kluever, 1997).

6. Clarity and Understanding of Academic Program Procedures/Requirements (Lovitts, 2004; Weidman \& Stein, 2003).

7. Dissertation Chair Contact (Campbell, 1992; Lee, 2003; Lovitts, 2004; Malmberg, 2004; Pauley, 1998; Tinto, 1993; Wagner, 1986).

8. Academic Involvement (Ethington \& Smart, 1986; Golde, 2005; Lee, 2003; Tinto, 1993).

9. Support Groups (Hatley \& Fiene, 1995; Kluever, Green, \& Katz, 1997).

10. Mentor (Dorn \& Papalewis, 1995; King \& Chepyator-Thompson, 1996).

\section{Literature Review Streams of Research}

\section{Socialization}

The studies addressed in this section explain the issues of the student experience when beginning a new college career. The encounters, which graduate students commonly experience, occur when students become socialized and integrated into the 
culture of the institution. The socialization of the student involves a transition into a new career and a new set of values based on the chosen field of study. As Tinto explained in his theory, doctoral students are shaped by the various types of interactions between various individuals at multiple social layers within the institution. Doctoral students are socialized while shifting into a new responsibility and will develop new academic, social, and institutional needs based on adjustment to the student's new institutional and departmental culture. The socialization of the graduate student includes the understanding of institutional and departmental culture held by the student and faculty when considering student role, expectations, and support. Both students and faculty can harbor perceptions, sometimes negative, about the socialization experience of becoming a new graduate student.

Gottlieb (1961) conducted a study to assess the extent faculty-student socialization influences effect changes in career orientations of graduate students. Gottlieb utilized data from the National Opinion Research Center's sample of graduate students. The researcher selected the participants through a two-stage stratified cluster sample of graduate students $(N=2,842)$ from 25 American graduate schools. The participants ranked their preference of items located in the following four categories: (a) career preferences, (b) level of integration with faculty, (c) faculty value climate, and (d) specific encouragement. Gottlieb found a large portion of graduate students reported a change in their career preferences. The investigator discovered the more integrated a student was with the faculty, the more likely the student would change career preference. Gottlieb determined that single-minded departments produced the greatest amount of changers towards research than do eclectic departments. 
Winston (1976) assessed the perceptions of graduate students and faculty in relation to enrollment and departmental environments. The researcher sought to understand the graduate student environment in order to produce programmatic responses in reaction to the needed change indicated by graduate students. The participants in the Winston study responded to the Graduate Environmental Perception Scales (GEPS) instrument mailed to all entering graduate students, established graduate students, and faculty from the History, Psychology, and Counseling and Student Personnel Services departments at the University of Georgia. The participants $(N=180)$ in the Winston study rated perceptions and expectations in five sections. Winston found entering students had significantly unrealistic expectations that did not match those of continuing students or faculty. The researcher noted entering graduate students expected a much more intimate, personal, caring, and social character to their relationships with peers and faculty than was reported to exist in any department.

Kuh and Thomas (1983) examined whether graduate students experienced developmental transitions. The researchers grounded the study in a composite developmental framework of adult development theory. The participants in the study were randomly selected from a group of graduate students $(N=20)$ enrolled in the spring semester at a midwestern university. The research subjects in this study responded to questions that assessed developmental tasks while raters assessed behavioral patterns of the participants' responses.

The investigators' analysis demonstrated significant differences in behavioral patterns of adult students and younger students. A majority of older students' behavior patterns fit into a category of responsible adulthood, while almost $100 \%$ of the younger 
students' behavior patterns rested into categories of either novice adult or rethinking adulthood. Kuh and Thomas (1983) reported four themes that emerged from content analysis of students' responses: (a) redefinition of self, (b) purposeful independence, (c) exploration versus maintenance of a stable life pattern, and (d) the dream.

Corcoran and Clark (1984) conducted a study to assess the differences in socialization experiences and career attitudes that indicate career success for two groups of faculty. The researchers selected the study participants $(N=129)$ from one institution in two separate phases. The participants responded to 50 open-ended interview questions in the following areas: (a) the decision to pursue an academic career; (b) graduate school dimensions of career socialization; (c) career stages and socialization as a faculty member; (d) work interests and preference orientations; (e) dimensions of productivity and success; (g) morale, satisfaction, and perceptions of change; and (h) appraisals and future considerations.

Investigators determined most faculty decided to pursue a faculty career after the undergraduate experience and were influenced by both undergraduate and graduate faculty. The researchers indicated participants recognized the anticipatory socialization gained through both observation of faculty in their career roles and participation in teaching and research. Corcoran and Clark (1984) discovered the highly active faculty group utilized peer relations developed in graduate school both during school and after graduation to advance their careers. Researchers determined the highly active faculty benefited more professionally from relationships with advisers both during school and after graduation. 
Brown-Wright, Dubick, and Newman (1997) conducted a study to assess the level of congruence between graduate assistant (GA) role expectations and the expectations of them by the faculty. The researchers also investigated attitudes of faculty and graduate assistants concerning authorship and the perception of the need for GA training and mentorship. The participants $(N=223)$ in the Brown-Wright et al. study responded to separate survey instruments administered to graduate assistants $(n=151)$ and faculty members $(n=72)$ at a comprehensive, doctoral granting, urban university in the midwest. Participants ranked items that they considered most important in the role of a GA and responded to open-ended questions on the survey.

Brown-Wright et al. (1997) reported both graduate assistants and faculty highly ranked teaching strategies and techniques as an important training need. Researchers found both graduate assistants and faculty indicated that if the GA's assist with the analysis of the research data, they should be listed as an author. Brown-Wright et al. explained graduate assistants included responses to the open-ended questions with comments including initial orientation good idea, sent into the classroom cold, and follow-up orientation needed to be scheduled.

Nyquist et al. (1999) reported on a previous collaborative longitudinal study conducted by multiple authors. The researchers focused this study on the examination of how graduate students' understanding about becoming a faculty member changed throughout the graduate experience. The study participants were a purposive sample of graduate students $(N=99)$ at three universities who aspired to be college professors and held teaching assistantships. Participants responded to open-ended interview questions by reflecting on their experiences as graduate students and participating in focus groups. 
The researchers reported that after 4 years of the study a significant number of students did not wish to pursue a career in the professoriate. Nyquist et al. (1999) found three common themes concerning the graduate students' experiences: (a) graduate students experienced tension when adapting to the values embodied in higher education, (b) graduate students received mixed or ambiguous messages about priorities with academic values and the academic life, and (c) graduate students exhibited implicit and explicit pleas for support during their education.

Poock (2001) conducted a study to present a model used to assess professional development needs of graduate students. The study participants were a purposive sample of current graduate students, recent alumni, junior faculty, directors of graduate studies or chairs of departments, and employers who recruit at the university. The participants $(N=$ 97) in the study either took part in a focus group or responded to a survey of structured and open-ended questions.

Overall, Poock (2001) reported that participants believed that all graduate students should develop common core professional development skills. Poock identified five key professional development themes needed by graduate students: (a) communication, (b) leadership, (c) teaching and instruction, (d) professional adaptability, and (e) self-awareness. The researcher indicated the importance of including the five themes in an overall model of professional development offered to graduate students. Austin (2002) based an article on a previous collaborative longitudinal study conducted by multiple authors. The researcher focused this study on the examination of doctoral education as socialization for the professoriate. The investigator undergirded the research through the lens that described socialization as a systematic process in which 
students constructed their individual roles through interaction and engagement with others. The study participants were a purposive sample of graduate students $(N=79)$ in various disciplines (humanities, sciences, social sciences, professional) at two universities who aspired to be college professors and held teaching assistantships. Participants responded to open-ended interview questions that asked the students to reflect on their experiences as graduate students.

Austin (2002) found several personal factors influenced individual experiences and development in graduate school: (a) age, (b) educational background, (c) family situation, (d) previous employment, (e) student's locus of control, (f) student's sense of self-efficacy, and (g) ability to make connections with people and opportunities. Austin determined important aspects of the socialization process involved (a) observation, (b) listening, (c) interaction with faculty, (d) interaction with peers, and (e) interaction with family and friends. The researcher found that participants noted five needs or recommendations for improvement of graduate education: (a) more attention to regular mentoring, advising, and feedback; (b) structured opportunities to observe, meet, and talk with peers; (c) diverse, developmentally oriented teaching opportunities; (d) information and guidance concerning the full scope of faculty responsibilities; and (e) regular and guided reflection.

Weidman and Stein (2003) conducted a study to assess the informal socialization of doctoral students to the academic norms of research and scholarship. The researchers undergirded the concepts and variables tested with the Weidman, Twale, and Stein (2001) framework of graduate and professional student socialization. The participants in the study were doctoral students $(N=50)$ in the sociology department and department of 
educational policy and administration at a major research university. The participants responded to a mailed questionnaire that assessed characteristics of socialization of graduate students. Weidman and Stein found students' perceptions of being in a supportive faculty environment and departmental collegiality were associated with student scholarly encouragement. The researchers determined that perceptions of being in a supportive faculty environment were associated with collegiality among the departmental faculty and student-faculty interaction. Weidman and Stein determined that students' perception of the clarity and understanding of departmental norms were important to the student experience.

The most significant general findings discovered by the above studies related to incoming graduate student perceptions on expectations being unrealistic (Winston, 1976) and the finding that graduate students reported positive career changes and career affirmations related to stronger integration with faculty during their transition into the department (Corcoran \& Clark, 1984; Gottlieb, 1961; Nyquist et al., 1999; Winston, 1976). Researchers indicated socialization into graduate education produced opportunities to reflect on personal growth and development, understanding, and camaraderie (Kuh \& Thomas, 1983; Poock, 2001). Confirming concepts postulated by Tinto's doctoral student attrition theory, researchers found the key components needed to foster graduate student socialization were interaction with faculty, interaction with peers, and opportunities for observation and participation (Austin, 2002; Brown-Wright et al., 1997; Corcoran \& Clark, 1984; Poock, 2001). Students reported an emphasis on the development of personal/quality life goals when entering graduate education (Kuh \& Thomas, 1983). Nyquist et al. (1999) found that graduate students indicated a need for 
help in managing stress and anxiety of the new role. The understanding of departmental and career norms strongly associated with greater likelihood of doctoral student persistence (Weidman \& Stein, 2003). Furthering Tinto's thoughts on students developing career norms and belonging to nested communities, researchers indicated that graduate assistantships and teaching assistantships contributed to departmental and career socialization (Corcoran \& Clark, 1984).

\section{Orientation}

The studies addressed in this section reviewed the issues of general practices and effects of orientation on student adjustment. Orientation programs typically occur prior to the start of the new student's academic endeavor. Tinto's doctoral student attrition theory postulated that one of the stages of persistence included a time of initial transition and adjustment. Orientation programs serve to address perception, transition, and role acquisition that graduate students' experience. These topics addressed programmatic, structural, and policy concepts that surround graduate student orientation. Certain common practices occur in orientation programs at a variety of institutions. Universities offered orientations that contained distinctions as either campus-wide or departmental specific. Orientation programs serve as the initial organized experience that graduate students encounter as an incoming member at the institution.

Rosenblatt and Christensen (1993) conducted a study to assess the utility of a pilot graduate orientation program in the department of psychology at the University of Haverford. The pilot graduate orientation program attempted to address deficiencies and anxieties of new graduate students when entering the university. The participants in the study responded to the Graduate Student Orientation Survey (GSOS) given to all new 
graduate students $(N=14)$ who attended the orientation session. The respondents in the study rated the importance of orientation activities and answered open-ended questions, which ascertained strengths of the program and suggestions for improvement.

Rosenblatt and Christensen (1993) explained all participants found the program to be extremely helpful. The researchers reported students' unanimity when indicating positively that the program should be offered again. Rosenblatt and Christensen determined students noted that the information presented, the chance to meet faculty and students, and the chance to register for classes were all positive aspects of the program. Barker, Felstehausen, Couch, and Henry (1997) examined the perceptions of orientation programs among students aged 27 and older. The researchers surveyed a random sample of graduate students $(N=323)$ meeting the specified age criteria at Texas Tech University. The investigators developed the Graduate Student Orientation Inventory (GSOI) to measure demographics, orientation topics, orientation participation, and orientation format. The investigators found that age significantly affected the perceived importance of several orientation topics. Overall, researchers concluded participants would attend an orientation program and the majority indicated an orientation would be helpful.

Taub and Komives (1998) conducted a study to assess graduate student perceptions of the effectiveness and importance of the various components of the comprehensive orientation approach in the college student personnel (CSP) program at the University of Maryland. The goals of the CSP comprehensive orientation program allowed the students to assess themselves, the chosen professional field, and the institution for proper "fit." Participants in the study responded to a survey administered in 
the fall to the incoming class of CSP students $(N=15)$. The research subjects rated perceptions of the importance and the effectiveness of the various components of the comprehensive orientation approach.

Taub and Komives (1998) reported respondents indicated no difference in their perceptions of importance and their perceptions of effectiveness on most items. The participants rated the entire Preview Program as extremely important. Researchers found students indicated the following key elements that were important in the preview program: meeting faculty, meeting advisers, meeting classmates, and receiving Preview Program mailings and assistantship information. Taub and Komives indicated students rated the admissions interview and the buddy system as very important.

Poock and Love (2001) conducted a study to assess important factors that influenced students' decisions to attend the current university and how those factors varied by age, enrollment status, gender, and race. The researchers based the study on the final phase of the selection process explained by Hossler and Gallagher's model of college choice. The participants in the study were doctoral students $(N=180)$ from 24 randomly selected institutions across the United States enrolled for at least one term in higher education administration programs. The participants responded to the Program Choice Questionnaire by assessing factors that influenced enrollment based decisions. The researchers indicated faculty relationships including friendliness, positive interaction, and unsolicited contact were important factors that influenced program choice. Poock and Love (2001) determined social influences including personal life, professional life, and academic life strongly influenced students' decisions to attend a 
program. Investigators noted a number of results varied significantly when comparing by groups based on race, age, and enrollment status.

Poock (2002) conducted a study to determine if orientation needs of graduate students were best met through departmental or campus-wide efforts. The participants in the study responded to the Graduate Orientation Assessment Questionnaire (GOAQ) mailed to all new graduate students $(N=208)$ who attended the campus-wide orientation programs at the University of North Carolina at Chapel Hill in the fall of 1999 or 2000. The respondents in the study rated the importance of orientation-related activities and whether those activities were best provided by department or campus-wide orientation programs.

Poock (2002) noted five important findings: (a) respondents viewed both campuswide and departmental orientations as important; (b) many of the highest rated orientation activities addressed academic information; (c) respondents felt that orientation activities related to personal considerations (health care services, public transportation) and university services (health center, career services, parking services) were best met by the campus-wide orientation; (d) respondents felt that social activities (meeting new and current students) and academic information were best delivered through departmental orientations; and (e) respondents indicated a clear willingness to arrive on campus several days prior to the beginning of classes to participate in orientation activities.

Coulter, Goin, and Gerard (2004) conducted a study to assess academic needs of graduate students and perceived role in graduate student organizations in meeting their expressed needs. The participants in the study responded to a survey mailed to all graduate students $(N=31)$ enrolled in a Child and Family Studies department from a 
large land-grant institution. The research subjects responded to an open-ended question about the role graduate student organizations played in delivering student needs and ranked their interest in activities.

Coulter et al. (2004) indicated the highest ranking of graduate student needs centered on the area of orientation to graduate life with respect to resources for conducting research and general resources available to students provided by the university. The authors identified five distinct themes from the coding of the open-ended question: (a) communication, (b) orientation, (c) research opportunities, (d) physical space, and (e) technological resources. The qualitative findings supported the quantitative results in that items rated as most important were the resources that needed to be communicated to students during orientation.

Poock (2004) assessed the content and method of delivery of campus-wide graduate orientation programs offered by colleges and universities nationwide. The respondents $(N=191)$ in the study responded to an online questionnaire emailed to all members of the Council of Graduate Schools. The investigator reported the vast majority of respondents (73\%) offered some form of campus-wide orientation. The researcher explained the majority of respondents $(60 \%)$ indicated the cost for orientation was paid by the Graduate School at the institution. Poock determined the most common components of the orientation were institutional policies, student services available, computer facilities, libraries, and healthcare topics. The investigator noted $91 \%$ of the respondents offered the program in the fall semester or quarter, $56 \%$ of the respondents indicated the program lasted a half day, and $75 \%$ of the respondents indicated they had between one and 400 participants. 
The most significant general findings discovered by the above studies included: (a) graduate students indicated a need for services and orientation activities to help understand university resources and meet academic and educational objectives (Rosenblatt \& Christensen, 1993); (b) time to meet faculty and other students when transitioning were positive opportunities to orientation programs (Poock, 2002; Rosenblatt \& Christensen, 1993; Taub \& Komives, 1998); and (c) graduate students perceived orientations were needed for the improvement of the graduate experience (Coulter et al., 2004). Research explained that a majority of graduate students perceived an orientation program would be helpful and that they would attend (Barker et al., 1997; Rosenblatt \& Christensen, 1993). Orientations allowed students time to meet faculty and classmates and provided needed information (Taub \& Komives, 1998). Graduate students viewed orientations as important and were willing to arrive early to campus prior to the semester to attend an orientation (Barker et al., 1997; Poock, 2002). Investigators explained the most common components of orientation included awareness of institutional policies, student services, and academic facilities and resources available to students (Poock, 2002). Orientation programs generally produced an effect on issues of graduate student adjustment to a new role and institution (Barker et al., 1997). The results from these various students highlighted importance that Tinto explained of building the nested levels of community that serve to maintain persistence throughout a doctoral program. The orientation event functioned as a mechanism for programs and institutions to introduce the students to the people, structures, values, and career roles that serve to support the students' adjustment and development of layers of community that Tinto attributed to persistence. 


\section{Graduate Student Support}

The studies addressed in this section reviewed the issues of graduate student support throughout the graduate and doctoral studies career. The forms of support measured included spouse/family, adviser, financial, cohort, employer support while pursuing the degree, faculty support, and departmental support. Varying levels of support types tend to have positive and negative effects on the level of commitment and progress. Tinto's theory on doctoral attrition explained that in a second stage of persistence the student is adjusting and developing competency. It is at this point that the nested layers of community (academic, social, family, career, etc.) assist in furthering the students' development in order to integrate the academic and social experiences which can propel the doctoral student forward into candidacy and along the way to completion. Doctoral student support within the department, with the adviser/committee, and with other peers could provide a connection to the pulse of the university and the department and serve as a strong tool to motivate student persistence. The transition into graduate school and eventually into doctoral candidacy manifested as the unknown situations in which students most often indicated the need for support.

Goplerud (1980) conducted a study to investigate how peer interaction during the beginning of graduate school affected perceived stressfulness of the first semester of graduate school. The investigator also sought to explore whether the frequency or quality of faculty interaction during the beginning of graduate school affected perceptions of stress in the first semester of graduate school. The participants $(N=22)$ in the study were psychology graduate students at the State University of New York at Buffalo. The research subjects were part of participant-observation situation and completed a survey 
instrument that measured general satisfaction and quality of students' relationships with faculty and peers.

Goplerud (1980) found socially isolated students reported more events, more intense incidents, greater cumulative stress, and more pronounced number of emotional and health problems compared to socially supported students. The investigator found that more faculty interaction outside of class in the first weeks of school reduced reports of intense or prolonged life disruptions. Goplerud found stronger emotional and intellectual faculty/student relationships reduced the likelihood of health and emotional problems in the first semester of graduate school.

Rimmer, Lammert, and McClain (1982) conducted a study to assess the needs of graduate students at Miami University. The researchers developed the study to answer the call of previous research on the need for attention on issues related to graduate students. The participants responded to a self-developed questionnaire administered to graduate students $(N=82)$ while in graduate courses at Miami University. The research subjects responded to items by indicating their feelings and perceptions of each need.

Rimmer et al. (1982) reported the top five greatest needs perceived by all graduate students in the study included (a) departmental workshops on career planning and placement, (b) workshops on professional development, (c) centralized location for information on graduate social activities, (d) departmental orientation programs, and (e) a graduate student newsletter. The researchers reported female students perceived a significantly higher need for personal growth counseling, childcare, and a centralized location for information on graduate social activities. Rimmer et al. explained minority graduate students perceived a significantly greater need for personal growth counseling 
and support groups for minority students. Single graduate students perceived a significantly higher need for time management workshops, opportunities for sports and cultural events, on-campus apartment options, and support groups for minority students.

Berg and Ferber (1983) conducted a study to examine various success measures of male and female graduate students and whether the measures led to different results. The participants $(N=459)$ in the study were graduate students from 32 academic units at the University of Illinois at Urbana-Champaign. The respondents completed a mailed questionnaire that measured, among other things, importance of intellectual challenge, satisfaction, intellectual and social contact, and support.

Berg and Ferber (1983) indicated more women than men received support from their family and spouse. The researchers found men and women were similar in satisfaction and problems in graduate school. The investigators explained that, in forming relationships with faculty, students gravitated to faculty of the same sex. Berg and Ferber determined three measures associated with earning a doctoral degree: (a) intellectual challenge was very important in choosing the field of study, (b) the student was more likely treated as a junior colleague by at least one male faculty, and (c) the student was more likely to develop a strong relationship with two or more male faculty members.

Lawson and Fuehrer (1989) conducted a study to assess whether or not social support buffered stress experienced by graduate students and to connect what types of support would best address varying types of stress. The study participants were a randomly sampled group of first-year graduate students $(N=20)$ in the English, history, and zoology departments of a midwestern university. The participants in the study responded to semi-structured interview questions about stressful situations while in 
school. Researchers indicated social support served as a main effect of negating stress and improving satisfaction with graduate school. Lawson and Fuehrer explained highly stressed individuals gained more from social support. Researchers noted students that reported the most satisfaction also reported the most stress and subsequently reported the highest usage and need of social support.

Globetti, Globetti, and Smith (1991) conducted a study to examine the perceived needs of graduate students at a southern public university. The researchers developed the study to respond to a need for practical and policy considerations in the provision of student services and programs for graduate students. The participants in the study responded to the Student Needs Assessment Survey (SNAS) mailed to a random sample of 1,700 undergraduate and graduate students who attended the state-supported university. The student response $(N=762)$ provided 122 responses from graduate students.

The investigators found graduate students placed a heavier emphasis on personal/quality of life goals than on academic professional or service goals. The researchers explained graduate students reported a strong need in career development areas. Globetti et al. (1991) determined graduate students needed help with educational planning, especially in acquiring financial resources. Overall, investigators indicated graduate students expressed a need for help in handling stress and anxiety.

Hodgson and Simoni (1995) conducted a study to examine how students in various fields of study differed with respect to graduate social support, financial problems, perceived academic functioning, and psychological distress. The researchers undergirded the study with previous research by the National Research Council 
indicating students in non-science fields of study experienced longer time to degree compared to students in life and physical sciences. The participants in the study responded to the Graduate Student Stress Survey offered to all full-time, first-year and second-year doctoral students $(N=538)$ in the School of Letters and Science at a large urban university in the southwest. The investigators explained the need for more financial aid for students in humanities and social sciences. The researchers found no difference in psychological distress between the students in differing disciplines. Hodgson and Simoni reported a lack of graduate social support and financial problems strongly related to psychological distress.

Webb, Njoku, and Allen (1996) conducted a study to assess doctoral students' perceptions of institutional and program quality. The study participants were a random sample of doctoral business students $(N=392)$ from 12 northeastern public and private colleges. Respondents indicated their level of agreement or disagreement to survey questions related to quality of service in six different areas of institutional services.

Webb et al. (1996) found four significant differences between institution type and perception of quality: (a) international/global studies, (b) external grant assistance, (c) quality of library publications, and (d) circulation time for library materials. Investigators indicated both types of institutions needed to improve the following services: (a) preparation of students for changes in job markets, (b) mentoring programs, (c) training on Internet/e-mail, (d) preparation of students for data analysis, (e) offering evening courses, (f) assistance in grant writing, (g) supply of research rooms in library, and (h) involvement of students in policy and curriculum changes. 
Hahs (1998) conducted a study that analyzed graduate student assistants' needs for perseverance toward graduation in order to create a model for graduate student support. The participants $(N=144)$ in the study were graduate students holding assistantships at the University of Alabama. The research subjects responded to the Graduate Student Services Survey, which measured, among other things, time on campus, graduate level involvement, and interest in workshops and social activities.

Hahs (1998) determined the graduate students indicated strong interest in workshops involving topics on thesis and dissertation writing, computer training, resume writing, grant writing, and financial aid. The researcher found graduate students desired information on research expositions, conferences, research forums, and involvement in social activities. The investigator explained less than half of the graduate students attended the university provided graduate student orientation. Hahs found the graduate students indicated a need for resources on the following topics: (a) financial aid, (b) research and travel support, (c) library resources, (d) usage of the library, (e) writing a thesis or dissertation, (f) employment resources, and (g) student insurance. Hahs developed a model for graduate student support based on programming, services, and resources that focused on the following areas: (a) pre-graduate school education, (b) financial needs, (c) orientation, (d) faculty involvement, (e) research activities, (f) mentoring, (g) seminars/workshops, (h) publications, and (i) options to avoid the ABD syndrome.

Seagram, Gould, and Pyke (1998) conducted a study to assess male and female doctoral training experiences, financial support, adviser relationship, and enrollment status on time taken to complete the doctoral degree. The participants $(N=154)$ in the 
study were graduates of various doctoral programs at York University. The respondents completed a mailed questionnaire designed to assess experiences as doctoral students, experiences with supervision, and financial/enrollment information.

Seagram et al. (1998) found no significant effects of gender on time to completion. Conversely, the researchers indicated women more often determined their committees delayed their degree progress. The investigators discovered initial full-time students who changed status to part-time enrollment took significantly longer to complete the degree compared to the full-time students. The researchers found those that completed the degree in the fastest time had several traits in common: (a) more involved with dissertation supervisor, (b) less likely to change dissertation supervisors, (c) met more frequently with the dissertation supervisor, (d) demonstrated increased research collaboration with their dissertation supervisor, (e) experienced less difficulty selecting the dissertation topic, (f) began research work sooner, and (g) less likely to change dissertation topic. Seagram et al. explained women reported significantly more obstacles, delays, and conflict with dissertation supervisors that in turn led to delayed progress on dissertation completion.

Kelly and Schweitzer (1999) conducted a study to explore which graduate students mentor other students and to assess the effects of mentoring on graduate students' perception of university climate, grades, and provision of funding. The study participants were a stratified random sample of caucasian graduate students, minority graduate students, and international graduate students. Participants $(N=670)$ in the study responded to either a survey by phone or a mailed questionnaire that assessed aspects of 
mentoring with questions that required simple answers (yes, no) and aspects of the institutional climate.

Graduate students with some type of mentor reported better perceptions of the institutional climate (Kelly \& Schweitzer, 1999). The researchers revealed a significantly higher number of minority students mentor students outside of their respective racial groups. The investigators found graduate students with mentors received better grades and had a higher propensity to receive financial funding.

The most significant general findings discovered by the above studies included the following: (a) social support increased satisfaction and decreased stress (Goplerud, 1980; Lawson \& Fuehrer, 1989); (b) lack of social support and financial support greatly increased stress (Hodgson \& Simoni, 1995; Lawson \& Fuehrer, 1989); and (c) stronger emotional and intellectual faculty/student relationships reduced the likelihood of health and emotional problems in the first semester of graduate school (Goplerud, 1980); (d) frequent and consistent adviser interaction increased persistence (Berg \& Ferber, 1983); and (e) graduate students expressed a need for help in handling stress and anxiety (Globetti, Globetti, \& Smith, 1991). Graduate students explained a need for structured opportunities to meet with peers and faculty along with regular mentoring and advising (Kelly \& Schweitzer, 1999). Beginning graduate school brought on a time of major life transitions. Hahs (1998) determined the graduate students indicated strong interest in workshops involving topics on thesis and dissertation writing, computer training, resume writing, grant writing, and financial aid. Students continued to express needs for assistance in many facets of both the academic and personal issues faced while in graduate school. Investigators found graduate students with mentors received better 
grades and had a higher propensity to receive financial funding (Kelly \& Schweitzer, 1999). The research in this section found that doctoral students needed and were developing understanding of the roles and tools for success. As Tinto' theory on doctoral attrition explained, the layers of commitment (goal and institutional) shape the participation within the various communities of a doctoral program. The researchers in this section found that integration of the institutional experiences and nested community layers Tinto explained, provided satisfaction and better doctoral student success.

\section{Dissertation Preparation/Structure}

The studies reviewed in this section discussed the concepts centered on structured programming to service needs of doctoral students. The following studies continually demonstrate the strong need of doctoral students to have structured support and clearly established procedures throughout the dissertation process. Doctoral students in multiple studies indicate a need for stronger departmental communication concerning requirements, procedures, and resources connected to completing the doctoral degree. Tinto's theory on doctoral attrition explained that a final phase of persistence was completing the research project or dissertation. This final phase, as Tinto described, included faculty/advisor relationships and research opportunities as being central to the students' experience within the department/program. At the beginning of doctoral study and in the dissertation phase, defined structure serves as the single most effective tool in persistence and degree completion. Courses, seminars, support groups, and departmental resources can provide doctoral students with much needed structure, experience, and guidance in eliminating the sometimes mystifying process of completing the doctoral degree. 
Heiss (1967) conducted a study to assess the quality and character doctoral students experienced in their education and to highlight stressful points in the doctoral process. The participants $(N=2,251)$ in the study were doctoral students from various departments at the University of California at Berkley. The respondents completed a mailed questionnaire designed to assess doctoral degree requirements and the quality of student/faculty relationships along with a smaller sample $(n=100)$ that completed semistructured interviews.

Heiss (1967) explained most students indicated they pursued doctoral education either to become a faculty member or due to an interest in an intellectual life. The researcher found only half of the students began their doctoral education expecting to complete the degree. The investigator determined nearly one third of students experienced the first year of doctoral education without an adviser. Heiss stated many students noted the selection of the dissertation topic took too long and proved to be an isolating process. The researcher reported some students felt ill-prepared for research and unable to cope with the writing required for the dissertation. The investigator found parttime students and off-campus students expressed alienation and hostility toward the institution more frequently compared to students with higher peer interaction.

Cuetara and LeCapitaine (1991) conducted a study to examine training procedures of doctoral programs and to explore the relationship between training environment and student dissertation writing experiences. The participants $(N=192)$ in the study were recent graduates of doctoral programs in counseling psychology from various universities throughout the United States. The research subjects completed a mailed questionnaire that contained the Training Environment for the Dissertation Scale, the Dissertation 
Implementation Scale, the Multiple Affect Adjective Check List, and a small qualitative component.

Cuetara and LeCapitaine (1991) found respondents indicated strongly that research courses helped prepare students to select a researchable problem for the dissertation and write the dissertation. The researchers indicated a higher level of student research exposure correlated with lower negative effects such as depression, anxiety, and hostility toward the dissertation. The investigators explained higher student research preparation helped stimulate research interest and lower student research preparation strongly reduced research interest. Students found that a lack of structure and direction from the adviser became a serious problem and led to delayed or failed completion of the dissertation.

Baker (1992) examined whether the perceptions of selected service needs differed among specific age groups of graduate students. The researcher surveyed students enrolled in 60 graduate courses in the spring of 1989 at American University, representing a cross-section of academic disciplines and day/evening courses. The researcher employed the Graduate Student Services Inventory (GSSI), comprised of demographic data questions and 23 university-provided graduate services. Participants ( $N$ $=604)$ expressed their level of need based on a 4-point scale from 1 (low) to 4 (high). Baker found traditional age students expressed a greater need for and use of most services than adult students. The researcher determined graduate students desired services to fulfill academic and educational needs.

Hatley and Fiene (1995) conducted an experiment aimed at improving the experience and the completion rate of doctoral students. The program highlighted in this 
study evolved out of trouble doctoral students experienced with potential barriers such as (a) balancing academic responsibilities with career responsibilities, (b) distance away from campus, (c) choosing a topic, and (d) developing structure. The participants in the study were ABD Educational Administration doctoral students $(N=10)$ at a large Midwestern university. The program the researchers implemented consisted of a seminar for the ABD doctoral students focused on (a) providing social support; (b) developing deeper knowledge of research methodologies; (c) providing a dissertation structure with set deadlines; (d) developing a multi-tiered support system including family, co-workers, peers, advisers, and faculty; (e) facilitating cooperative work and mentorship between the student and adviser; and (f) producing a complete research proposal.

Hatley and Fiene (1995) found that all students that enrolled in the seminar had completed the seminar requirements, received dissertation proposal approval, completed the dissertation, and received the doctoral degree. The researchers explained the department continued to offer the seminar after the initial experiment and the seminar has served more than 100 students successfully. The investigators found the departmental seminar drastically reduced the population of ABD students. The researchers determined the departmental seminar led to the following improvements: (a) enhanced timely degree attainment, (b) increased consistency in writing, (c) enhanced clarity in research design, and (d) encouraged a more cooperative departmental environment.

Kluever (1997) conducted a study that compared intellectual and academic attributes of doctoral graduates with ABD doctoral students. The participants $(N=239)$ in the study were doctoral graduates $(n=142)$ and ABD doctoral students $(n=97)$ from the college of education at the University of Denver. The respondents completed a mailed 
questionnaire that consisted of the Procrastination Scale, the Help-Hindrance Scale, and the Responsibility Scale.

Kluever (1997) found student experience with research assists in dissertation completion. The investigator explained adviser contact and access to university resources contributed to dissertation completion. The researcher determined doctoral graduates had a greater sense of independence and personal responsibility compared to ABD doctoral students. Kluever found financial concerns served as the strongest predictor of the time required to complete the dissertation. The researcher indicated a lack of structure at the dissertation stage represented a problem for students. Kluever summarized respondent recommendations for easing dissertation completion: (a) regular adviser meetings, (b) dissertation education seminars, and (c) understanding the dissertation guidelines.

Kluever, Green, and Katz (1997) conducted a study to explore personal and program experiences that affected dissertation completion and non-completion. The participants $(N=22)$ in the study were both graduates $(n=13)$ and ABD doctoral students $(n=9)$ from the education department of a private college in the western United States. The research subjects participated in semi-structured interviews focused on traits that led to persistence or lack of persistence toward the doctoral degree.

Kluever et al. (1997) found common themes of student recommendations: (a) coursework in dissertation proposal writing, (b) dissertation support groups, (c) careful choice of advisers, (d) persistence, (e) good communication with their committee, and (f) well-managed time allocation. The researchers summarized common themes students expressed concerning difficulties experienced: (a) the dissertation process lacks structure, has no defined beginning or end, and has no prescribed outcome; (b) the dissertation 
process lacks clarity and guidelines; (c) students had difficulty getting the dissertation started; (d) students had difficulty finding time to work on the dissertation among other responsibilities; and (e) students had difficulty finding a supportive adviser and committee.

Sigafus (1998) conducted a study to focus on the point in which doctoral students exhibited disenchantment with their doctoral studies. The researcher based the exploration on a previous study centered on understanding how full-time professional educators adjusted when adding a doctoral program to their commitments. The participants $(N=25)$ in the study were doctoral students in the latter stages of a doctoral program in educational administration and supervision at the University of Kentucky. The respondents participated in both small group and individual interviews to gather information on the perceptions of their experiences.

Golde and Dore (2001) conducted a national study to provide a summary of the experiences of doctoral students in the arts and sciences. The participants $(N=4,114)$ of the study were doctoral students in various disciplines in the arts and sciences from universities across the United States. The research subjects responded to the Survey of Doctoral Education and Career Preparation, which measured reasons for pursuit of the doctoral degree, perception of effectiveness of their programs, and their expectations and understanding of their programs.

The researchers found doctoral students did not receive the educational training they wanted, and the training did not prepare them for their desired jobs. Golde and Dore (2001) explained many students did not understand how the process of doctoral education functioned, how to navigate the process, or what was involved in doctoral study. The 
investigators determined students satisfied with their adviser utilized many more adviser selection criteria than the students dissatisfied with their adviser. The researchers found less than half of the respondents indicated a clear understanding of graduation criteria, and barely one third of the respondents clearly understood the length of time for doctoral study. Golde and Dore summarized that a mismatch occurred among the purpose of doctoral education, the student goals of doctoral education, and the careers available for doctoral graduates.

Lampley (2001) used gap analysis in a study to assess the differences among service quality expectations and experiences of doctoral students. The study participants were a random sample of doctoral students $(N=300)$ in either the department of education or philosophy at six universities. Respondents completed a questionnaire, which asked students to compare their experiences with their expectations of service quality at the institution they attended. The researcher utilized $t$ tests to determine gaps in differences between doctoral student expectations and doctoral student experiences. Lampley explained that the larger the gap score, the higher the dissatisfaction doctoral students experienced with his or her academic endeavors. The investigator found a significant relationship between the gap score and six of the seven dimensions that explained differences between doctoral student expectations and doctoral student experiences. The researcher determined age influenced satisfaction with education. Lampley explained that participants with large gap scores were less satisfied with services provided by the institution. The areas with the largest gap scores included (a) course scheduling reflects the needs of students, (b) university possesses up-to-date 
technology, (c) university records are maintained error-free, and (d) business and support staff resolve student problems in a fair manner.

Forney and Davis (2002) conducted a qualitative study of ongoing transition sessions provided for graduate students to ascertain the perceptions of the most and least helpful aspects of the sessions, impacts on the students individually and collectively, and suggestions for improvement. The researchers undergirded the transition sessions by the theoretical base on transition established by Schlossberg, Waters, and Goodman (1995). The participants in the study were a purposive sample of first-year and second-year students $(N=119)$ in the college student personnel program at Western Illinois University. The respondents completed an open-ended anonymous survey assessing their perceptions at the final transition session for the year.

Forney and Davis (2002) analyzed the data in search of emergent themes. Four major themes emerged concerning the helpful aspects of the sessions: (a) sessions instilled a sense of universality, (b) sessions provided a safe forum for open and honest dialogue, (c) sessions allowed space for focus and reflection, and (d) sessions gave students a chance to clarify expectations and receive feedback. Three themes surfaced concerning individual outcomes: increased communication skills, improved coping skills, and increased empathy. The researchers reported three themes emerged concerning group outcomes: open communication, increased group cohesion, increased understanding.

The most significant general findings discovered by the above studies included the following: (a) students were not prepared academically (Heiss, 1967; Kluever, 1997;); (b) dissertation process was unstructured and isolating (Cuetara \& LeCapitaine, 1991; Heiss, 1967); and (c) graduate students desired student services to fulfill academic needs 
(Baker, 1992). Doctoral students indicated a need to clarify dissertation guidelines and requirements and that the transition into doctoral candidacy began a period of needed structure and clarity (Kluever et al., 1997). Investigators concluded dissertation support groups assisted in motivation, support, structure, and persistence (Forney \& Davis, 2002; Hatley \& Fiene, 1995). The researchers in this section presented results that supported Tinto's concepts on attrition in that support, structure, and involvement at multiple levels within a department/program were critical in moving or not moving to degree completion.

A lack of structure and direction from advisers led to delayed or even failed completion (Cuetara \& LeCapitaine, 1991; Kluever et al., 1997). Researchers suggested departments invest resources in coursework and student programs centered on training for the dissertation process, career roles, and addressing student concerns (Golde \& Dore, 2001; Hatley \& Fiene, 1995; Kluever et al., 1997; Lampley, 2001). Multiple studies indicated a lack of understanding of the time required for doctoral completion, skills needed for doctoral completion, criteria required for doctoral completion, who the student's adviser was and how to choose the adviser, and clear starting and ending points of the doctoral degree (Cuetara \& LeCapitaine, 1991; Golde \& Dore, 2001; Heiss, 1967;).

\section{Retention/Attrition}

The studies covered in this section addressed the issues of retention/attrition of students in higher education. Graduate students have demonstrated dismal persistence rates throughout the country. Addressing graduate student needs when adjusting to a new environment serve as an important element of retention. Graduate student retention may be affected by a variety of aspects that are independent of the student. Structural, 
individual, and institutional methods are discussed; these factors allow the opportunity for students to develop a more meaningful connection to the institution and persist at greater rates. The research in this section highlighted the multiple phases of persistence, as well as the influence of socialization, student support, orientation, and dissertation structure on persistence as described by Tinto's theory on doctoral attrition.

Lunneborg and Lunneborg (1973) conducted a study to assess the problem of attrition of doctoral students. The participants $(N=123)$ for the study were psychology doctoral students at the University of Washington. The researchers collected doctoral student data from the institution in order to analyze predictor variables for doctoral attrition. The investigators correlated the data, computed tests of difference, and ran multiple regressions on the data. Lunneborg and Lunneborg found attrition was significantly higher for women than men. The researchers determined the strongest predictors of completing the doctoral degree were having a master's degree prior to entering the doctoral program, age, marital status, and first-year faculty evaluation. The investigators further explained that completion of the first-year evaluation strongly correlated to both doctoral degree attainment and length of study.

Wood (1976) conducted a study to identify attrition factors, critical attrition periods within a doctoral program, and differences between completers and noncompleters of a doctoral degree. The participants $(N=325)$ in the study were doctoral student graduates $(n=139)$, Education Specialist students $(n=11)$, and inactive doctoral students $(n=72)$ in the College of Education at the University of Toledo. The research subjects responded to a questionnaire designed to assess perceptions or barriers to completion along with assessments of doctoral student characteristics. 
Wood (1976) found that overall graduates experienced fewer stressful incidents during academic pursuit than did dropouts. The researcher explained dropouts expressed more financial trouble, less spousal support, and incongruence between the academic degree and career interests. The investigator determined that dropouts indicated weaker faculty relationships, higher academic pressures, and stronger work pressures than did graduates. Wood found a much larger proportion of graduates received scholarship or assistantship than did dropouts. The researcher indicated dropouts tended to be older and averaged a longer time between receipt of their last degree and enrollment in the doctoral program than did graduates.

Cook and Swanson (1978) conducted a study to determine factors that may predict the probability of graduation from doctoral programs. The researchers focused on factors used by the selection committee at the time of admission and factors that emerged after admission and throughout pursuit of the doctoral degree. The participants $(N=214)$ in the study were doctoral students in the educational administration department at the State University of New York at Buffalo. The investigators developed an exploratory model to utilize with the technique of path analysis to identify possible predictors sought in the research.

Cook and Swanson (1978) found that as age increases at the time of admission, the likelihood of graduation decreases. The researchers determined both full-time student status and serving as a graduate assistant each increased the likelihood of graduation. The investigators explained if a student had the dissertation proposal accepted, likelihood of graduation was almost certain. Cook and Swanson found two specific concentrations in the program where students drop out: (a) the majority of dropouts occur while taking 
basic coursework, and (b) the time between program acceptance and dissertation research proposal acceptance.

Cheatham, Edwards, and Erickson (1982) conducted a study to determine the status of the dissertation experience in the speech communication discipline. The participants $(N=316)$ of the study were members of the Speech Communication Association who completed their doctoral degree. The respondents completed mailed questionnaires measuring opinions on the role of the dissertation, relationship with their adviser and committee, and time and money considerations. Cheatham et al. found the respondents indicated multiple reasons for dissatisfaction: (a) unclear expectations, (b) adviser not familiar with research area, and (c) expectations unclear or inconsistent. The investigators explained respondents identified factors that interfered with dissertation completion: (a) inadequate motivation, (b) personal problems, (c) financial problems, (d) problems with scope of topic, (e) needed more research skills, (f) took job prior to completing degree, and (g) employment responsibilities interfered with dissertation work. Jacks, Chubin, Porter, and Connolly (1983) conducted a study to shed light on the $\mathrm{ABD}$ experiences in graduate education. The participants $(N=25)$ of the study were selected from a larger study of doctoral candidates who reached the status of $\mathrm{ABD}$ and never completed the degree. The research subjects participated in semi-structured telephone interviews centered on the topics of: (a) reasons for leaving doctoral studies, (b) impacts of non-completion on life and career, and (c) assessment of value of doctoral degree and suggestions for improvement.

Jacks et al. (1983) found that students in some disciplines indicated the responsibilities of their employment took precedence over the dissertation, and the 
dissertation was delayed indefinitely. The researchers summarized respondents' beliefs that the lack of the doctoral degree was a major barrier to an academic career. The investigators explained the common problem theme for all $\mathrm{ABD}$ doctoral students was financial pressure. Jacks et al. cited the most common reason for leaving doctoral programs as (a) financial difficulties, (b) poor relationship with adviser or committee, (c) problems with dissertation research, (d) personal problems, (e) receiving attractive job offer, (f) interference of paid work with dissertation, (g) family demands, (h) lack of peer support, and (i) loss of interest.

Leadabrand (1985) conducted a study to investigate doctoral student attrition while interpreting the results through the lens of previous theory focused on the effects of commitment and integration on attrition. The researcher grounded the study in the research of Pascarella and Terenzini's (1979) extension of Tinto's assertion that academic and social integration of a student affects attrition and retention. The participants $(N=240)$ in the study were both graduates of and students in the Community and Human Resources doctoral program at the University of Nebraska-Lincoln. The research subjects responded to a questionnaire modified from a previous Pascarella and Terenzini (1979) study that measured student and faculty relationships and students' academic and intellectual development.

Leadabrand found those students that temporarily halted study indicated problems with work pressure, family issues, or financial trouble. The researcher discovered the students rated their adviser and spouse as a positive factor in the doctoral program. The investigator determined the following factors to be significant to persistence: (a) 
academic and intellectual development, (b) peer group relations, (c) informal relations with faculty, (d) institutional and goal commitment, and (e) motivation.

Ott and Markewich (1985) conducted a study to identify predictors of graduation within a range of years after admission and to identify predictors of retention each year after entry to programs of both master's and doctoral students. The researchers desired to develop a model of graduate student retention and graduation. The participants $(N=$ $4,512)$ in the study included both master's students $(n=3,058)$ and doctoral students $(n=$ 1,454) at the University of Maryland, College Park. The investigators developed the desired model and applied the model to the sample group using logit analysis to identify the various potential predictors sought in the research. Ott and Markewich found differences in predicted retention of academic departments related to specific perceived advantages of a compared discipline to sacrifices required for completion of the degree. The researchers explained full-time student status had greater predicted retention and graduation rates and could result in stronger social integration than part-time students.

Ethington and Smart (1986) conducted a study to assess a model of enrollment decision for graduate schools. The researchers utilized data drawn from the longitudinal study of the Cooperative Institutional Research Program (CIRP) which was designed to study cognitive and affective student outcomes of the college experience $(N=6,242)$. The investigators identified 12 independent variables and categorized them as either exogenous or endogenous. The investigators determined the model utilizing the abovementioned independent variables accounted for more than $33 \%$ of variance in graduate school attendance. Researchers found the stronger the social and academic involvement 
of students while at the undergraduate institution, the greater the likelihood of attending graduate school.

Wagner (1986) conducted a study to examine possible personality differences between completers and non-completers of the doctoral degree and to determine if fear of success and/or locus of control were related to degree completion. The participants $(N=$ $107)$ in the study were doctoral students $(n=48)$ and doctoral graduates $(n=59)$ from various disciplines at the University of Michigan. The research subjects responded to an instrument consisting of the Internal-External Locus of Control Scale, the Fear of Success Scale, and a demographic section.

Wagner found that no statistical significance existed between doctoral graduates and ABD students on fear of success or locus of control. The researcher determined, however, that certain factors emerged as barriers for ABD students: (a) dissertation adviser and committee, (b) the dissertation topic, (c) statistical research skills, (d) geographic distance from campus, (e) finances, (f) job schedules, and (g) time allotted for dissertation work. The investigator explained first-born and only children completed the degree more often and men more often completed the degree than women.

White (1986) conducted a study to examine factors that contributed to doctoral students halting the pursuit of the doctoral degree. The participants in the study were doctoral students $(N=34)$ who withdrew from doctoral studies from the Florida State University and the University of West Florida Cooperative External Doctoral Program. The research subjects completed a questionnaire designed to assess factors related to doctoral attrition based on previous research studies. White determined personal factors more heavily influenced attrition than did institutional factors. The researcher explained 
most subjects began the program employed full-time and seeking greater career opportunities. The investigator reported the frequently cited reasons for attrition included (a) personal or family illness, (b) dissatisfaction with course offerings, (c) financial difficulties, (d) dissatisfaction with professors, (e) academic difficulty, and (f) dissatisfaction with peer group. White found most doctoral students withdrew during the coursework stage of the program.

Abedi and Benkin (1987) conducted a study to examine the effects of a set of variables on the predicted time to doctorate. The participants $(N=4,255)$ in the survey were drawn from a data set collected through the Survey of Earned Doctorates administered by the National Research Council. The researchers in the present study focused the data collection on demographic variables (sex, age, ethnicity, marital status, number of dependants), financial variables (off-campus earning, family/spouse earning, teaching/research assistantships, fellowship, grants, loans), and academic variables. Abedi and Benkin found sources of support account for the greatest difference between time to doctorate. The researchers indicated a student supporting themselves and a family through off-campus employment would take longer to complete the doctorate. The investigators found the following variables demonstrated good predictability of time to doctorate: (a) postdoctoral plans, (b) number of dependents, (c) field of doctorate, (d) sex, and (e) citizenship status.

Huguley (1988) conducted a study to identify the following: (a) greatest obstacles to completion of the dissertation; (b) factors or circumstances which may be effective in facilitating student progress on the dissertation; and (c) doctoral student attitudes and beliefs toward the dissertation, the dissertation chairperson, and the dissertation 
committee. The population consisted of doctor of education students $(N=100)$ at Pepperdine University that had completed the Ed.D., along with active, inactive, and dropout ABD students ranging from 1979-1987. The participants completed a questionnaire developed to measure the following categories of variables: (a) demographic data including age, gender, marital status, and ethnicity; (b) attitudinal statements related to obstacles to completion of the dissertation; and (c) attitudinal statements related to the dissertation, the dissertation chairperson, and the dissertation committee.

Huguley (1988) reported the greatest obstacles to completion of the dissertation were full-time employment, personal problems, and lack of structure of the dissertation phase. The researcher reported overall both groups of students reported a positive attitude to the dissertation experience with the completed students reporting a more positive experience than the ABD students. The researcher explained students suggested the following ideas to facilitate progress on the dissertation: (a) carefully select the dissertation committee chairperson, (b) begin the dissertation early, and (c) establish and follow a timetable.

Germeroth (1991) conducted a study to identify and quantify areas of the dissertation process that serve as barriers. The researcher intended to highlight further forms of useful support for doctoral students and gather advice for dissertation completion. The participants $(N=132)$ in the study were doctoral graduates belonging the Speech Communication Association. The respondents completed a mailed questionnaire that measured usefulness of emotional support, financial support, and barriers to dissertation completion. Germeroth found the three most cited barriers to 
dissertation completion, from highest to lowest, included (a) job related pressures and demands, (b) finding time for dissertation work, and (c) personal perfectionism. The researcher noted students who conducted quantitative research suffered more difficulty in data collection and data interpretation than did qualitative researchers.

Gillingham, Seneca, and Taussig (1991) conducted a study to determine the effects of economic factors on the time doctoral students expected to complete their degree. The researchers sought to develop an economic model of time to degree. The participants $(N=723)$ in the study were doctoral students in the arts and sciences departments at Rutgers University. The research subjects responded to a mailed questionnaire designed to assess resource constraints experienced by the doctoral students. Gillingham et al. (1991) found the variables field of study, amount of borrowing, household income, and study hours had a direct effect on time to degree. The researchers determined employment hours and the amount of fellowship, scholarship, or grant aid had indirect effects on time to degree. Gillingham et al. explained foreign doctoral students completed degree requirements in a shorter time span than U.S. doctoral students.

Wright (1991) conducted a study to assess barriers to successful completion of the dissertation while employed. The participants $(N=54)$ of the study were both doctoral graduates $(n=28)$ and ABD doctoral students $(n=26)$ who had taught full-time while at the ABD stage in their doctoral studies. The research subjects participated in a semistructured telephone interview based on a questionnaire developed to assess the effects time, distance, and employment had on dissertation completion. 
Wright (1991) explained members of both groups indicated the loss of committee members led to problems with completing the dissertation. The researcher found noncompleters identified distance away from campus decreased the ability for committee interaction. The investigator summarized that teaching load served as the most cited reason for non-completion and for those with responsibilities beyond full-time teaching, the extra involvements became ever more difficult barriers to dissertation completion. Wright indicated both groups cited reduced workload as the major factor enabling dissertation completion. The researcher found the absence of student support structure and daily faculty interaction due to full-time employment served as a barrier to dissertation completion.

Campbell (1992) examined the relationship between selected demographic variables, including age, and attrition/completion variables and the completion of the doctoral degree in educational leadership at one university. The researcher sought to understand the differences, related to selected variables, between those students that completed the degree and those that stalled out at the All But Dissertation (ABD) stage. The population consisted of admitted students $(N=58)$ in the educational leadership program at the University of Delaware. Campbell designed a survey questionnaire based on previous doctoral attrition research.

Campbell (1992) reported the single most important variable for both the completers and non-completers was the relationship with their adviser. Students that completed the degree reported a positive relationship with their adviser and indicated that to be the most important factor contributing to their completion. Students that did not complete the degree reported that their relationship with their adviser to be the biggest 
contributor to non-completion. Overall the relationship between the student and adviser seemed most critical during the dissertation stage. Other factors reported by noncompleters included problems with one's committee and fatigue.

Isaac, Quinlan, and Walker (1992) conducted a study to understand faculty views on the role and function of the doctoral dissertation. The participants $(N=596)$ of the study were faculty members of various disciplines who advise doctoral students at universities across the United States. The participants responded to a mailed questionnaire that measured perceptions and practices of the doctoral process.

Isaac et al. (1992) indicated that faculty deemed the dissertation important and that it served as a demonstration of research skills, development of research skills, and a contribution to the knowledge base of the field. The investigators explained faculty stressed the belief that full-time enrollment is important and increased in importance along the duration of the doctoral process. Isaac et al. found that faculty members rated certain variables as barriers to completion of the dissertation: (a) lack of stipend, (b) increasing complexity of field, (c) decreasing quality of students, (d) lack of financial support for research, (e) difficulty in defining dissertation topic, (f) lack of career prospects, $(\mathrm{g})$ increased demands on adviser's time, $(\mathrm{h})$ lack of student preparation for independent research, and (i) holding or obtaining full-time employment.

Berry (1993) conducted a study to assess faculty members' perceptions of importance of factors that affect doctoral student attrition. The research subjects were graduate faculty members $(N=214)$ in departments of educational administration at institutions throughout the United States. The participants in the study responded to a survey developed by the researcher to measure perceived importance of pre-defined 
attrition variables. Berry found that student-focused variables, including persistence or goal orientation, employment outside the department, and personal and/or family problems served as the strongest barriers to doctoral completion. The researcher indicated variables related to the department contributed moderately to doctoral attrition. The departmental variables included (a) lack of effective adviser relationship, (b) lack of interaction among students and faculty, (c) lack of student peer interaction, (d) not holding an assistantship, and (e) isolation during dissertation research and writing.

Sheridan and Pyke (1994) conducted a study to assess the impact the effects of demographic, academic, and financial factors had on time required to complete the master's and doctoral degree. The participants $(N=474)$ in the study were master's students $(n=395)$ and doctoral students $(n=79)$ from various disciplines at York University in Canada. The investigators performed a multiple regression procedure to predict the effect of certain variables on the time to degree completion.

The researchers found full-time enrollment status, a natural sciences discipline, and Canadian citizenship indicated shorter time to doctoral degree. Sheridan and Pyke explained length of time in a doctoral program decreased as the amount of funding increased. The investigators determined that neither marital status, incoming grades, graduate grades, gender, age, nor leaves of absence served as significant predictors of time to doctoral degree completion.

Cooke, Sims, and Peyrefitte (1995) conducted a study to identify personal attributes that predicted graduate student attrition. In order to provide stronger minority representation, the study participants were a cluster sampling of graduate students $(N=$ 230) enrolled in the business, engineering, public administration, and education 
departments at a southeastern urban university. Participants responded to a survey, which incorporated multiple questionnaires from previous research that were adapted to address various factors needing to be studied. The researchers divided the survey in sections, each with a unique Likert scale used to measure participant responses. The investigators indicated more than $84 \%$ of dropouts were correctly classified and more than $80 \%$ of graduated/current students were correctly classified. Researchers explained graduate student attitudes and intention to continue were significant predictors of attrition. The investigators found graduate students with higher school satisfaction and commitment continued with school at a higher rate.

Dorn and Papalewis (1995) conducted a study to analyze persistence motivators of doctoral students including social interaction, peer mentoring, and group cohesiveness. The participants $(N=108)$ in the study were doctoral students in educational administration from eight universities. The research subjects responded to the Cohesiveness and Persistence Questionnaire. The researchers reported commitment to the doctoral group correlated to persistence toward degree completion and remaining in the doctoral program. The investigators explained subjects believed membership in the doctoral group increased commitment to degree completion. Dorn and Papalewis found respondents felt the doctoral group provided nurturing, support, motivation and encouragement and that the group proved vital in completing coursework, remaining in the program, and making consistent progress.

Ehrenberg and Mavros (1995) conducted a study to assess doctoral student completion rates and time-to-degree for students in select disciplines. The participants of the study were doctoral students in the departments of economics, English, physics, and 
mathematics at Cornell University. The researchers computed frequencies and estimated models based on the collected data. Ehrenberg and Mavros found that almost half of all those that dropped out of doctoral programs did so in the first 2 years of study. The researchers determined student GRE scores were not associated with completion and dropout. The investigators explained students starting the doctoral programs with a master's degree had a greater likelihood of completing the program and a lower likelihood of dropping out. Ehrenberg and Mavros found students receiving fellowships or research assistantships had higher completion rates and shorter time-to-degree compared to students with teaching assistantships, tuition waivers, or self-support.

King and Chepyator-Thompson (1996) conducted a study to assess factors, including financial aid and mentors, that affected enrollment and degree attainment of African-American doctoral students. The participants $(N=74)$ in the study were AfricanAmerican doctoral recipients in sport and exercise science from institutions throughout the United States. The participants responded to a mailed questionnaire designed to assess factors influencing enrollment decisions, persistence, and degree completion. King and Chepyator-Thompson reported more than half the subjects stated intrinsic motivation as the key enrollment factor. The investigators explained the majority of students found a positive campus racial climate. The researchers included important persistence factors:

(a) mentors of the same race, (b) family support, (c) academic and/or professional support from adviser or professor, (d) institutional financial aid, and (e) intrinsic motivation.

Nerad and Miller (1996) conducted a study to investigate causes of doctoral student attrition at the University of California, Berkley. The researchers implemented the research in order to demonstrate how research can inform policies and strategies for 
increasing graduate student retention. The participants represented cluster samples of three groups of three annual cohorts retrieved from the University of California, Berkley Graduate Division's longitudinal database of all graduate students enrolled at the institution since 1962. The researchers failed to report the sample size and statistical procedures utilized in analysis of the mixed methods study. Nerad and Miller assessed graduate student attrition before advancement to candidacy as a student not being registered for 2 consecutive years and after advancement to candidacy as official notification of lapsed candidacy.

The researchers found that $80 \%$ of all doctoral students completed a graduate program. Nerad and Miller (1996) determined a low completion rate correlated with long time-to-degree. The researchers explained students are far more likely to leave before advancement to candidacy (between years one and three of the doctoral program). The investigators explained early leavers fell into several categories: (a) those who never intended to get a doctorate, (b) field switchers, (c) institution switchers, (d) students whose interests did not match the faculty, (e) those frustrated with the degree program, and (f) students with professional careers outside the university. Late leavers fell into several categories: (a) students undecided about the goal of their studies, (b) those whose relationship with their adviser went sour, (c) those who lacked adequate financial support, and (d) those discouraged by a chilly departmental climate. Nerad and Miller determined that typically the interplay of the student's specific personal characteristics with circumstantial or structural events of the program caused a student to withdraw.

Dorn and Papalewis (1997) conducted a study to examine the effect group cohesiveness had on persistence of doctoral students in an educational leadership 
program. The participants in the study were doctoral students $(N=108)$ in educational leadership programs from eight universities across the country. The research subjects responded to a mailed questionnaire that assessed measures of cohesiveness and measures of persistence.

Dorn and Papalewis (1997) found a significant correlation of .767 $(p<.01)$ between the cohesiveness measures and the persistence measures. The investigators determined peer mentors provided doctoral student support, motivation, and encouragement. The researchers explained students felt deep positive relationships between cohesiveness and persistence. Dorn and Papalewis summarized that belonging to a doctoral cohort encouraged students to remain in the program and persist toward the degree. The researchers found cohorts of doctoral students develop group identity and the members encourage one another to persist in the doctoral program.

Green and Kluever (1997) conducted a study to clarify the presence and importance of barriers to dissertation completion and to develop a scale to measure the barriers. The participants $(N=239)$ in the study included both graduates $(n=142)$ and ABD doctoral candidates $(n=97)$ in the education department of a private college in the western United States. The research subjects completed a mailed questionnaire constructed based on available dissertation completion literature and focus group recommendations and centered on sources of support, funding, and student preparation.

Green and Kluever (1997) found respondents indicated concerns about time pressures and financial/family issues rated as major hindrances to dissertation completion. The researchers explained that on the subscale items, students indicated all areas as barriers to a greater extent than graduates. The investigators determined 
individuals that rated task structure, time management, and personal organization skills lowest felt these same items were the greatest barriers to dissertation completion. The researchers summarized family support, persistence, and adviser relationships as serving to help doctoral students. Green and Kluever found students living away from campus had greater perceptions of barriers.

Emerson (1998) conducted a study to identify characteristics that facilitate or inhibit completion of a doctoral degree among Inquiry students, a nontraditionally organized doctoral program in educational administration. The Inquiry Program, an expanded option of the educational administration program at Columbia University, based its design on the need for increased flexibility and individualization of preparation programs for practicing administrators. The population $(N=168)$ consisted of students that entered the Inquiry program within a 10-year period.

Emerson (1998) found the non-completion rate of students in the Inquiry program was $12.5 \%$, which was dramatically lower than the national average of $50 \%$ and that the students completed the degree on an average of 2.7 years. The researcher indicated that completers of the Inquiry program noted characteristics such as family support, perseverance, and peer support contributed to success in the program. The investigator indicated non-completers of the Inquiry program noted characteristics such as personal problems, job pressures, and problems with research topics contributed to their lack of progress in the program. Overall most students indicated the most difficult aspects of the program occurred at the dissertation stage. The difficulties encountered at this stage stemmed mainly from lack of cohort support structure and problems with research topics. 
Kluever and Green (1998) conducted a study to create and evaluate a scale designed to assess graduate student concepts of responsibility in conjunction with doctoral dissertation completion. The participants $(N=239)$ of the study were ABD doctoral candidates $(n=97)$ and doctoral graduates $(n=142)$ in the education department at an urban private college in the western United States. The research subjects completed a mailed questionnaire composed of the Responsibility Scale, Dissertation Barriers Scale, and the Procrastination Inventory.

Kluever and Green (1998) explained respondents felt the student does and should bear the most responsibility for dissertation progress more than the university or the committee. The investigators reported current students felt more strongly than graduates about taking responsibility for their preparation. Kluever and Green explained higher procrastination levels and stronger barrier perceptions to dissertation completion were found for those with stronger perception of university responsibility for dissertation tasks. The investigators concluded the Responsibility Scale demonstrated viability for assessing respondents' attitudes toward responsibility for degree and dissertation completion.

Pauley (1998) examined the statistical relationship between selected demographic (age, marital status, gender, number of dependants) and situational variables (financial support, family support, peer support, chairperson support, faculty support, motivation) and the completion of the doctoral degree within a cooperative doctoral degree program. The researcher aimed to understand what factors increased the chance of attaining the doctoral degree and what factors impeded the process. The population consisted of admitted students $(N=131)$ to a cooperative doctoral degree program of West Virginia University and Marshall University between 1980-1993. Pauley developed a survey using 
variables drawn from prior research on doctoral student attrition and included variables from the Doctoral Student Survey. Of the 12 variables studied, the researcher found six variables statistically significant to influence doctoral completion. The statistically significant variables found to influence doctoral completion included: (a) level of financial support available to the student, (b) family support, (c) peer support, (d) faculty support, (e) chairperson support, and (f) motivation of the student.

Sigafus (1998) found four common themes that served as barriers in the pursuit of the degree: (a) lack of structure, (b) pressure, (c) lack of support, and (d) authority. The researcher determined all the experiences of the students shifted to a negative and dissatisfied story at the point when the students transitioned from coursework to doctoral candidacy. The investigator explained at this transition point students indicated a need for (a) social connection, (b) academic structure, (c) peer and departmental support, (d) faculty guidance, and (e) clarity of the dissertation process.

Bair and Haworth (1999) conducted a study to perform a meta-synthesis of literature in order to produce a comprehensive understanding of doctoral student attrition and persistence. The researchers utilized both qualitative and quantitative research studies $(N=118)$ to sort and integrate findings from the overall body of research on the topic. Bair and Haworth determined increased time spent in pursuit of the doctorate decreased the likelihood of doctoral degree completion. The researchers explained the ABD stage of a doctoral degree did not comprise the greatest segment of doctoral dropouts. The investigators found doctoral student persistence and degree completion increased when the following variables were present: (a) higher amount and higher quality student interaction within the department; (b) student involvement in programmatic, 
departmental, institutional, and professional activities; (c) student satisfaction with their academic program; (d) higher involvement with academic peer interaction; (e) holding research assistantships, teaching assistantships, fellowships, or graduate assistantships compared to other funding types; and (f) doctoral programs with smaller entering cohorts. Bair and Haworth indicated academic achievement variables and demographic variables did not serve as significant predictors of doctoral degree completion.

Myers (1999) conducted a study to examine doctoral student attrition and to develop a better understanding of attrition over time. The participants in the study were Educational Leadership and Policy Studies doctoral students $(N=11)$ who did not complete the doctoral degree at Virginia Polytechnic Institute and State University. The research subjects participated in semi-structured interviews designed to learn the experiences of the doctoral students and to highlight significant barriers to the completion process.

Myers found respondents indicated time and finances served as the most common barriers to degree completion. The researcher explained that doctoral students related family or personal obligations including children, death, guilt, medical attention to child, and medical attention to self as significant factors impeding progress to doctoral degree completion. The investigator stated more than $70 \%$ of subjects found personal finances produced significant factors in not completing the degree. Myers determined job related factors such as changing jobs during education, lack of employer support, and professional responsibilities accounted for a large barrier to dissertation completion.

Golde (2000) conducted a study to understand the process of attrition in doctoral education. The researcher undergirded the study with a theoretical framework based on 
organizational socialization theory and the integration theory of attrition. Participants in the study were a purposive sample of doctoral students $(N=68)$ who did not complete their program from nine different disciplines at six institutions. The researcher focused this study on the interviews of three doctoral students and their responses to questions about their experiences in graduate school and why they left the program. The researcher found three common themes among the student responses: (a) academic integration: relationships with faculty; (b) social integration: the student community; and (c) telling others about leaving.

Lovitts and Nelson (2000) conducted a mixed-methods study to assess the shortterm and long-term effects of completing or not completing a doctoral degree. The study participants were a randomly sampled group of students $(N=816)$ who entered doctoral programs at two distinguished research universities, one private, urban university, the other a public, rural university. The participants in the study responded to a detailed survey designed to examine reasons students leave or do not leave the academic program. A select group $(n=18)$ of two students for each of the nine academic departments represented in the study also completed an hour-long telephone interview. Lovitts and Nelson found integration into the department's social and professional life highly correlated with successful completion of the doctorate. The investigators indicated students who completed their degree were twice more likely to be satisfied with their relationship with the faculty adviser than those who did not complete their degree.

Malmberg (2000) examined attrition and retention factors of doctoral candidates that had reached the level of admission to candidacy. The participants $(N=63)$ in the study consisted of current $\mathrm{ABD}$ students, attrited ABD students, and students who 
completed the degree in a higher education doctoral program at a public Research II institution. The author administered a qualitative questionnaire containing demographic questions such as age, gender, ethnicity, and marital status along with open-ended response questions. The researcher indicated the top six factors (at least $90 \%$ or more students noting the factor) that affected degree progress: (a) relationship with dissertation chair, (b) relationship with dissertation committee, (c) employer supportiveness, (d) family support of doctoral study, (e) committee chair, and (f) motivation. de Valero (2001) conducted a study to examine time-to-degree and completion rates of departmental factors of differing disciplines and to identify the factors affecting degree progress and completion. The participants $(N=876)$ of the study were doctoral students at one university in the mid-Atlantic region of the United States. Along with a quantitative review of completion rates and time-to-degree, the research subjects participated in semi-structured interviews exploring departmental factors.

de Valero (2001) found students that completed degrees in the shortest time and most frequency shared the following factors: (a) financial support, (b) departmental orientation and advising, (c) relationship between coursework and research training, (d) required significant results during the dissertation, (e) student-committee/adviser relationship, (f) department focused on students, (g) student participation, and (h) peer support. The researcher determined for the most successful students, departmental climate was positive and advisers were involved from the beginning of the doctoral study to the final dissertation defense. The investigator found students who completed degrees in the longest time and least frequency shared the following factors: (a) departmental 
advising and orientation impeded success, (b) conflicts among people, (c) limited departmental social and academic activities, and (d) lack of student/faculty collaboration.

Leppel (2002) conducted a study to examine similarities and differences in persistence of men and women. The investigator undergirded the research based on the understanding that students compare the satisfaction they expect to obtain from attending/persisting in college with the satisfaction they expect from nonattendance/dropping out. The researcher based the study on data gathered in the 1990 survey of Beginning Graduate Students (BPS). The participants in this study were a stratified sample of male and female first-time students $(N=5,384)$ starting college at institutions across the nation and enrolled in courses leading to a bachelor's degree. Respondents completed a survey of demographic data and questions about their participation in certain activities and their perceived abilities.

The researcher found children had a significant negative impact on persistence for men, but a significant positive impact on persistence for women. The investigator determined the variable of being Black had positive impacts on persistence for women, but negative impacts on persistence for men. Leppel (2002) determined that age, marriage, and hours worked had a negative impact on persistence for all students and that family income and grade point average had a positive impact on persistence for all students. The researcher explained persistence was higher for all students who had higher integration into the institution.

Lee (2003) conducted a study to determine factors that affected the noncompletion of doctoral degrees by students who had completed all degree requirements except the dissertation. The population for the study consisted of students $(N=312)$ who 
were enrolled, enrolled but later discontinued, and those who graduated from the educational administration and curriculum and instruction doctoral programs at Tennessee State University from 1988-1998. Lee specifically referenced Tinto's (1993) research as the theoretical basis for this study. The researcher utilized variables drawn directly from the model postulated by Tinto (1993). Demographic variables included age, ethnicity, gender, financial support, employment, marital status, number of dependants, and enrollment status. Program variables utilized included departmental assistance factors, social involvement, dissertation chair contact, and academic involvement. Lee administered the Doctoral Studies Questionnaire, which was adapted from the National Science Foundation (NSF) instrument developed by Tinto (1995-1996) while at Syracuse University.

Lee found the following results: (a) a significant difference existed between the levels of overall satisfaction of doctoral degree recipients and $\mathrm{ABD}$ responders, (b) a significant difference existed regarding perceptions of research satisfaction between doctoral degree recipients and $\mathrm{ABD}$ responders, (c) a significant difference existed between doctoral degree recipients and $\mathrm{ABD}$ responders based on overall satisfaction with the faculty adviser, and (d) a significant difference existed between doctoral degree recipients and $\mathrm{ABD}$ responders based on satisfaction with the dissertation chair.

Stallone (2003) conducted a study to examine the personal and individual factors related to doctoral student attrition. The participants in the study consisted of both currently and previously enrolled doctoral students in the Joint Educational Leadership Doctoral Program among the regional campuses of Texas A\&M University. The research subjects completed a survey and open-ended questions along with participation in semi- 
structured interviews designed to gain an understanding of the factors associated with doctoral student attrition. Stallone found that overall students experienced some trouble in balancing the demand between their academic pursuit and family. The researcher explained evidence existed both positively and negatively on the benefits of doctoral student cohort structure on doctoral student attrition. The investigator determined faculty student relationships and program culture contributed highest to doctoral degree completion. The researcher indicated that human factors served as the greatest and most influential contributor to doctoral degree completion.

Wynn (2003) conducted a study to assess the effects of research environment, involvement, and student/adviser relationships had on doctoral student progress. The researcher conducted the study in two components including a case study of derailed doctoral students $(n=3)$ and their departmental professors $(n=3)$ along with a survey of educational leadership department chairs $(n=61)$ from institutions across the country. The case study subjects completed semi-structured interviews to assess barriers to completion as perceived by doctoral students and faculty. The investigator developed a questionnaire to assess the perceptions of department heads on attrition factors of doctoral students.

Wynn (2003) found ABD students indicated the following factors as obstacles to completion of the doctoral degree: (a) family problems, (b) finances, (c) changing jobs, (d) financial cost, and (e) inaccessible chairperson or limited dissertation guidance. The researcher explained that faculty members from the case study determined the following factors contributed to not completing the doctoral degree: (a) the committee, (b) level of priority student makes the dissertation, (c) new or demanding job, (d) viewing the 
dissertation as a burden, and (e) poor communication with adviser. When reviewing the survey administered to department chairs, the investigator found research skills, low ability to work independently, and low initiative contributed to non-completion of the doctoral degree.

Bauer (2004) conducted a study to assess doctoral students' perceptions of their department and how the perceptions affected doctoral degree completion rates. The researcher grounded the study based on Tinto's model of persistence for doctoral students. The participants in the study were both ABD and graduated doctoral students $(N$ = 16) from four departments at a comprehensive urban university. Research subjects responded to a semi-structured, open-ended instrument designed to explore departmental relationships, financial support, program design, and student orientation.

Bauer (2004) found that the following attributes contributed positively to degree completion: (a) detailed orientation, (b) structured advising, (c) internships or assistantships, (d) facilitation of student cohorts, (e) supportive faculty relationships, and (f) family and work support. The researcher determined lack of clarity of mission and goals and unstable department atmosphere negatively affected degree completion. There was a consistent indication that where strong peer support and faculty support prevailed, student cohesiveness and degree completion increased. Bauer indicated that all participants cited peer relationships as a key component of the student experience. The researcher found that graduates compared to ABD students had a clearer understanding of the dissertation and departmental expectations. The investigator explained that outside of departmental factors, student internal motivation accounted strongly for persistence. 
Lovitts (2004) conducted a study to determine the social-structural causes of attrition. The researcher grounded the research in the theory of cognitive maps and the theory of integration. The participants $(N=816)$ in the study were students that completed the doctoral degree $(n=511)$ and students that did not complete the doctoral degree $(n=305)$ at two universities. The research subjects participated in a survey and a select group of non-completers $(n=30)$ took part in semi-structured telephone interviews.

Lovitts (2004) determined academic background characteristics did not predict completion status. The investigator found completion rates related to the development level of departmental cognitive maps of formal requirements and informal expectations. The researcher found completers overwhelmingly received research assistantships or teaching assistantships compared to non-completers and one quarter of non-completers received no financial support at all. Lovitts explained completers were more likely to have an adviser, more likely to be satisfied with their adviser, and more likely to have selected the adviser based on academic interests. The researcher summarized attrition related to unequal distribution of support resources for dissertation completion.

Golde (2005) conducted a study to understand the department and the disciplinary influence on doctoral student attrition. The researcher undergirded the study with theoretical framework defined initially by Tinto (1993) and further explained by Lovitts. The framework or model explained three postulates: (a) doctoral attrition evolved through the interaction/lack of interaction between the student and the institution; (b) doctoral students must be integrated into both the discipline and the department; and (c) academic integration was most important to doctoral integration, while social integration 
has an indirect effect. Participants in the study were a purposive sample of doctoral students $(N=58)$ who had left the doctoral program in four departments at one midwestern university. The research subjects responded to semi-structured interview questions regarding their reason for choosing the school, their graduate school experience, and contributions to their decision to leave the program.

Golde (2005) found six themes emerged that led to attrition: (a) research practices not matched with student's strengths; (b) poor fit of expectations between student and department, inaccurate expectations about nature of graduate school, and academically under prepared; (c) mismatch between adviser and student; (d) student perceived research university faculty life was incompatible; (e) student perceived job market to be poor; and (f) structural isolation of student. The researcher explained a common theme that students perceived a looming departmental requirement, which usually led to advancement to candidacy, as a significant hurdle and contributed to attrition.

The most significant general findings discovered by the above studies included the following: (a) social integration and student's institutional commitment had direct effects on persistence (Golde, 2000); (b) developing a social network helped retain students at a higher rate (Berry, 1993; de Valero, 2001; Lovitts \& Nelson, 2000; Stallone, 2003); (c) the relationship with the faculty adviser was the key to remaining at the university and key during the dissertation stage (Bair \& Haworth, 1999; Campbell, 1992; de Valero, 2001; Green \& Kluever, 1997; Lovitts \& Nelson, 2000; Malmberg, 2000; Stallone, 2003; Wood, 1978); (d) integration of graduate students into the social and professional aspects of their department and holding graduate assistantships increased retention (de Valero, 2001; Golde, 2000; Lovitts, 2004; Lovitts \& Nelson, 2000; Stallone, 
2003); (e) stronger communication/relationship with adviser and committee chair had positive effects on persistence (Berry, 1993; de Valero, 2001; Lee, 2003; Lovitts \& Nelson, 2000; Wynn, 2003); (f) scholarships/financial support or assistantships increased persistence (Abedi \& Benkin, 1987; Bair \& Haworth, 1999; Bauer, 2004; Cook \& Swanson, 1978; de Valero, 2001; Ehrenberg \& Mavros, 1995; Gillingham et al., 1991; Isaac et al., 1991; King \& Chepyator-Thompson, 1996; Pauley, 1998; Sheridan \& Pyke, 1994); (g) more research preparation assisted in dissertation completion (Wagner, 1986); and $(\mathrm{h})$ orientation program participation produced higher grade point averages and higher graduation rates (Bauer, 2004; Poock, 2002).

The studies echoed a need for centralized information within the department on aspects of professional and academic development, social activities, and support groups (Bauer, 2004; Pauley, 1998). Researchers determined orientation program attendance produced long-term positive retention benefits for students and that students who attended orientation were more likely to persist, more likely to re-enroll, and more likely to obtain a degree (de Valero, 2001). Investigators noted that contrary to popular belief, doctoral attrition occurred early in the program and prior to completion of doctoral coursework (Cook \& Swanson, 1978; Ehrenberg \& Mavros, 1995; Nerad \& Miller, 1996; White, 1986).

Along the lines of personal or individual characteristics, multiple researchers found human variables connected to persistence/attrition. Various studies found the following attributes to play a role in doctoral student attrition: (a) priority placed on dissertation (Berry, 1993; Cooke et al., 1995; Cheatham et al., 1982; Germeroth, 1991; Green \& Kluever, 1997; Kluever \& Green, 1998; Wynn, 2003); (b) starting a new or 
demanding career role (Berry, 1993; Cheatham et al., 1982; Myers, 1999; Nerad \& Miller, 1996; Wynn, 2003); (c) personal problems (Berry, 1993; Jacks et al., 1983; Myers, 1999; White, 1986); and (d) balancing the career and family demand with academic pursuits (Cheatham et al., 1982.; Germeroth, 1991; Green \& Kluever, 1997; Huguley, 1988; Isaac et al., 1992; Jacks et al., 1983; Leppel, 2002; Myers, 1999; Nerad \& Miller, 1996; Stallone, 2003; Wood, 1978; Wright, 1991; Wynn, 2003). The colossal task of the dissertation seemed so large to some students, that advancement to candidacy never occurred (Golde, 2005). Investigators determined structural isolation of a student reduced retention (Berry, 1993; Golde, 2005; Leppel, 2002). Researchers indicated an overall need for mentoring programs and that a strong relationship existed between cohesiveness and persistence (Bair \& Haworth, 1999; Dorn \& Papalewis, 1995, 1997; King \& Chepyator-Thompson, 1996). Belonging to a doctoral group/cohort was found to increase support and benefited persistence (Bair \& Haworth, 1999; Dorn \& Papalewis, 1995, 1997). Researchers determined that social support not only helped reduce stress among graduate students, but family support, peer support, and faculty support worked to increase persistence (Bauer, 2004; Emerson, 1998; King \& Chepyator-Thompson, 1996; Leadabrand, 1985; Malmberg, 2000; Pauley, 1998). Research indicated students with higher institutional satisfaction and commitment to the institution were more likely to persist (Cooke et al., 1995; Leppel, 2002). The research in this section demonstrated the key concepts of persistence as postulated by Tinto's theory of doctoral attrition. The researchers in this section demonstrated that goals and commitments, orientation opportunities, layers of institutional and program experiences, nested levels of academic 
and social integration, and structure research/dissertation experiences served to influence doctoral student attrition/persistence as explained by Tinto.

\section{Themes Reviewed}

The socialization stream of research included in this chapter discussed the adaptation of new norms, roles, responsibilities, and expectations that doctoral students experience when pursuing graduate education. When starting a new graduate program, Kezar (2001) described how students again, just as with undergraduate work, gave up security and familiarity to allow growth and knowledge acquisition to occur. Tinto (1993) noted new graduate students experienced challenges with respect to both academic and social integration. Poock (2002) reported many graduate students experienced confusion and anxiety when entering their programs similar to feelings experienced when they were new undergraduates. Polson (2003) indicated many institutions expended a large amount of resources in the recruitment of graduate students, yet offered very little assistance to graduate students as they transitioned and persisted through the demands of graduate study. Golde (1998) explained many graduate students confronted a dual socialization process that involved both the transition into the graduate student role and the preparation for a new profession. Brown-Wright et al. (1997) noted among the major purposes of graduate education, socialization into the academic culture was integral. Komives and Taub (1998) reported institutions rarely applied the knowledge found in undergraduate socialization research and programs to the graduate student experience.

The orientation stream of research included in this chapter discussed the benefits and roles that graduate student orientations play in the adaptation to a graduate student's role, department, and institution. Vlisides and Eddy (1993) agreed with other researchers 
when they noted graduate students appear to be a neglected segment of the student population in areas spanning from orientation to research. Polson (2003) explained student services played an important supportive role in graduate student socialization through offering orientation programs. Vlisides and Eddy concluded the role of graduate orientation programs was to welcome and allay incoming student anxiety. Poock (2002) noted departmental and general orientation programs played important roles in graduate student socialization.

The graduate student support stream of research included in this chapter discussed personal, departmental, and institutional forms of support that doctoral students experience during graduate education. Ethington and Smart (1986) explained group support and peer mentoring provided an added boost on the path to doctoral degree completion. Hahs (1998) emphasized the importance of a university support structure that provides academic and personal support for graduate students. Kluever (1997) found doctoral graduates indicated receiving higher emotional support from various sources than did non-graduates.

The dissertation preparation stream of research included in this chapter discussed institutional and departmental attempts at providing structure and guidance to doctoral students during the dissertation process. Cesari (1990) explained master's and doctoral students garner less student services attention. Vlisides and Eddy (1993) recommended special services be developed for graduate students and should be addressed in student or academic affairs. Cesari reported dissertation support groups effectively assisted in navigating graduate students through a confusing process. Dorn and Papalewis (1995) suggested the incorporation of support group and cohort development components in 
doctoral programs to improve retention and persistence. Baker (1992) concluded that graduate students expressed the need for services that helped them meet their academic and educational objectives. Polson (2003) stated, "It was assumed because graduate students were mature, well-focused, goal oriented, and college graduates, they were capable of handling the responsibilities of graduate study without needing special services" (p. 59).

The retention/attrition stream of research included in this chapter discussed a variety of research on the possible contributions to doctoral student retention/attrition. Vlisides and Eddy (1993) explained that institutional resources were ever shrinking and recruitment and retention of graduate students has become increasingly urgent. Attrition during the first year of graduate school accounted for nearly a third of all doctoral student attrition (Bowen \& Rudenstine, 1992; Golde, 1996, 1998). Polson (2003) suggested that investment in opportunities that help graduate students transition into their new roles were more likely to retain graduate students through degree completion. Dorn and Papalewis (1997) summarized that peer mentoring served as a powerful support, with increased likelihood of doctoral student persistence. Dorn and Papalewis (1995) noted group support and peer support served as a major tool in completing the doctoral degree. Poock (2002) surmised graduate student orientation programs demonstrated a positive effect in reducing attrition rate in graduate education. Gilliam and Kristsonis (2006) stated "The most academically capable, most academically successful, most stringently evaluated, and most carefully selected students in the entire higher education system, doctoral students, are the least likely to complete their chosen academic goals" (p. 3). 


\section{Summary}

Graduate students experience the acquisition of an entirely new culture when entering graduate education. Graduate students can experience, positively or negatively, a socialization process that introduces them to both the academic department and their future career (Tinto, 1993). Lawson and Fuehrer (1989) explained that graduate students experienced more satisfaction with increased contact from faculty. Importance of the relationship between faculty and graduate students has been well documented (Kelly \& Schweitzer, 1999). The socialization process involved a transition and adoption of new roles and responsibilities as well as a formation of opinion about the institution (Taub \& Komives, 1998). The transition process was laden with stress, anxiety, expectation, and responsibility (Rosenblatt \& Christensen, 1993). Social support served as an effective moderator of stress experienced in the early aspects of graduate school (Lawson \& Fuehrer, 1989).

Orientation programs served important roles for graduate students transitioning to graduate education (Barker et al., 1997; Poock, 2002; Taub \& Komives, 1998). Orientation programs served as an opportunity for institutions to address adjustment and transition concerns that negatively affect attrition (Polson 2003; Poock, 2002). Socialization into higher education can be directly fostered through the use of institutional orientation programs (Boyle \& Boice, 1998; Polson, 2003; Poock, 2002).

Attrition in graduate education due to rejection of the issues and concerns with this early transition is a paramount concern among researchers and institutions (Bowen \& Rudenstine, 1992; Golde, 1996, 1998; Tinto, 1993). Golde (2005) explained that almost $40 \%$ of doctoral students do not complete their program. Poor integration into the 
institution increases the likelihood of a student withdrawing from the institution (Leppel, 2002). Graduate students with greater stress and lower social support were more likely to drop out (Cooke et al., 1995). Leppel (2002) explained that shrinking enrollment in higher education due to demographic changes in the United States placed more importance financially on higher education to increase student persistence. Golde (2005) indicated that non-economic costs of graduate student attrition, such as social and emotional costs, affected students and faculty in higher education.

In summary, this chapter addressed multiple strands of research on the topic of doctoral student degree completion. Each of the streams presented in the literature review highlight research that served to demonstrate concepts postulated by Tinto's theory of doctoral attrition. The socialization literature explained the induction of a graduate student into a new career and discipline. The transition of starting the endeavor of graduate education involved beginning socialization into a new culture within the department of a student's graduate program. The section on graduate student support highlighted the various forms of doctoral and graduate student support and the benefits in persistence and completion gained through various forms of support. Within the stream of the graduate student orientation literature, this review addressed the general practices and the effects of orientation on graduate student adjustment. The literature on dissertation preparation programs detailed the guidance and structure provided through coursework, seminars, and/or services designed to assist doctoral students throughout the dissertation process. The retention/attrition stream of literature explained the effects of socialization, support, dissertation preparation programs, and institutional and departmental orientations on student retention. Tinto's theory is longitudinal in focus and 
incorporated the interactivity of the various levels and layers connected to a student's development, growth, academic/career integration, and hopefully successful completion of the doctoral degree. Tinto's work on doctoral persistence served as a guide and a frame of reference for the current study. 


\section{CHAPTER III}

\section{METHODOLOGY}

Introduction

This chapter provides an explanation of the research methods used in conducting this study. The goal of this study focused on the effects of individual doctoral student characteristics and components of doctoral programs that affected doctoral student degree completion. In order to reach the educational level of a doctorate, students have successfully navigated the waters of higher education by attaining at least bachelor's degree and likely a master's degree. Given the earlier academic success achieved by doctoral students as demonstrated by completing prior degrees, academic failure is rarely the reason for a doctoral student to not complete the degree. Yet of all the doctoral students who enter their terminal degree experience, less than half of these students complete the doctoral degree. While individual characteristics of doctoral students may play a role in some doctoral attrition, institutions of higher learning and the programs that enroll the doctoral students may also contribute to doctoral attrition and could, in fact, be an integral component to the successful completion of a doctoral degree.

Due to higher education reform enacted in 1997, this study placed focus on two universities within the state of Kentucky. The University of Kentucky and the University of Louisville were given hefty aspirations and achievement goals set forth through the enactment of The Kentucky Postsecondary Improvement Act of 1997. The passing of 
The Kentucky Postsecondary Improvement Act of 1997 included provisions for the University of Kentucky and the University of Louisville to strengthen research programs and to become nationally competitive institutions. The Kentucky Postsecondary Improvement Act of 1997, commonly referred to as House Bill One (HB1), specifically created structures to develop and accountability systems to measure educational quality and student progress. This mandate to measure student progress directly affected all levels of students including doctoral students at the University of Kentucky and the University of Louisville.

Sheathed within the parameters of the higher education reform in the state of Kentucky, this study sought to understand not only how individual doctoral student characteristics may affect doctoral degree completion, but also how doctoral program characteristics at the University of Kentucky and the University of Louisville may affect doctoral degree completion. This chapter includes the research questions, research design, population, sample, instrumentation, data collection, and the data analysis.

\section{Research Questions}

With national statistics of doctoral completion rates hovering at or below $50 \%$ (Lovitts \& Nelson, 2000) and the passing of higher education reform in Kentucky in 1997, universities have received new and more stringent requirements or mandates on retention and graduation at the graduate level. Program Accountability mandates by the Council for Postsecondary Education in Kentucky began a formal process of connecting funding for undergraduate and graduate programs. Therefore, all degree programs, but more specifically doctoral degree programs, now had marching orders to not only graduate more doctoral students, but if they were unsuccessful, they must justify why 
they failed or risk losing funding. This mandate now puts a very direct focus on evaluation, adjustment, and refinement of doctoral program characteristics. The researcher sought to find any influence of individual and doctoral program characteristics on doctoral student completion rates. General research questions were as follows:

1. Do certain doctoral student demographic variables (age, ethnicity, gender, financial support, employment, marital status, dependents, distance from campus, debt load, employment status change after comprehensive exams, and enrollment status) affect doctoral student degree completion?

2. Do doctoral program characteristics (graduate student orientation programs, departmental assistance, social involvement, dissertation preparation courses, dissertation preparation seminars, clarity and understanding of academic program procedures/requirements, dissertation chair contact, academic involvement, support groups, and mentoring) affect doctoral student degree completion?

\section{Hypotheses}

The following directional hypotheses were tested at the .05 level of significance:

$\mathrm{H} 1_{\mathrm{a}}$ : Students who are employed full-time will be less likely to complete the doctoral degree.

$\mathrm{H} 2 \mathrm{a}$ : Students who experience an employment status change after comprehensive exams will be less likely to complete the doctoral degree.

$\mathrm{H} 3_{\mathrm{a}}$ : Students who are enrolled part-time will be less likely to complete the doctoral degree.

$\mathrm{H} 44_{\mathrm{a}}$ : Students who are satisfied with the departmental assistance available will be more likely to complete the doctoral degree.

$\mathrm{H} 5_{\mathrm{a}}$ : Students who are satisfied with the opportunity for social involvement during their doctoral degree will be more likely to complete the doctoral degree.

$\mathrm{H6}_{\mathrm{a}}$ : Students who are satisfied with the clarity and understanding of academic procedures/requirements within their program will be more likely to complete the doctoral degree.

$\mathrm{H} 7_{\mathrm{a}}$ : Students who are satisfied with the dissertation chair contact will be more likely to complete the doctoral degree. 
H8 $8_{\mathrm{a}}$ : Students who are satisfied with the opportunities for academic involvement within their program will be more likely to complete the doctoral degree.

\section{Description of Variables}

Primarily the independent variables were drawn heavily from the research and doctoral persistence model created by Tinto (1993) in a seminal book on undergraduate attrition in which he extended his attrition work into the realm of doctoral students. Kluever, Green, and Katz (1997) surmised that Tinto's (1993) research explained that factors important to attrition include (a) student attributes (gender, race, age, ability, and social class); (b) entry goals and orientation (educational and career goals and goal and institutional commitment); (c) institutional and program experiences; (d) academic and social integration; and (e) research experiences (involved in faculty research or student research groups, faculty-adviser relationships, and financial support). The Tinto (1993) model also incorporated external commitments (work and family responsibilities) and financial resources (type and amount of financial aid) that play an important role at the time a student enters a doctoral program. The independent variables were categorized into either individual doctoral student characteristics or doctoral program characteristics.

The researcher used the dependent variable of doctoral degree completion and it served as a single defined method of measuring doctoral student progress. The survey instrument, attached as Appendix A, will consist of a series of Likert scales measuring student perceptions of their doctoral experiences at the personal level and program level. The survey also included questions with Likert scales that cover demographic detail of the doctoral students and topics of educational background and support received throughout the doctoral degree. 


\section{Independent Variables}

The independent variables in this study were grouped in two key factors, and within each factor the variables are further defined as more specific measurable attributes.

Individual doctoral student characteristic variables:

1. Age - Ratio scale based on self-reported date of birth by year.

2. Ethnicity - Dummy coded nominal variables of various ethnicities.

3. Gender - Nominal level variables indicating gender with ordering implied.

4. Financial Support - Nominal variables individually selected as they apply to each participant.

5. Employment - Dummy coded nominal variables of levels of employment.

6. Marital Status - Dummy coded nominal variables of status levels.

7. Dependents - Ratio scale based on self-report indicating the number of dependents.

8. Distance From Campus - Ratio scale based on self-report of miles from campus.

9. Debt Load - Interval item scale with 9-point Likert response of debt levels in dollar amounts.

10. Employment Status Change After Comprehensive Exams - Dummy coded nominal variables indicating status change.

11. Enrollment Status - Interval item scale with 4-point Likert response of enrollment levels.

Doctoral Program Characteristic variables:

1. Orientation - Dummy coded nominal variables indicating attendance.

2. Departmental Assistance - Interval six item scale with 5-point Likert response measuring satisfaction of elements within the department.

3. Social Involvement - Interval seven item scale with 5-point Likert response measuring elements of opportunity for social involvement during pursuit of the doctoral degree.

4. Dissertation Preparation Courses - Dummy coded nominal variable indicating completion of this type of coursework.

5. Dissertation Preparation Seminars - Dummy coded nominal variable indicating participation in this type of seminar.

6. Clarity and Understanding of Academic Program Procedures/Requirements Interval five item scale with 5-point Likert response measuring satisfaction of elements and offerings within the academic program.

7. Dissertation Chair Contact - Interval six item scale with 5-point Likert response measuring satisfaction of various aspects with the dissertation chair. 
8. Academic Involvement - Interval four item scale with 5-point Likert-type response measuring satisfaction with opportunities for academic involvement within the doctoral program.

9. Support Groups - Dummy coded nominal variable indicating participation in this type of support group.

10. Mentor - Dummy coded nominal variable indicating utilization of a mentor.

\section{Dependent Variable}

The dependent variable in this study was doctoral student degree completion. Throughout the body of research on doctoral student attrition or retention doctoral student degree completion stood as the definitive item of success measurement. For the purpose of this study, doctoral student degree completion was defined as graduation from a doctoral degree program that would include completion of all coursework, passing doctoral comprehensive exams, and fulfillment of the dissertation requirement of the academic department. The dependent variable categorized a subject in one of two groups (no doctoral degree completion, doctoral degree completion) and therefore was a dichotomous variable.

\section{Research Design and Analysis \\ Description of Research}

Glatthorn and Joyner (2005) deduced that the nature of the research problem and the subsequent choice of the research methodology should be viewed as an interactive process. Quantitative research by nature is experimental, searches for relationships between variables, can be interpreted numerically, and can be measured (Glatthorn \& Joyner, 2005; Vogt, 2005). This study followed a correlational research design that analyzed relationships between two or more variables and sought to find patterns among variables (Glatthorn \& Joyner, 2005). Vogt (2005) summarized correlational research 
uses measures of association to explain that some of the variance of the dependant variable is caused by a correlation between groups. According to Vogt, "Regression analysis seeks to explain or predict the variability of a dependent variable using information about one or more independent variables" (p. 269). Due to the nature of the dependent variable being dichotomous, the researcher utilized logistic regression for statistical analysis. Vogt stated:

Logistic regression is based on transforming data by taking their natural logarithms so as to reduce nonlinearity. Only the dependent variable is transformed and the independent variables are left in their natural units. While linear regression uses the straight line to approximate the data, logistic regression uses the logarithmic curve that best approximates it. Rather than use Ordinary Least Squares, logistic regression estimates parameters using maximum likelihood estimation. (p. 179)

Logistic regression is commonly used to predict the occurrence of an event, in this case doctoral degree completion.

\section{Data Analysis}

Data analysis was carried out using the Statistical Package for the Social Sciences (SPSS) version 17.0 software program. The researcher employed the use of descriptive statistics, Pearson Correlations, and logistic regression to observe the relationship between individual and doctoral program characteristics on doctoral student degree completion. Factor analysis was used to establish construct validity for survey items.

\section{Population}

The population for the study consisted of all doctoral students across various departments that entered the University of Kentucky and the University of Louisville spanning the academic years of 1997-2003. Students pursuing professional degrees in medicine, law, dentistry, and pharmacy were eliminated from consideration. The students 
pursuing a professional degree in the areas mentioned above do not have the same degree completion requirements as doctoral students including, but not limited to, the completion of the dissertation, which serves as the capstone of doctoral study in American graduate education.

The University of Kentucky is a comprehensive doctoral granting public institution with an overall enrollment of more than 26,000 students of which more than 7,000 are in pursuit of graduate degrees and more than 2,300 of the graduate students are doctoral students. Excluding professional schools (law, medicine, and pharmacy) doctoral students at the University of Kentucky reside in the following divisions: Graduate School, Agriculture, Arts and Sciences, Business and Economics, Communications and Information Studies, Architecture, Education, Engineering, Fine Arts, Health Sciences, Nursing, Public Health, and Social Work.

The University of Louisville is a comprehensive doctoral granting public institution with an overall enrollment of more than 21,000 students of which more than 6,000 are in pursuit of graduate degrees and more than 1,000 of the graduate students are doctoral students. Excluding professional schools (law, dental, medicine), doctoral students at the University of Louisville reside in the following divisions: College of Arts and Sciences, College of Business, College of Education and Human Development, Kent School of Social Work, School of Music, School of Nursing, School of Public Health and Information Sciences, and J. B. Speed School of Engineering.

\section{Instrumentation}

The study consisted of surveying all doctoral students that entered the two institutions in the academic years of 1997-2003. The population completed a survey 
based primarily on the previous work of Vincent Tinto and his survey designed for the NSF called the Doctoral Studies Questionnaire along with a nationally vetted instrument called the Survey of Earned Doctorates. The Doctoral Studies Questionnaire developed by Tinto, was field-tested at Syracuse University and further used in research at Arizona State University and the University of Texas at Austin (Lee, 2003). Lee (2003) adapted the survey designed by Tinto in order to study the relationship between selected variables that influenced attrition in a doctoral program at Tennessee State University. Abedi and Benkin (1987) utilized data collected through the Survey of Earned Doctorates specifically for UCLA. The researchers utilized this data to examine the degree to which a set of variables predicted a student's time to doctoral degree.

The questionnaire, attached in Appendix A, contains sections on demographics, doctoral educational information, doctoral student experiences, and support received. Section A consists of questions related doctoral student background and demographic topics. Section B covers questions centered on educational experiences and characteristics and includes a subset of questions for those students that discontinued their doctoral education. This subset of questions includes anchors for a five answer Likert scale with the range of $1=$ not at all important, $2=$ of little importance, $3=$ neutral, $4=$ important, and $5=$ very important.

Section C covers questions concentrated on doctoral student experiences while pursuing their doctoral degree and includes subsets of questions on the following topics: (a) satisfaction, (b) social involvement, (c) clarity and understanding of degree requirements, (d) interaction with dissertation chair, and (e) satisfaction with academic involvement opportunities. The subset of questions on satisfaction, clarity and 
understanding of degree requirements, interaction with dissertation chair, and satisfaction with academic involvement opportunities includes anchors for a five answer Likert scale with the range of $1=$ very dissatisfied, $2=$ dissatisfied, $3=$ neutral, $4=$ satisfied, and $5=$ very satisfied. The subset of questions on social involvement includes anchors for a five answer Likert-type scale with the range $1=$ strongly disagree, $2=$ disagree, $3=$ neutral, $4=$ agree, and $5=$ strongly agree. Section D consists of questions related to various forms of support received by doctoral students during the pursuit of their doctoral degree.

\section{Validity and Reliability}

The trustworthiness of a research instrument is paramount to the collection of reliable and valid data. The survey instrument used in this study was based on design elements and content contained in two previously vetted national instruments, but due to the alterations and adaptations has no data on validity or reliability. Therefore, to provide trustworthiness of the instrument, additional steps were required to confirm validity and reliability of the instrument designed by the researcher.

\section{Validity}

Validity refers to the "degree to which all the accumulated evidence supports the intended interpretation of test scores for the proposed purpose" (Mertler \& Charles, 2005, p. 149). Vogt (2005) explained that validity for a survey instrument occurs when the instrument simply and accurately measures what it is supposed to measure. Since other research instruments influenced the instrument used, procedures will be utilized to establish validity. 


\section{Content Validity}

As Vogt (2005) stated: “A measure [on a survey instrument] has content validity when its items accurately represent the thing being measured" (p. 59). Vogt also explained content validity is simply a matter of expert judgment and is not a statistical property. A panel of experts serves to review the items on an instrument to determine accurate representation of the items measured (Huck, 2008).

In order to address the content validity, the researcher submitted the instrument for review by a panel of experts. The panel of experts included Dr. Steve Miller and a group of doctoral students enrolled in a survey design course at the University of Louisville. Dr Steve Miller is an Associate Professor in the Department of Educational Administration, Leadership, and Research at Western Kentucky University. The doctoral students were enrolled in ELFH 602, Survey Research and Design, offered through the Educational Leadership and Foundations department. The panel of experts reviewed the instrument and assessed it for concepts such as a) clarity, b) practicality, c) instrument length, d) instrument structure, e) wording, f) appropriateness of items within scales, and g) variable measurement effectiveness. The researcher utilized the suggestions and findings of the panel of experts to adjust the survey instrument. Common suggestions included (a) adjust the phrasing to better define and specify what is requested in the questions on have you graduated, marital status, and ethnicity; (b) further definition/clarity of enrollment status question; (c) adding in a question that allows the respondent to choose which institution (University of Kentucky, University of Louisville) the respondent attended; (d) adding in a response of orientation not available to the orientation attendance question; (e) further definition/clarification on the question 
requesting degree progress; and (f) addition of skip logic to questions that do not pertain to all respondents in order to have the respondent automatically skip sections based on answers they provide. The panel of experts also suggested various grammar and sentence structure revisions to further clarify the survey to future respondents.

\section{Construct Validity}

Construct validity refers to the extent to which variables accurately measure the constructs of interest (Vogt, 2005). The survey items in this research were analyzed to determine if the survey items are measuring the factors being studied. Factor Analysis (FA) is a procedure that allows a researcher to reduce the number of variables. Vogt explained that, in survey research, factor analysis often serves to permit the researcher to explore the possibility of reducing or grouping longer series of questions into shorter series of questions and seeks to find patterns within the variations of several variables.

Generally the most common forms of factor analysis include exploratory factor analysis and confirmatory factor analysis. Exploratory factor analysis allows a researcher to discover the factors inherent in certain variables or measures. Exploratory factor analysis requires no prior theory and allows the investigator to model the factor structure based on the factor loadings. In confirmatory factor analysis, the researcher generally starts with a theory and utilizes the technique to test hypotheses on factors that are

expected to be found (Vogt). The investigator sought to confirm that variables would load as predicted on the expected number of factors and, therefore, factor analysis was used to assess construct validity. 


\section{Reliability}

Reliability is demonstrated through consistency (Mertler \& Charles, 2005). According to Upton and Cook (2006), "Reliability is a measure of the confidence that we can have in the results obtained [from research]" (p. 368). The investigator subjected the instrument to a pilot study to determine how well the survey measures doctoral student experiences. The pilot study participants $(N=16)$ were members of the most recent cohort of doctoral students admitted into the Educational Administration program at Western Kentucky University. The researcher utilized this population due to the similarity of the intended population for the actual study. Cronbach's alpha procedures were utilized on the scaled items within the instrument in order to determine survey reliability. The pilot study participants were invited to complete the survey instrument. The researcher e-mailed the online survey link to the professor of record of the incoming cohort class and the students were requested to complete the survey on a volunteer basis. The professor on record explained that completion of the survey instrument and the results would be used solely to assist the researcher in determining reliability of the instrument. Students were free to choose not to participate. The scaled question related to clarity and understanding of academic requirements produced a lower Cronbach's alpha of $\alpha=.227$. All of the remaining scaled questions produced Cronbach's alpha results ranging from $\alpha=.656$ to $\alpha=.894$. The results were judged high enough to demonstrate consistency of the scaled items in the instrument.

\section{Data Collection Procedures}

The data collection consisted of administration of the survey online and was designed through the use of design tools provided by the company SurveyMonkey. 
SurveyMonkey provided an online survey tool that enables a user to create surveys quickly and easily. SurveyMonkey also hosts the survey on the Web by providing a unique survey Website address for each survey designed. SurveyMonkey described the company as the leading survey tool on the Web, and the company has provided design and administration services for surveys since 1999. The company employs multiple layers of security to ensure the collected data remains private and secure. SurveyMonkey employs a third-party firm to conduct daily audits of their security, and the data reside behind the latest in firewall and intrusion prevention technology. All data the researcher collected were kept completely and absolutely confidential. SurveyMonkey is not affiliated with any third-parties, and they never accept any advertising in order to maximize data security. The researcher obtained permission to access the mailing addresses of the doctoral students from the Office of Institutional Research at the University of Kentucky (Appendix B) and the Office of Institutional Research and Planning at the University of Louisville (Appendix C). In order to comply with the guidelines of the Family Educational Rights to Privacy Act (FERPA), confidentiality and anonymity of the research subjects was maintained. No identifiable questions were asked on the survey and the online survey allowed for anonymous access and completion.

According to Dillman (2000), "Web surveys have a refined appearance, and also provide survey capabilities far beyond those available for any other type of selfadministered questionnaire" (p. 354). As stated by Dillman, Smyth, \& Christian (2009), "The Internet is a useful mode for conducting surveys targeted at very specific populations such as college students and certain professionals" (p. 44). Furthermore, Dillman, Smyth, \& Christian noted that, "Due to specific populations, such as students in 
universities, having high internet access rates and skill levels internet surveys can be designed and implemented and results reported faster than with any of the traditional survey modes and often at lower costs" (p. 9). Under the guidelines of survey construction and Web-based survey administration techniques provided by Dillman (2000) and Dillman, Smyth, \& Christian (2009), the instrument used was constructed by the researcher for Web-based administration utilizing the design program provided by SurveyMonkey.

The researcher recruited subjects for participation based on the populations defined by all doctoral students admitted to the University of Kentucky and the University of Louisville from 1997-2003. Since the survey participants could date back to a period of 12 years, the e-mail address that the university had on file may have a higher likelihood of being an invalid e-mail address. Therefore, the researcher utilized a postcard that included a Web link to complete the survey and was mailed to the entire research population (Appendix D). The University of Louisville Postal Services Office provided the opportunity to utilize the United States Postal Service (USPS) National Change of Address Database (NCOA). The NCOA database sought to reduce incorrect mailing addresses and returned mail by comparing the list of participants addresses provided to the USPS national database of addresses and updated the most recent address for the individuals listed in the database. Through the use of this database, the most accurate mailing list was utilized when trying to reach the survey population. The postcard served the function of providing anonymity and also provided the most accurate method to contact the survey participants. 
The investigator mailed a postcard to the home addresses of the defined population. Based on suggestions by Dillman, Smyth, \& Christian (2009), the postcard contained an invitation to complete the online survey along with the Web address where the survey was located online. The doctoral students then had the opportunity to input the Web address into a Web browser. Once the doctoral students arrived at the Web address provided on the postcard, they encountered the preamble that explained why response is important. Once the doctoral students read the preamble, they began the online survey. The survey did not collect e-mail addresses or any personally identifiable information. By sending a postcard through the postal system, the survey participants had the freedom to utilize any computer and complete the survey anonymously and at the participants' convenience.

Dillman, Smyth, \& Christian explained that multiple contacts were essential to maximizing survey results; therefore, based on Dillman, Smyth, \& Christian's suggestions 3 weeks after the initial postcard mailing, the researcher mailed a "Thank You" postcard that expressed appreciation for those that already responded and encouraged survey completion for those who had yet to complete (p. 243). The "Thank You" postcard contained the Web address where the survey was located online in order for the participants to complete the survey. Subjects again had the opportunity to respond to a mailed postcard to a home address, and they had the opportunity to anonymously complete the survey online through a Web address included on the postcard.

\section{Ethical Considerations}

The researcher took all steps and measures necessary to make certain that the study conforms with ethical research standards. Research involving human subjects is 
regulated by federal guidelines. The researcher, guided by paramount concern, strove to ensure anonymity of subjects, confidentiality of data, minimization of any possible harm to subjects, and opportunity for any potential benefit for participation to subjects.

The researcher is a doctoral student within the Cooperative Doctoral Program between the University of Louisville and Western Kentucky University. Due to the partnership between the University of Louisville and Western Kentucky University, doctoral students enrolled in the Cooperative Doctoral program must fulfill the educational requirements at both institutions. Therefore, Cooperative Doctoral Students must submit the dissertation project for formal Human Subjects Committee review at both the University of Louisville and Western Kentucky University. In order to comply with ethical and legal mandates and in conjunction with submitting the dissertation project to the Human Subject Review Committee at both institutions, both the Dissertation Committee Chair and the doctoral student must complete the official Human Subjects certification program (CITI) at the University of Louisville.

The study received initial approval of the proposal by the dissertation committee before being submitted to the Human Subject Review Committee at both institutions. Prior to the start of data collection the Human Subjects Review Board (HSRB) at Western Kentucky University approved the study and the Human Subjects Protection Program (HSPPO) at the University of Louisville (Appendix E and Appendix F). Because the study involved data collection at both the University of Kentucky and the University of Louisville, extra measures were required to gain approval from the University of Kentucky. Once approval was received from the HSPPO at the University of Louisville, the researcher submitted an open records request for the needed data for 
doctoral students that attended the University of Kentucky from 1997-2003. The approval document from the HSPPO of the University of Louisville was submitted to the University of Kentucky along with the open records request to seek approval from the University of Kentucky.

In combination, each step and requirement explained in this section should provide the necessary level of protection of subjects in this study. All copies of consent forms and letters of approval from both the University of Kentucky and the University of Louisville are included in Appendices B and C. Appendices E and F contain all approval documents received from the HSRB at Western Kentucky University and the HSPPO at the University of Louisville.

Summary

This research study was a non-experimental analysis of survey data and doctoral student persistence data from both the University of Kentucky and the University of Louisville. The dependent variable was doctoral student completion, as defined as graduation from a doctoral degree program that would include completion of all coursework, passing doctoral comprehensive exams, and fulfillment of the dissertation requirement of the academic department. The independent variables in this study were grouped in two key factors and within each factor the variables were further defined as more specific measurable attributes. These variables included (a) individual doctoral student characteristics (age, ethnicity, gender, financial support, employment, marital status, dependents, distance from campus, debt load, employment status change after comprehensive exams, and enrollment status); and (b) doctoral program characteristics (graduate student orientation programs, departmental assistance, social involvement, 
dissertation preparation courses, dissertation preparation seminars, clarity and understanding of academic program procedures/requirements, dissertation chair contact, academic involvement, support groups, and mentoring).

This study attempted to address the following research questions: (1) Do certain student demographic variables (age, ethnicity, gender, financial support, employment, marital status, dependents, distance from campus, debt load, employment status change after comprehensive exams, and enrollment status) affect doctoral student degree completion? and (2) Do program characteristics (graduate student orientation programs, departmental assistance, social involvement, dissertation preparation courses, dissertation preparation seminars, clarity and understanding of academic program procedures/requirements, dissertation chair contact, academic involvement, support groups, and mentoring) affect doctoral student degree completion?

Eight directional hypotheses were tested: (1) Students who are employed full-time will be less likely to complete the doctoral degree; (2) Students who experience an employment status change after comprehensive exams will be less likely to complete the doctoral degree; (3) Students who are enrolled part-time will be less likely to complete the doctoral degree; (4) Students who are satisfied with the departmental assistance available will be more likely to complete the doctoral degree; (5) Students who are satisfied with the opportunity for social involvement during their doctoral degree will be more likely to complete the doctoral degree; (6) Students who are satisfied with the clarity and understanding of academic procedures/requirements within their program will be more likely to complete the doctoral degree; (7) Students who are satisfied with the dissertation chair contact will be more likely to complete the doctoral degree; and (8) 
Students who are satisfied with the opportunities for academic involvement within their program will be more likely to complete the doctoral degree.

In order to address these questions, the researcher used a survey instrument adapted from previous surveys used in research on doctoral student attrition designed to assess the influence of individual doctoral student attributes and doctoral program attributes on doctoral student degree completion. Through the use of logistic regression analysis, the researcher explored the relationship that individual doctoral student characteristics and doctoral program characteristics may have with doctoral student degree completion. 


\section{CHAPTER IV}

\section{RESULTS}

Introduction

The purpose of this study was to diagnose both individual doctoral student characteristics and doctoral program characteristics that lead to successful doctoral degree completion among doctoral students at the University of Kentucky and the University of Louisville. The key research questions for the study sought to determine a) Do certain doctoral student demographic variables affect doctoral student degree completion? and b) Do doctoral program characteristics affect doctoral student degree completion?

The independent variables were identified through prior use in research or further suggestion from researchers within the topic of doctoral degree completion (Abedi \& Benkin, 1987; Bair \& Haworth, 1999; Bauer, 2004; Campbell, 1992; Cheatham et. al., 1982; Coulter et al., 2004; Dorn \& Papalewis, 1995; Dorn \& Papalewis, 1997; Emerson, 1998; Golde, 2000; Golde \& Dore, 2001; Hahs, 1998; Hatley \& Fiene, 1995; Jacks et. al., 1983; King \& Chepyator-Thompson, 1996; Kluever, 1997; Kluever et al., 1997;

Leadabrand, 1985; Lee, 2003; Leppel, 2002; Malmberg, 2000; Meyers, 1999; Pauley, 1998; Poock, 2002; Rimmer, Lammert, \& McClain, 1982; Seagram et al., 1998; Sigafus, 1998; Taub \& Komives, 1998; Tinto, 1993; Wagner, 1986; Wright, 1991; Wynn, 2003). The independent variables clustered around two broad categories: a) doctoral student 
characteristics (age, ethnicity, gender, financial support, employment, marital status, dependents, distance from campus, debt load, employment status change after comprehensive exams, and enrollment status); and b) doctoral program characteristics (graduate student orientation programs, departmental assistance, social involvement, dissertation preparation courses, dissertation preparation seminars, clarity and understanding of academic program procedures/requirements, dissertation chair contact, academic involvement, support groups, and mentoring).

The dependent variable was doctoral student degree completion and it served as a single defining method of measuring doctoral student progress. The researcher used the dependent variable based on prior research utilization (Bauer, 2004; Campbell, 1992; Dorn \& Papalewis, 1995; Dorn \& Papalewis, 1997; Emerson, 1998; Hatley \& Fiene, 1995; King \& Chepyator-Thompson, 1996; Leadabrand, 1985; Lovitts, 2004; Malmberg, 2000; Pauley, 1998; Stallone, 2003; Tinto, 1993).

Study participants consisted of doctoral students that entered the University of Kentucky ( $n=163)$ and the University of Louisville $(n=107)$ spanning the academic years of 1997-2003 $(N=275)$. Due to differences in structure and degree completion requirements, students pursuing professional degrees in medicine, law, dentistry, and pharmacy were eliminated from consideration. Participants completed a survey based primarily on the previous work of Vincent Tinto and his survey designed for the National Science Foundation (NSF) called the Doctoral Studies Questionnaire along with a nationally vetted instrument called the Survey of Earned Doctorates.

The research hypotheses were tested using logistic regression. Since the dependent variable of doctoral degree completion is a dichotomous variable and therefore 
categorizes a subject in one of two groups (no doctoral degree completion, doctoral degree completion), the proper route for analysis was logistic regression. The first logistic regression equation included independent variables centered on individual doctoral student characteristics in an attempt to predict the occurrence of the dependent variable of doctoral degree completion. The second logistic regression equation included independent variables centered on doctoral program characteristics in an attempt to predict the occurrence of the dependent variable of doctoral degree completion. After completing the two initial regression equations, the researcher removed variables that did not demonstrate significance ( $\mathrm{p}<.05$ ) for parsimony. This allowed the investigator to run a logistic regression equation that included only variables that demonstrated significance from the first and second logistic regressions as well as any variables that demonstrated significance in the bivariate Pearson correlations in an attempt to predict the occurrence of the dependent variable of doctoral degree completion.

\section{Pilot Study}

The survey instrument utilized in this research draws from two nationally tested and vetted survey instruments. Although each instrument has been tested separately, processes to establish validity and reliability were conducted prior to formal collection of data for this study due to the use of an amended study and combination of instruments. A pilot study was conducted to test the validity of the revised instrument. The pilot study participants $(N=16)$ were members of a recent cohort of doctoral students admitted in 2008 into the Educational Administration program at Western Kentucky University. The researcher utilized this population due to the similarity of the intended population for the actual study. 


\section{Construct Validity}

In order to assess the extent to which variables accurately measured the constructs

of interest, the survey items in this research were analyzed using factor analysis based on a pilot study performed by the researcher. Costello and Osborne (2005) explained that "Exploratory factor analysis is a widely utilized and broadly applied statistical technique in the social sciences" (p. 1). Based on prior research by Costello and Osborne, the research used maximum likelihood as the method of extraction for the factor analysis. In order to allow for the possibility of factors to correlate, the investigator utilized oblique rotation as the rotation method. The factor analysis was performed on the survey items that consisted of scales.

\section{Reliability}

Cronbach's alpha procedures were utilized on the scaled items within the instrument in order to determine survey reliability. The pilot study participants $(N=16)$ from the same cohort of doctoral students used in the above validity results were invited to complete the survey instrument. The researcher e-mailed the online survey link to the professor of record of the incoming cohort class and the students were requested to complete the survey on a volunteer basis. The professor on record explained that completion of the survey instrument and the results would be used solely to assist the researcher in determining reliability of the instrument. Students were free to choose not to participate. 
The scaled question related to clarity and understanding of academic requirements produced a lower Cronbach's alpha of $\alpha=.227$. All of the remaining scaled questions produced Cronbach's alpha results that ranged from $\alpha=.656$ to $\alpha=.894$. The results were judged high enough to demonstrate consistency of the scaled items in the instrument.

\section{ContentValidity}

A panel of experts reviewed the survey instrument designed by the researcher to determine if the survey items accurately measured what each construct was intended to measure. The panel of experts included Dr. Steve Miller and group of doctoral students enrolled in a survey design course at Western Kentucky University. Dr Steve Miller is an Associate Professor in the Department of Educational Administration, Leadership, and Research at Western Kentucky University. The doctoral students $(N=6)$ from the University of Louisville were enrolled in ELFH 602, Survey Research and Design, offered through the Educational Leadership and Foundations department.

The panel of experts reviewed the instrument and assessed it for concepts such as a) clarity, b) practicality, c) instrument length, d) instrument structure, e) wording, f) appropriateness of items within scales, and g) variable measurement effectiveness. The researcher utilized the suggestions and findings of Dr. Miller and the doctoral student reviews to adjust the survey instrument. The final version of the revised survey can be found in Appendix A

\section{Procedure}

The researcher administered the survey following guidelines defined by Dillman (2000) and Dillman, Smyth, \& Christian (2009) and used the design program provided by 
the company SurveyMonkey. The Official Records Custodian at the University of Kentucky granted permission to contact doctoral students enrolled from 1997-2003 at the University of Kentucky (Appendix B). The Office of Institutional Research and Planning at the University of Louisville granted permission to contact doctoral students enrolled from 1997-2003 at the University of Louisville (Appendix C).

The investigator created a set of four postcards to be mailed to the entire research population (Appendix D). The initial mailing consisted of two postcards that included the exact same message but were designed in a variable data method in order to personalize and target the postcard to University of Kentucky students $(n=1,927)$ and University of Louisville $(n=1,231)$ students respectively. The initial postcards mailed to the entire population of doctoral students $(N=3,158)$ enrolled from $1997-2003$ at both the University of Kentucky and the University of Louisville, briefly explained the purpose of the study, requested participation, and provided the Web address to access the survey. Three weeks later, a second set of postcards was sent to the survey population. The second set of postcards again consisted of two postcards that included the exact same message but were designed in the same variable data method in order to personalize and target the postcard University of Kentucky students $(n=1,927)$ and University of Louisville $(n=1,231)$ students respectively. The second set of postcards acknowledged the initial postcard mailed to the potential participant, briefly explained the purpose of the study, requested participation, and provided the Web address to access the survey. After the second set of mailings, the maximum limits of doctoral student participation at the University of Kentucky and the University of Louisville appeared to have been reached $(N=275)$. 


\section{Descriptive Statistics}

Table 1 shows participation data and response rates by institution. There were a total of 275 doctoral student responses from a population pool of 3,158 doctoral students, yielding a response rate of $8.7 \%$.

Table 1

Participation Information: Institutions

\begin{tabular}{lccc}
\hline & Possible & Frequency & $\begin{array}{c}\text { Percent } \\
\text { Participation }\end{array}$ \\
\hline University of Kentucky & 1927 & 163 & 8.5 \\
University of Louisville & 1231 & 107 & 8.7 \\
$\begin{array}{l}\text { Unidentified } \\
\text { Total }\end{array}$ & 3158 & 5 & \\
\hline
\end{tabular}

Descriptive Statistics

Study participants included doctoral students $(N=275)$ admitted between 19972003 at both the University of Kentucky and the University of Louisville. Respondents completed an online survey assessing personal doctoral student experiences while enrolled in a doctoral program. Demographic information was also obtained in the survey. More participants responded to commuted to campus in miles than reported age. The average age of reporting respondents was 43.41 . The average commute to campus in miles was 29.24, suggesting that most doctoral students lived within the geographic region where the institution they attended was located.

Table 2 reports gender, ethnicity, and ethnicity as white or non-white. Due to the sample size concentration reaching $86 \%$ indication as white, the other ethnicities did not constitute a large enough category individually and were therefore grouped together. This 
led to the ethnicity variable being explained as White or Non-White for statistical comparison. A majority of respondents were female (57.5\%). An overwhelming majority of respondents were white $(85.8 \%)$.

Table 2

Demographic Information: Gender, Ethnicity, and Ethnicity: White or Non-White

\begin{tabular}{lccc}
\hline & & Frequency & Percentage \\
& Female & 158 & 57.5 \\
Mender: & 115 & 41.8 \\
Ethnicity: & American Indian & 0 & 0.0 \\
& Asian & 11 & 4.0 \\
& Black or African & American & 5.8 \\
& Hispanic & 16 & 1.5 \\
& Pacific Islander & 4 & 0.4 \\
& White & 1 & 85.8 \\
& Other & 236 & 1.8 \\
Ethnicity: White or & White & 5 & 85.8 \\
Non-White & Non-White & 37 & 13.5 \\
\hline
\end{tabular}

In Table 3, employment status was identified not only by full-time or part-time but allowing for not working and pursuing other education. The high majority of respondents worked full-time while pursuing their doctoral studies (73.6\%) while a much smaller minority worked only part-time $(16.5 \%)$. The remaining portion of respondents only represented small proportions of the population with $8.8 \%$ not in the labor force and 4.6\% pursuing further studies. There were 14 non-responders to this question. 
Table 3

Employment Status

Frequency Percentage

\begin{tabular}{lcc} 
Not in Labor Force & 23 & 8.8 \\
Employed (full-time) & 192 & 73.6 \\
$\begin{array}{l}\text { Employed (part-time) } \\
\begin{array}{l}\text { Pursuing Further Studies (i.e., postdoctoral } \\
\text { research, other degree) }\end{array}\end{array}$ & 43 & 16.5 \\
\hline
\end{tabular}

In Table 4 enrollment status was reported by respondents and identified in a scaled manner from Enrolled Mostly Part-Time to Enrolled All Full-Time. The Mostly Part-Time and Mostly Full-Time statements pertained to the students that may have had sporadic semesters in which they may have fit into either a part-time or full-time definition, but overall they can define the majority of their enrollment experience as being either part-time or full-time. The All Part-Time or All Full-Time statements pertained to students that can unequivocally state that their enrollment experience was entirely part-time or entirely full-time. The majority of respondents indicated enrollment at the all full-time equivalent of 9 hours or more per semester (31.7\%). Closely behind the statistical majority, $30.6 \%$ of respondents indicated enrollment at the mostly part-time equivalent of below 9 hours. When the categories of mostly part-time and all part-time are combined they account for the majority of total respondents responses the number is $51.5 \%$, indicating an overall enrollment profile of part-time. There were seven participants that did not respond to this question. 
Table 4

Enrollment Status

\begin{tabular}{lcc}
\hline & Frequency & Percentage \\
\hline Mostly Part-Time (below 9 hours) & 82 & 30.6 \\
Mostly Full-Time (9 hours or more) & 45 & 16.8 \\
All Part-Time (below 9 hours) & 56 & 20.9 \\
All Full-Time (9 hours or more) & 85 & 31.7 \\
\hline
\end{tabular}

Factor Analyses

The researcher utilized a factor analysis in order to determine, as Mertler and Vannatta (2005) explained, "The underlying purpose of factor analysis is to determine if measures for different variables are, in fact, measuring something in common" (p. 249). A factor analysis was run on the full sample using maximum likelihood extraction with oblique rotation (Costello \& Osborne, 2005). Costello and Osborne (2005) explained that oblique rotation should render more accurate and more reproducible solutions. Once factors were identified, the items comprising individual factors were re-run to create the factor-score weighted scales. The instrument contained both non-Likert scaled items and Likert scaled items. Several of the questions on the survey instrument that measured various independent variables were scaled questions using multiple items. Factor analysis does not require all items to be on the same scale as it operates on the correlation matrix between items. Tabachnick and Fidell (2007) explain that as long as factor analysis is used to summarize the relationships in a large set of observed variables, assumptions about the distributions of those variables are not in force. Therefore, the researcher did 
nothing unique to the variables that were not Likert scaled. All variables that were categorical, were dummy coded. All of the scaled items were located in Section C of the instrument which measured the doctoral student experiences.

According to Costello and Osborne (2005), "The data and literature supports the argument that optimal results will be achieved by use of a true factor analysis extraction method of maximum likelihood, oblique rotation such as direct oblimin, and the use of scree plots for information on how many meaningful factors might be in a data set" (p. 7). In order to decide on the number of factors, the researcher used the scree test, examining the graph of the eigenvalues on the scree plot, looking for the natural bend in the data where the curve flattens. Costello and Osborne (2005) explained that the number of data points above the break is usually the number of factors to choose. Furthermore, the researcher looked for a clean factor structure, those items loading above .30, no items crossloading on two factors, no factors with fewer than three items, and interpretable factors.

\section{Satisfaction With Departmental Assistance}

The first scaled question sought to measure satisfaction with departmental assistance and consisted of six items. The items loaded on two factors (see Table 5). The first factor was labeled Material Satisfaction (MATSAT) and consisted of the items: (a) Access to research material, and (b) Quality of research material. The second factor was labeled Department Satisfaction (DEPTSAT) and consisted of the following items: (a) Faculty availability, (b) Departmental advising, (c) Support from staff, and (d) Support from faculty. Table 5 displays the pattern matrix for the variable departmental assistance 
and the results explained that all six factors cannot be treated together and that it was best to create two separate scales (MATSAT, DEPTSAT).

Table 5

Pattern Matrix for Satisfaction with Departmental Assistance Scale

Pattern Matrix ${ }^{a}$

\begin{tabular}{|l|c|c|}
\hline \multirow{2}{*}{} & \multicolumn{2}{|c|}{ Factor } \\
\cline { 2 - 3 } & 1 & 2 \\
\hline Faculty availability & .913 & .035 \\
Access to research material & .037 & -.905 \\
Quality of research material & -.018 & -.948 \\
Departmental advising & .861 & -.018 \\
Support from staff & .579 & -.197 \\
Support from faculty & .927 & .077 \\
\hline
\end{tabular}

Extraction Method: Maximum Likelihood.

Rotation Method: Oblimin with Kaiser Normalization.

a. Rotation converged in 5 iterations.

Once the items were divided by the factor loadings, Cronbach's alpha reliability measures demonstrated the factor Material Satisfaction (MATSAT) had an alpha of $\alpha=$ .929 and the factor Department Satisfaction (DEPTSAT) had an alpha of $\alpha=.900$.

\section{Social Involvement}

The second scaled question sought to measure doctoral student involvement and consisted of seven items. The items loaded on one factor (see Table 6). The factor was labeled Social Involvement (SOCINVOL1) and consisted of the items: (a) Easy to make friends, (b) Easy to develop faculty relationships, (c) High contact with faculty out of class, (d) Had strong sense of community, (e) Maintaining peer relationships, (f) Involvement in graduate organizations, and $(\mathrm{g})$ Involvement in campus recreation. 
Table 6

Pattern Matrix for Social Involvement

\begin{tabular}{|l|c|c|}
\hline \multicolumn{1}{|c|}{ Pattern Matrix $^{\mathbf{a}}$} \\
\cline { 2 - 3 } \multicolumn{1}{|c|}{ Factor } \\
\hline Easy to make friends & 1 & 2 \\
Easy to develop faculty relationships & .741 & -.047 \\
High contact with faculty out of class & .701 & .032 \\
Students had strong sense of community & .728 & .002 \\
Maintaining peer relationships & .826 & .063 \\
Involvement in graduate organizations & .753 & -.094 \\
Involvement in campus recreation & -.012 & -.850 \\
\end{tabular}

Extraction Method: Maximum Likelihood.

Rotation Method: Oblimin with Kaiser Normalization.

a. Rotation converged in 4 iterations.

Table 7

Factor Correlation Matrix for Social Involvement

Factor Correlation Matrix

\begin{tabular}{|l|c|c|}
\hline Factor & 1 & 2 \\
\hline 1 & 1.000 & -.485 \\
2 & -.485 & 1.000 \\
\hline
\end{tabular}

Extraction Method: Maximum Likelihood.

Rotation Method: Oblimin with Kaiser Normalization.

Cronbach's alpha reliability measures demonstrated the factor Social Involvement had an alpha of $\alpha=.856$.

\section{Clarity and Understanding of Academic Program}

The third scaled question sought to measure satisfaction of the clarity and understanding of the doctoral student's academic program and consisted of five items. 
The items loaded on loaded on one factor (see Table 8). The factor was labeled Satisfaction of Program (SATPROG) and consisted of the items: (a) Availability of courses, (b) Program requirements (c) Departmental advising, (d) Comprehensives preparation, and (e) Financial aid information.

Table 8

Factor Matrix for Satisfaction of Program

\section{Factor Matrix}

\begin{tabular}{|l|c|}
\hline & Factor \\
\cline { 2 - 2 } & 1 \\
\hline Availability of courses & .705 \\
Program requirements & .813 \\
Departmental advising & .827 \\
Comprehensives preparation & .729 \\
Financial aid information & .598 \\
\hline
\end{tabular}

Extraction Method: Maximum Likelihood.

a. 1 factors extracted. 4 iterations required.

Cronbach's alpha reliability measures demonstrated the factor Satisfaction of Program had an alpha of $\alpha=.853$.

\section{Dissertation Chair}

The fourth scaled question sought to measure satisfaction of the doctoral student's dissertation chair and consisted of six items. The items loaded on loaded on one factor (see Table 9). The factor was labeled Satisfaction of Chair (SATCHAIR) and consisted of the items: (a) Dissertation topic selection, (b) Dissertation committee selection (c) Proposal preparation, (d) Dissertation research, (e) Dissertation writing, and (f) Dissertation chair accessibility. 
Table 9

Factor Matrix for Satisfaction of Chair

Factor Matrix ${ }^{a}$

\begin{tabular}{|l|c|}
\hline & Factor \\
\cline { 2 - 2 } & 1 \\
\hline Dissertation topic selection & .875 \\
Dissertation committee selection & .822 \\
Proposal preparation & .924 \\
Dissertation research & .947 \\
Dissertation writing & .934 \\
Dissertation chair accessibility & .873 \\
\hline
\end{tabular}

Extraction Method: Maximum Likelihood.

a. 1 factor extracted. 4 iterations required.

Cronbach's alpha reliability measures demonstrated the factor Satisfaction of Chair had an alpha of $\alpha=.96$.

Opportunity for Academic Involvement

The fifth and final scaled question sought to measure satisfaction of the doctoral student's opportunity for academic involvement and consisted of four items. The items loaded on loaded on one factor (see Table 10). The factor was labeled Satisfaction of Academic Involvement (SATACAD1) and consisted of the items: (a) Research presentation in department, (b) Attending national conferences (c) Research presentations at national conferences, and (d) Opportunity to publish. 
Table 10

Factor Matrix for Satisfaction of Academic Involvement

Factor Matrix ${ }^{a}$

\begin{tabular}{|l|c|}
\hline & Factor \\
\cline { 2 - 2 } & 1 \\
\hline Research presentation in department & .732 \\
Attending national conferences & .932 \\
Research presentations at national conferences & .991 \\
Opportunity to publish & .728 \\
\hline
\end{tabular}

Extraction Method: Maximum Likelihood.

a. 1 factor extracted. 16 iterations required.

Cronbach's alpha reliability measures demonstrated the factor Satisfaction of Academic Involvement had an alpha of $\alpha=.91$.

Research Questions

The research questions for the study sought to determine the following: a) Do certain doctoral student demographic variables affect doctoral student degree completion; and b) Do doctoral program characteristics affect doctoral student degree completion?

There were eight directional hypotheses tested at the significance level of .05.

Using the Statistical Package for the Social Sciences (SPSS) for data analysis, the hypotheses were tested using logistic regression. The dependent variable categorizes a subject in one of two groups (no doctoral degree completion, doctoral degree completion) and therefore is a dichotomous variable which guides the researcher to employ logistic regression. The researcher made use of correlations between all variables for all respondents to ascertain if relationships between variables could be identified. 
In Table 11, correlation results between the variables associated with the first research question (Do certain doctoral student demographic variables affect doctoral student degree completion) and all participants are displayed. Only four variables demonstrate significance $(\mathrm{p}<.05)$. Age $(.153, \mathrm{p}<.05)$ was observed as a positive correlation. A surprising result was that Not Working $(-.149, \mathrm{p}<.05)$ produced a negative correlation to completing the degree. Conversely, Employed Full-Time (.174, $\mathrm{p}<.05)$ demonstrated significance with a positive correlation to completing the degree. Finally, Employment Status Change After Comprehensive Exam $(-.363, \mathrm{p}<.05)$ produced a slight significance with a negative correlation. 
Table 11

Correlations with Doctoral Degree Completion for All Variables Addressed in Research Question One for All Respondents

\begin{tabular}{lcc}
\hline Independent Variable & Pearson Correlation & Significance (2-tailed) \\
\hline Age & .153 & $.014^{*}$ \\
Race (White/Non-White) & .047 & .448 \\
Gender & -.109 & .077 \\
Fellowship or Scholarship & .021 & .727 \\
Grant & .001 & .990 \\
Teaching Assistantship & .017 & .783 \\
Research Assistantship & -.042 & .491 \\
Other Support & .027 & .660 \\
Loans & -.107 & .080 \\
Personal Savings & .078 & .204 \\
Personal Earnings & .041 & .503 \\
Spouse/Partner Family Earnings & -.007 & .915 \\
Employer Assistance & -.048 & .434 \\
Not Working & -.149 & $.014 *$ \\
Working Full-Time & .174 & $.004 *$ \\
Working Part-Time & -.076 & .216 \\
Post-Doctoral Studies & -.039 & .526 \\
Married & -.021 & .733 \\
Divorced & .041 & .501 \\
Single & -.008 & .891 \\
Number of Dependents & .030 & .630 \\
Commute to Campus & .109 & .078 \\
Amount of Doctoral Debt & -.029 & .645 \\
Employment Status Change & -.363 & $.000^{*}$ \\
After Comp Exams & .091 & .139 \\
Enrollment Full-Time/Part-Time & & \\
\hline
\end{tabular}

*Correlation is significant at the 0.05 level (2-tailed). 
In Table 12, correlation results between the variables associated with the second research question (Do doctoral program characteristics affect doctoral student degree completion) and all participants are displayed. With this correlation, the researcher found that eight of the eleven variables demonstrated significance $(\mathrm{p}<.05)$. Department Satisfaction $(.292, \mathrm{p}<.05)$ was observed as a weaker positive correlation. Material Satisfaction $(.123, \mathrm{p}<.05)$ produced moderate correlation, indicating that doctoral students satisfaction with both the access and quality of research material created a positive correlation to doctoral degree completion. Social Involvement $(.147, \mathrm{p}<.05)$ also demonstrated a moderate correlation to completing the doctoral degree.

The variables of Dissertation Seminar $(-.159, \mathrm{p}<.05)$ and Dissertation Preparation Courses $(-.151, \mathrm{p}<.05)$ displayed a negative correlation, but due the structure of the questions (Yes $=1$, No $=2$ ), the negative results actually demonstrate a positive correlation with attending dissertation seminars or enrolling in dissertation preparation courses and completing the doctoral degree. The variable scales of Satisfaction of Clarity and Understanding of Program (.329, p <.05) and Satisfaction of Chair (.372, p <.05) both had a flat significance of .000 indicating low correlation. Finally, the variable of Doctoral Student Support Group (-.121, p <.05) displayed a negative correlation, but due to the structure of the questions (Yes $=1$, No $=2$ ), the negative results actually demonstrate a positive correlation with belonging to a doctoral student support group and completing the doctoral degree. 
Table 12

Correlations for Doctoral Degree Completion with all Variables

Addressed in Research Question Two for All Respondents

\begin{tabular}{lcc}
\hline Independent Variable & Pearson Correlation & Significance (2-tailed) \\
\hline Doctoral Student Orientation & -.094 & .127 \\
Department Satisfaction & .292 & $.000^{*}$ \\
Material Satisfaction & .123 & $.047^{*}$ \\
Social Involvement & .147 & $.018^{*}$ \\
Dissertation Seminar & -.159 & $.011^{*}$ \\
Dissertation Preparation Courses & -.151 & $.015^{*}$ \\
$\begin{array}{l}\text { Satisfaction of Clarity \& Understanding } \\
\text { of Program }\end{array}$ & .329 & $.000^{*}$ \\
Satisfaction of Chair & .372 & $.000^{*}$ \\
Satisfaction of Academic Involvement & .022 & .722 \\
Doctoral Student Support Group & -.121 & $.050^{*}$ \\
Mentor & -.080 & .197 \\
\hline
\end{tabular}

*Correlation is significant at the 0.05 level (2-tailed).

\section{Regression Analyses}

The study had two research questions that sought to determine the following: a)

Do certain doctoral student demographic variables affect doctoral student degree completion; and b) Do doctoral program characteristics affect doctoral student degree completion? Initially, logistic regression was conducted within each research question to determine which doctoral student demographic characteristics and which doctoral program characteristics were predictors of doctoral student degree completion (no doctoral degree completion, doctoral degree completion). Once the researcher determined which variables from the regression results of each research were significant $(p<.05)$, 
the remaining non-significant factors were removed for parsimony. The investigator then ran a logistic regression with only the remaining variables that demonstrated significance $(\mathrm{p}<.05)$ from both of the research question regressions and the Pearson correlations run earlier. The following discussion, based on and explanation of logistic regression outputs by Mertler and Vannatta (2005), included the following components of output: a) statistics of overall model fit, b) a classification table, and c) summary of model variables.

Mertler \& Vannatta, 2005 provide a detailed explanation of the statistics within these components of output:

Indices of overall logistic regression model fit consist of -2 Log Likelihood, Cox \& Snell $-\mathrm{R}^{\wedge}$ 2, Nagelkerke - $\mathrm{R}^{\wedge}$ 2. -2 Log Likelihood indicates the fit of the model to the data. Cox \& Snell $-\mathrm{R}^{\wedge} 2$ and Nagelkerke $-\mathrm{R}^{\wedge} 2$ correlate to estimates of $\mathrm{R}^{2}$ but they attempt to indicate the proportion of variability in the dependent variable that may be accounted for by all predictor variables included in the equation. The Classification Table applies the regression model to predicting group membership, then compares predictions to the actual subject values, and finally produces a calculation of subjects correctly classified. The Summary of model variables presents several statistics: a) $\beta$, b) S.E., c) Wald, d) $d f$, e) Sig., f) $R$, and g) $\operatorname{Exp}(\beta) . \beta$ represents the unstandardized regression coefficient and the effect the independent variable has on the dependent variable. S.E. represent the standard error of $\beta$. Wald represents the significance of each variable in its ability to contribute to the model. The summary table reports degrees of freedom $(d f)$ and level of significance (Sig.) for the Wald statistic. The partial correlation $(R)$ of each independent variable with the dependent variable is presented. $\operatorname{Exp}(\beta)$ is the final value presented in the summary table and calculates the odds ratio for each variable. The odds ratio represents the increase (or decrease if $\operatorname{Exp}(\beta)$ is less than 1 ) in the odds of being classified in a category when the predictor variable increases by 1. (pp. 319-320)

\section{Initial Logistic Regression for Research Questions}

The first research question sought to determine which student demographic characteristics (age, ethnicity, gender, financial support, employment, marital status, dependents, distance from campus, debt load, employment status change after 
comprehensive exams, and enrollment status) were predictors doctoral student degree completion (no doctoral degree completion, doctoral degree completion). The regression results indicated that the model had a moderate fit $(-2$ Log Likelihood $=234.959)$ and that the model explained $30 \%$ of the variance in doctoral degree completion (Cox \& Snell $\left.\mathrm{R}^{\wedge} 2=.300\right)$. The model correctly classified $73.8 \%$ of the cases.

Table 13 displays the summary of model variables from the logistic regression for question one and explains that only three of the variables were significant $(\mathrm{p}<.05)$. Based on the regression results, as the respondent increased in age, the odds of completing the doctoral degree increased $(\operatorname{Exp}(\beta)=1.052, \beta=.051, \mathrm{p}<.05)$. If a respondent changed job status after comprehensive exams, the results demonstrated a decreased chance of graduating $(\operatorname{Exp}(\beta)=.221, \beta=-1.508, \mathrm{p}<.05)$. By controlling for other variables, the regression revealed a suppressed relationship between enrollment status and doctoral degree completion $(\operatorname{Exp}(\beta)=1.990, \beta=.688, \mathrm{p}<.05)$. 
Table 13

Summary of Model Variables from Logistic Regression for Research Question One

Variables in the Equation

\begin{tabular}{|l|c|c|c|c|c|c|}
\hline & B & S.E. & Wald & Df & Sig. & Exp(B) \\
\hline Step $1^{\mathrm{a}}$ Age & .051 & .018 & 7.883 & 1 & .005 & 1.052 \\
White & .749 & .576 & 1.689 & 1 & .194 & 2.114 \\
Gender & -.442 & .349 & 1.608 & 1 & .205 & .643 \\
Fellowship & -.069 & .416 & .028 & 1 & .868 & .933 \\
Grant & .119 & .628 & .036 & 1 & .849 & 1.127 \\
Teaching Assistant & .030 & .485 & .004 & 1 & .950 & 1.031 \\
Research Assistant & -.605 & .456 & 1.761 & 1 & .184 & .546 \\
Other Assistantship & -.098 & .630 & .024 & 1 & .877 & .907 \\
Loans & -1.125 & .593 & 3.601 & 1 & .058 & .325 \\
Personal Savings & .603 & .391 & 2.385 & 1 & .123 & 1.828 \\
Personal Earnings & .266 & .396 & .450 & 1 & .502 & 1.304 \\
Family Earnings & -.706 & .449 & 2.471 & 1 & .116 & .494 \\
Employer Assistance & -.320 & .454 & .496 & 1 & .481 & .726 \\
Not Working & -.710 & 1.348 & .277 & 1 & .599 & .492 \\
Full-time Employment & 1.573 & 1.257 & 1.567 & 1 & .211 & 4.822 \\
Part-time Employment & .640 & 1.193 & .287 & 1 & .592 & 1.896 \\
Pursuing further study & 1.085 & 1.062 & 1.044 & 1 & .307 & 2.961 \\
Married & -.569 & .445 & 1.633 & 1 & .201 & .566 \\
Divorced & .386 & .620 & .386 & 1 & .534 & 1.470 \\
Number of Dependents & .020 & .153 & .018 & 1 & .895 & 1.020 \\
Miles to Campus & .006 & .003 & 2.558 & 1 & .110 & 1.006 \\
Debt Related to Doctorate & .017 & .087 & .037 & 1 & .848 & 1.017 \\
Job Change After Comps & -1.508 & .311 & 23.548 & 1 & .000 & .221 \\
Enrollment Status & .688 & .214 & 10.372 & 1 & .001 & 1.990 \\
Constant & -2.137 & 1.997 & 1.145 & 1 & .285 & .118 \\
\hline
\end{tabular}

a. Variable(s) entered on step 1: age, white, gender, fellowship, grant, teaching assistant, research assistant, other assistantship, loans, personal savings, personal earnings, family earnings, employer assistance, not working, full-time employment, part-time employment, pursuing further study, married, divorced, number of dependents, miles to campus, debt related to doctorate, job change after comps, enrollment status. 
The second research question sought to determine which program characteristics (graduate student orientation programs, departmental assistance, social involvement, dissertation preparation courses, dissertation preparation seminars, clarity and understanding of academic program procedures/requirements, dissertation chair contact, academic involvement, support groups, and mentoring) were predictors doctoral student degree completion (no doctoral degree completion, doctoral degree completion). The regression results indicated that the model had a moderate fit $(-2$ Log Likelihood $=$ 230.288) and that the model explained $22.3 \%$ of the variance in doctoral degree completion $\left(\right.$ Cox \& Snell $\left.-\mathrm{R}^{\wedge} 2=.223\right)$. The model correctly classified $72.5 \%$ of the cases.

Table 14 displays the summary of model variables from the logistic regression for research question two and explains that only two of the variables were significant ( $\mathrm{p}<$ .05). Based on the regression results, the higher the respondent was satisfied with the dissertation chair, the odds of completing the doctoral degree dramatically increased $(\operatorname{Exp}(\beta)=2.750, \beta=1.102, \mathrm{p}<.05)$. By controlling for other variables, the regression revealed a suppressed relationship between the respondents increased Satisfaction of Academic Involvement and a decreased odds of doctoral degree completion $(\operatorname{Exp}(\beta)=$ $.558, \beta=-.584, \mathrm{p}<.05)$ 
Table 14

Summary of Model Variables from Logistic Regression for Research Question Two

\begin{tabular}{|ll|c|c|c|c|c|c|}
\hline \multicolumn{1}{|c|}{ Variables in the Equation } \\
\hline${\text { Step } 1^{\mathrm{a}}}^{\mathrm{a}}$ & B & S.E. & Wald & Df & Sig. & Exp(B) \\
& Orientation Attendance & -.036 & .223 & .026 & 1 & .872 & .965 \\
Department Satisfaction & .074 & .346 & .045 & 1 & .831 & 1.076 \\
Material Satisfaction & -.083 & .124 & .451 & 1 & .502 & .920 \\
Social Involvement & -.033 & .239 & .019 & 1 & .889 & .967 \\
Attended Dissertation & -.479 & .396 & 1.463 & 1 & .226 & .619 \\
Preparation Seminar & & & & & & \\
Completed Dissertation & -.432 & .370 & 1.359 & 1 & .244 & .649 \\
Preparation Course & & & & & & \\
Satisfaction of Clarity and & .350 & .310 & 1.275 & 1 & .259 & 1.420 \\
Understanding of Program & & & & & & \\
Satisfaction of Chair & 1.012 & .304 & 11.086 & 1 & .001 & 2.750 \\
Satisfaction of Academic & -.584 & .213 & 7.546 & 1 & .006 & .558 \\
Involvement & & & & & & \\
Member of a Doctoral & -.510 & .527 & .938 & 1 & .333 & .600 \\
Support Group & & & & & & \\
Had a Mentor & .005 & .190 & .001 & 1 & .981 & 1.005 \\
Constant & 3.005 & 1.559 & 3.717 & 1 & .054 & 20.190 \\
\hline
\end{tabular}

a. Variable(s) entered on step 1: orientation attendance, department satisfaction, material satisfaction, social involvement, attended dissertation seminar, completed dissertation preparation course, satisfaction of clarity and understanding of program, satisfaction of chair, satisfaction of academic involvement, member of a doctoral support group, had a mentor.

\section{Logistic Regression for Only Significant Variables}

Once initial logistic regression was performed on the variables from each of the research questions, the researcher conducted a final logistic regression that utilized only variables that indicated significance $(\mathrm{p}<.05)$ from all the previous bivariate correlations and the two previous logistic regression results. The researcher used all indications of low significance in order to remove factors from the regression equation in order to provide 
parsimony. Logistic regression was conducted to determine which of the significant variables were predictors of doctoral student degree completion (no doctoral degree completion, doctoral degree completion). Table 15 displays several indices of overall model fit. The regression results indicated that the model had a moderate fit $(-2 \log$ Likelihood $=181.627)$ and that the model explained $36.8 \%$ of the variance in doctoral degree completion $\left(\right.$ Cox \& Snell $\left.-\mathrm{R}^{\wedge} 2=.368\right)$.

Table 15

Overall Logistic Regression Model Fit for All Significant Variables

Model Summary

\begin{tabular}{|l|c|c|c|}
\hline Step & $\begin{array}{c}-2 \text { Log } \\
\text { likelihood }\end{array}$ & $\begin{array}{c}\text { Cox \& Snell } \\
\text { R Square }\end{array}$ & Nagelkerke R Square \\
\hline 1 & $181.627^{\mathrm{a}}$ & .368 & .491 \\
\hline
\end{tabular}

a. Estimation terminated at iteration number 5 because parameter estimates changed by less than .001 .

Table 16 demonstrates that the model correctly classified $76.6 \%$ of the cases.

Table 16

Classification Table of Logistic Regression for All Significant Variables

\section{Classification Table ${ }^{\mathrm{a}}$}

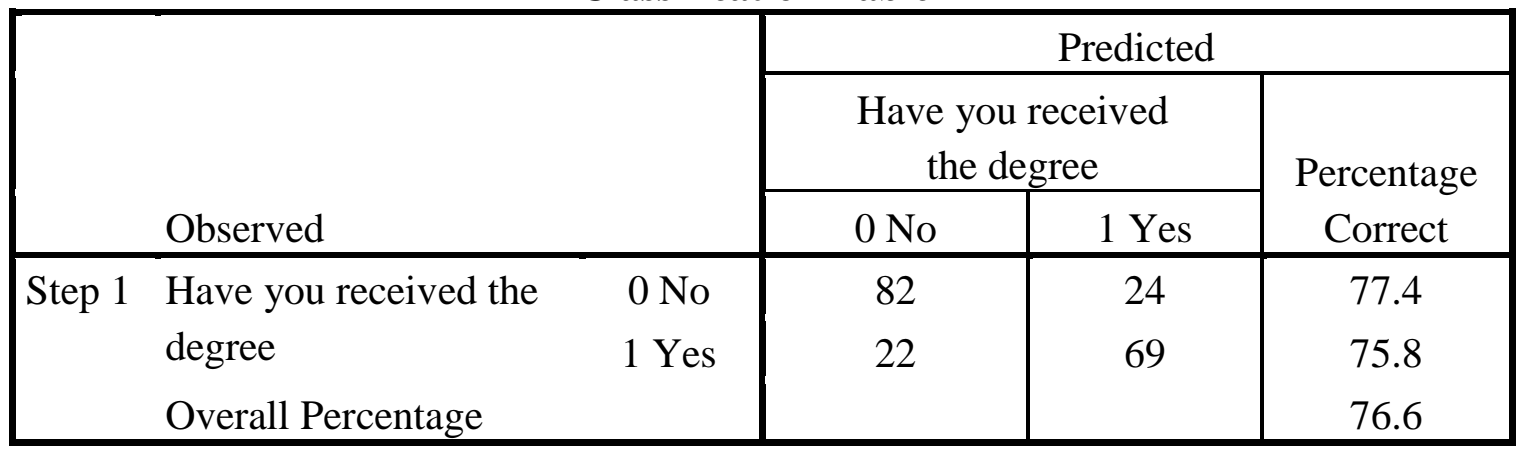

a. The cut value is .500 
Table 17 displays the summary of model variables from the logistic regression for all significant variables and explains that six of the variables were significant $(\mathrm{p}<.05)$. Based on the regression results, as the respondent increased in age, the odds of completing the doctoral degree increased $(\operatorname{Exp}(\beta)=1.043, \beta=.042, \mathrm{p}<.05)$. The results had a significant finding in that, if the respondent was employed full-time while pursuing the doctoral degree, the odds of completing the doctoral degree dramatically increased $(\operatorname{Exp}(\beta)=4.392, \beta=1.480, \mathrm{p}<.05)$. By controlling for other variables, the regression revealed a suppressed relationship between the fact if a respondent changed job status after comprehensive exams, the results demonstrated a decreased chance of graduating $(\operatorname{Exp}(\beta)=.218, \beta=-1.524, \mathrm{p}<.05)$. A minor finding concerning enrollment status was that there was a slight significance between enrollment status and doctoral degree completion $(\operatorname{Exp}(\beta)=1.694, \beta=.527, \mathrm{p}<.05)$. Based on the regression results, the higher the respondent was satisfied with the dissertation chair, the odds of completing the doctoral degree substantially increased $(\operatorname{Exp}(\beta)=3.012, \beta=1.103, \mathrm{p}<.05)$. By controlling for other variables, the regression revealed a suppressed relationship between the respondents increased satisfaction with academic involvement and a decreased odds of doctoral degree completion $(\operatorname{Exp}(\beta)=-.682, \beta=.527, \mathrm{p}<.05)$. 
Table 17

Summary of Model Variables from Logistic Regression for All Significant Variables

\begin{tabular}{|ll|c|c|c|c|c|c|}
\hline \multicolumn{8}{|c|}{ Variables in the Equation } \\
\hline${\text { Step } 1^{\mathrm{a}}}^{\mathrm{a}}$ Age & B & S.E. & Wald & Df & Sig. & Exp(B) \\
& Not working & .042 & .021 & 4.058 & 1 & .044 & 1.043 \\
Full-Time Employment & -1.078 & .810 & 1.770 & 1 & .183 & .340 \\
Job Change After Comps & 1.480 & .515 & 8.247 & 1 & .004 & 4.392 \\
Enrollment Status & -1.524 & .384 & 15.764 & 1 & .000 & .218 \\
Department Satisfaction & .527 & .195 & 7.321 & 1 & .007 & 1.694 \\
Material Satisfaction & .129 & .400 & .104 & 1 & .747 & 1.137 \\
Social Involvement & -.029 & .147 & .039 & 1 & .844 & .971 \\
Attended Dissertation & .255 & .296 & .740 & 1 & .390 & 1.290 \\
Preparation Seminar & -.572 & .474 & 1.459 & 1 & .227 & .564 \\
Completed Dissertation & & & & & & \\
Preparation Course & -.513 & .442 & 1.349 & 1 & .245 & .599 \\
Satisfaction of Clarity and & -.042 & .368 & .013 & 1 & .909 & .959 \\
Understanding of Program & & & & & & \\
Satisfaction of Chair & 1.103 & .345 & 10.211 & 1 & .001 & 3.012 \\
Satisfaction of Academic & -.682 & .267 & 6.498 & 1 & .011 & .506 \\
Involvement & & & & & & \\
Member of a Doctoral Support & -.648 & .573 & 1.276 & 1 & .259 & .523 \\
Group & & & & & & \\
Constant & 1.885 & 2.346 & .645 & 1 & .422 & 6.584 \\
\hline
\end{tabular}

a. Variable(s) entered on step 1: age, not working, full-time employment, job change after comps, enrollment status, department satisfaction, material satisfaction, social involvement, attended dissertation preparation seminar, completed a dissertation preparation course, satisfaction of clarity and understanding of program, satisfaction of chair, satisfaction of academic involvement, member of a doctoral support group.

\section{Summary}

The purpose of this study was to diagnose both individual student characteristics along with program characteristics that affect doctoral student degree completion. The primary research questions for this study sought to possibly predict: a) Do certain student 
demographic variables affect doctoral student degree completion; and b) Do program characteristics affect doctoral student degree completion?

The dependant variable was doctoral student degree completion (no doctoral degree completion, doctoral degree completion). The independent variables clustered around two broad categories: a) doctoral student characteristics (age, ethnicity, gender, financial support, employment, marital status, dependents, distance from campus, debt load, employment status change after comprehensive exams, and enrollment status); and b) doctoral program characteristics (graduate student orientation programs, departmental assistance, social involvement, dissertation preparation courses, dissertation preparation seminars, clarity and understanding of academic program procedures/requirements, dissertation chair contact, academic involvement, support groups, and mentoring).

The results of the data were analyzed using logistic regression to determine if individual student characteristics and program characteristics influenced doctoral degree completion. The researcher also utilized Pearson Correlations and produced descriptive statistics. Based on the logistic regression results, a statistically significant relationship existed between the independent variables of age, full-time employment, employment change after comprehensive exams, enrollment status, satisfaction with dissertation chair, satisfaction with academic and involvement and the dependent variable doctoral degree completion, Further discussion of the data and conclusions are presented in the following chapter. 


\section{CHAPTER V \\ DISCUSSION AND CONCLUSIONS}

Introduction

This study sought to ascertain doctoral student experiences from their pursuit of a doctoral degree in order to possibly identify individual student characteristics along with program characteristics that may affect doctoral degree completion. This chapter provides a synopsis of the study completed, a discussion of the research questions, discussion of additional research findings, and suggestions for further research. The implications of the research findings are included for each of the research questions.

Summary of the Study

This study collected data on doctoral student experiences with doctoral education. Specifically, students were asked to identify their experiences at the individual and program level of their pursuit of a doctoral degree. Subjects were doctoral students enrolled from 1997-2003 at the University of Kentucky and the University of Louisville. Data was gathered through an online survey. Participants provided demographic data and responded to survey questions about their experiences with doctoral education. The survey was based primarily on the previous work of Vincent Tinto and his survey designed for the National Science Foundation (NSF) called the Doctoral Studies Questionnaire along with a nationally vetted instrument called the Survey of Earned Doctorates. 
Two primary research questions guided this study: a) Do certain student demographic variables affect doctoral student degree completion; and b) Do program characteristics affect doctoral student degree completion? A series of logistic regression analyses were employed to answer the research questions. Logistic regression was utilized since the dependent variable of doctoral degree completion is a dichotomous variable and therefore categorizes a subject in one of two groups (no doctoral degree completion, doctoral degree completion). The first logistic regression equation included independent variables centered on individual student characteristics in an attempt to predict the occurrence of the dependent variable of doctoral degree completion. The second logistic regression equation included independent variables centered on program characteristics in an attempt to predict the occurrence of the dependent variable of doctoral degree completion. Based on variables found to be significant from the Pearson Correlations and the first two logistic regressions, the researcher employed a third logistic regression equation in an attempt to predict the occurrence of the dependent variable of doctoral degree completion.

\section{Discussions and Implications}

\section{Research Question One}

The first research question asked, "Do certain student demographic variables (age, ethnicity, gender, financial support, employment, marital status, dependents, distance from campus, debt load, employment status change after comprehensive exams, and enrollment status) affect doctoral student degree completion?" Directional hypotheses, tested at the .05 level of significance, guided the analysis to answer the question.

$\mathrm{H} 1_{\mathrm{a}}$ : Students who are employed full-time will be less likely to complete the doctoral degree. 
$\mathrm{H} 2_{\mathrm{a}}$ : Students who experience an employment status change after comprehensive exams will be less likely to complete the doctoral degree.

$\mathrm{H} 3_{\mathrm{a}}$ : Students who are enrolled part-time will be less likely to complete the doctoral degree.

Contrary to the assertion of the hypothesis, the regression revealed a highly

significant result in that if a respondent was employed full-time while pursuing a doctoral degree, they were significantly more likely to complete a doctoral degree $(\operatorname{Exp}(\beta)=$ $4.392, \beta=1.480, \mathrm{p}<.05)$. If a respondent changed employment status after comprehensive exams, the results confirmed the hypothesis by demonstrating a decreased chance of graduating $(\operatorname{Exp}(\beta)=.218, \beta=-1.524, \mathrm{p}<.05)$. Based on the regression results and confirming the hypothesis, enrollment status $(\operatorname{Exp}(\beta)=1.694, \beta=.527, \mathrm{p}<.05)$ positively influenced the odds of completing the doctoral degree. Independent of the hypotheses, the regression results also indicated that an increase in respondent age $(\operatorname{Exp}(\beta)=1.043, \beta=.042, \mathrm{p}<.05)$ positively influenced the odds of completing the doctoral degree

\section{Research Question Two}

The second research question asked, "Do program characteristics (graduate student orientation programs, departmental assistance, social involvement, dissertation preparation courses, dissertation preparation seminars, clarity and understanding of academic program procedures/requirements, dissertation chair contact, academic involvement, support groups, and mentoring) affect doctoral student degree completion?" Directional hypotheses, tested at the .05 level of significance, guided the analysis to answer the question. 
$\mathrm{H} 4_{\mathrm{a}}$ : Students who are satisfied with the departmental assistance available will be more likely to complete the doctoral degree.

H5 : Students who are satisfied with the opportunity for social involvement during their doctoral degree will be more likely to complete the doctoral degree.

H6: Students who are satisfied with the clarity and understanding of academic procedures/requirements within their program will be more likely to complete the doctoral degree.

$\mathrm{H7}_{\mathrm{a}}$ : Students who are satisfied with the dissertation chair contact will be more likely to complete the doctoral degree.

$\mathrm{H} 8 \mathrm{a}$ : Students who are satisfied with the opportunities for academic involvement within their program will be more likely to complete the doctoral degree.

The regression results lacked a high enough level of significance to either confirm

or deny the hypotheses centered on the variables of departmental assistance, social involvement, and clarity and understanding of academic procedures/requirements. Based on the regression results, increased respondent satisfaction with the dissertation chair confirmed the hypothesis by demonstrating that the odds of completing the doctoral degree dramatically increased with the higher level of satisfaction with the dissertation chair $(\operatorname{Exp}(\beta)=3.012, \beta=1.103, \mathrm{p}<.05)$. If a respondent demonstrated an increased satisfaction with academic involvement, the results did not support the hypothesis and conversely demonstrated a decreased chance of graduating $(\operatorname{Exp}(\beta)=.506, \beta=-.682, \mathrm{p}$ $<.05)$.

\section{Additional Findings}

Correlation results between all the variables associated with the first and second research questions and all participants were run prior to the logistic regressions. Within the confines of the first research question, the researcher found that four of the twentyfive variables demonstrated significance $(\mathrm{p}<.05)$. The variable Age $(.153, \mathrm{p}<.05)$ 
demonstrated a positive correlation, whereas Employed Full-Time $(.174, \mathrm{p}<.05)$ demonstrated significance with a positive correlation to completing the degree. A surprising result was that Not Working $(-.149, \mathrm{p}<.05)$ produced a negative correlation to completing the degree, along with Employment Status Change After Comprehensive Exam $(-.363, \mathrm{p}<.05)$

Within the confines of the second research question, the researcher found that eight of the eleven variables demonstrated significance $(p<.05)$. The variables of Satisfaction With Clarity and Understanding of Program $(.329, \mathrm{p}<.05)$ and Satisfaction With Dissertation Chair $(.372, \mathrm{p}<.05)$ both had a flat significance of .000 indicating low correlation. The following variables had slight to moderate positive correlations: Department Satisfaction (.292, $\mathrm{p}<.05)$, Material Satisfaction $(.123, \mathrm{p}<.05)$, Social Involvement $(.147, \mathrm{p}<.05)$. Although, the variables of Dissertation Seminar $(-.159, \mathrm{p}$ $<.05)$, Doctoral Student Support Group (-.121, $\mathrm{p}<.05)$, and Dissertation Preparation Courses $(-.151, \mathrm{p}<.05)$ displayed a negative correlation, due the structure of the questions ( Yes $=1$, No $=2$ ), the negative results actually demonstrated a positive correlation with completing the doctoral degree.

\section{Discussion and Implications}

The findings of the current research could provide important opportunities for doctoral programs to adjust the structure and the culture experienced by doctoral students. Policies within departments are designed to provide certain experiences, opportunity, and learning desired by the department. The actual practice of carrying out the departmental policies affects the individual and group experiences that both students and faculty encounter throughout a doctoral program. 


\section{Implications to Policy}

Doctoral programs should consider the implications of higher degree completion among older students and part-time enrollment status when considering composition of incoming cohorts of doctoral students and the structure of the coursework offered and the pattern of doctoral student enrollment status. When creating the course scheduling and offerings, doctoral programs could focus on course times and structures that would better appeal to older part-time enrolled students. Although most programs employ a multitude of evening coursework, the structuring of a single day that offers two courses in one evening may better appeal to students. Starting the first course in the late afternoon, followed by a small dinner break and then offering the second course in that same evening allows students to devote only one night a week to class, yet attend two courses. This block scheduling could be an attractive alternative in course scheduling. Weekend coursework and distance education coursework can also allow for varied opportunities for students to attend either only on select weekends throughout a semester or at the convenience of their home through the use of an online format. Simply working to offer these varied methods of scheduling may serve to remove impediments to efficiently completing the coursework component of the doctoral degree.

With age demonstrating a strong relationship with degree completion, it would behoove doctoral programs to integrate admissions practices and services that accommodate older students. The composition of the graduate students at both the University of Kentucky and the University of Louisville included an average age of just over 43. The composition also included a high majority of student employed full-time and a majority of students enrolled part-time. Therefore, it is obvious that the need is not 
only to plan for future students of an older age, but the current student population already represents a higher range of ages and would be well served by policies and services designed for their needs. A needs assessment of the current population could serve as a direct opportunity to understand what this population may desire to best succeed. Once these needs are understood, a program could then better serve the current students and the future incoming students that will most likely be represented by an older, full-time employed, and part-time enrolled composition.

Doctoral programs and incoming doctoral students should consider the implications of higher degree completion among students satisfied with their dissertation chair. Careful planning and consideration of selecting a dissertation chair in the early stages of a doctoral program could be facilitated by the program itself and could be designed to fit into the structure and the culture of the doctoral program. The better a student is informed of the interests and research of faculty the better a student can select a chair that aligns to their research interest and therefore have a stronger opportunity for higher dissertation chair satisfaction.

The correlation results of positive influence of degree completion when students complete either dissertation coursework or attend dissertation seminars could be important policy opportunities for doctoral programs. The dissertation is an exercise in independent research by a student who more than likely is an inexperienced researcher at best. Once the student is admitted to candidacy and begins the research component of the degree, a high majority of the structure, previously provided through the coursework phase, disappears. Doctoral programs could provide coursework that is focused on practicing the methods of dissertation writing. The more a student is exposed to 
structures, examples, and opportunities to begin guided work on the dissertation, the more prepared the student will be to complete the daunting task of overcoming the ABD status and completing the doctoral degree. Seminars or programs offered through the department on dissertation writing could also serve as both motivation and a tool to better equip a student with the ability to complete the doctoral degree.

\section{Implications to Practice}

Doctoral programs should consider the implications of higher degree completion among students employed full-time while pursuing a doctoral degree. This result would seem to go against a common perception that the more a student works, the less time that student has to complete a doctoral degree and therefore leading to a higher attrition rate. For the purposes of this study, Table 4 indicates the high majority of respondents worked full-time while pursuing their doctoral studies (73.6\%). While the results must be considered with caution since only a minority of the respondents were employed parttime, this may indicate a profile of a student that demonstrates a strong motivation, organization, and structure to complete a doctoral degree while remaining employed fulltime.

Doctoral student completion may increase if program advisers and dissertation chairs consider cautioning against, if at all possible, an employment status change after completing comprehensive exams. Many individuals within a doctoral program endure the needed commitment of the degree plan in order to eventually create future career opportunities. The fact of this desire is not lost on the researcher. Once students complete the comprehensive exams and enter into candidacy, the road to completion becomes an unstructured path of independent research. It is at this point, where a student needs 
further goal commitment and focus on the research requirement. Opportunities for promotion and new career roles can also become available due to the achievement of $\mathrm{ABD}$ status. It is at this point where the practice and guidance of faculty, staff, and mentors can serve to remind the student that beginning a new career opportunity can severely siphon away time, focus, and commitment to completing the degree. Any new professional role will require a stronger investment in time and energy to adjust and perform to the desired level. The results of this study can be used by programs to demonstrate this negative effect on degree completion and caution against changing employment status after completing the comprehensive exams.

Doctoral student completion may increase if program advisers and dissertation chairs consider recommending a part-time enrollment status. Yet conversely, doctoral programs should not shy away from those students employed full-time that desire to pursue a terminal degree. Tinto (1993) explained, "Individuals whose educational and career goals are such as to require the completion of a doctorate are more likely to finish than other persons whose goals are not so linked" (p. 239). This result of full-time employment status indicating higher degree completion is an implication that should be considered by doctoral students contemplating the start of a doctoral degree and doctoral programs when considering composition incoming cohorts of doctoral students and the structure of the coursework offered to accommodate doctoral student employment status.

The indication that doctoral student completion may decrease if respondents indicated higher satisfaction with academic involvement is a peculiar finding. This may be interpreted that possibly the student's focus and attention on the dissertation may be getting distracted due to other research interests within the department. It also may 
explain that over involvement, over commitment of non-required activities and research can sideline completion. Those students that take on too many volunteer research projects, attend a myriad of conferences, and simply take on too many things not connected to completing the coursework and dissertation, are inviting opportunities and excuses to reduce their focus on completing the doctoral degree. Tinto's theory on doctoral attrition seems to focus on the building of communities both socially and academically. The faculty, staff, and mentor community the student builds could serve as a cautionary force in the area and help reign the student's extracurricular activities in to a manageable amount.

\section{Limitations}

This study gathered data for only two institutions within the state if Kentucky and only included a specific time period of enrollment between the years of 1997-2003. Limiting the sample to only a specified 6-year time period does not encompass the entire population of doctoral students that have enrolled at any time period in the history of the institutions and selecting only two institutions in the state of Kentucky may not allow results to be generalized to other institutions across the United States. The study eliminated students pursuing a professional degree in the areas of Law, Medicine, Pharmacy, and Dentistry. The participants completed the survey online, and while the online environment provides for greater access to a population at a lower cost, it reduces the ability of the researcher to control the conditions in which the survey is administered. Finally, the response rate of the survey population was only $8.7 \%$, therefore interpretation of the results must be heeded with caution. 


\section{Suggestions for Future Research}

During the design, administration, and analysis of this study, questions arose which may provide opportunities for improvement and new streams of research in future studies. Future research could replicate this study using a different scope of population and even different states within the U.S. to determine if outcomes might be similar. Future research may include a measurement of how individual student academic attributes (GRE, GPA) that occur prior to the start of the program, affect the variable of doctoral degree completion. Based on the low response rate of this study, future studies may include provisions and resources to allow for more and varied methods for follow-up and reminder to the survey population in order to positively increase response rate. Along similar lines with response rate, future research may utilize institutional Alumni Associations in order to more precisely collect accurate data and follow up with participants. Cooperation with institutional Alumni Associations can help to clean up initial address information provided from the initial student enrollment at the university, based on the most recent address and activity the student may have engaged in with Alumni events and giving history.

Within this study, there was no analysis at the academic discipline level. Future studies could add research questions and analysis to determine the effect certain types of academic disciplines have on doctoral degree completion. The current study included only a 6-year window of doctoral enrollment from 1997-2003 in order to highlight the Higher Education reform occurring in the state of Kentucky. Expanding this study to include multiple decades of enrolled doctoral students may yield different and possibly 
more robust results on the effect of individual student characteristics and program characteristics on doctoral degree completion.

Also connected to higher education reform in the state of Kentucky, this study focused on only the University of Kentucky and the University of Louisville. More recent developments in the landscape of higher education in Kentucky have created the atmosphere in which other universities have developed doctoral programs. Therefore, further research could replicate this study at these institutions with newly developed doctoral programs. Based on a stream of research called survival analysis, a fruitful stream of future research could attempt to ascertain when and how long it took for doctoral students to pass through certain components of a doctoral degree (residency, completion of coursework, passing of comprehensive exams, admission into candidacy, and finally dissertation defense/doctoral degree completion). This research could assist in developing a way to assess stop out data of students at various points within the program and allow departments to actually collect this data to inform practice \& policy.

In order to try and understand student and faculty perceptions, future research may include a student ranking of the common reasons for attrition along with a faculty ranking of the common reasons for attrition and then a correlation of the two rankings. An important concern within doctoral programs that does not seem to be measured in research, but could have a strong impact on students would be for future research to include a variable that measures the impact on students when faculty leave the program. Faculty leaving could affect many components of a student's progress and satisfaction and would be an interesting variable to better understand. 
Results from this research study indicated a possible positive relationship exists between students employed full-time and successful completion of the doctoral degree. Future research could focus in on the variable of employment status in order to determine the effects and issues surrounding employment status and degree completion. Finally, some of the intricacies of individual motivations, barriers, relationships, and overall personal stories are not found within the statistical nature of quantitative research. Therefore, future research with this population, using a qualitative nature of inquiry, could discover the detail and insight on the personal nature of attrition /persistence. Bringing to light the qualitative reasons behind attrition/persistence could add to the depth and understanding of the quantitative data found in this study.

Conclusion

More than a decade after the state of Kentucky enacted higher education reform that provided specific direction to the University of Kentucky and the University of Louisville, this research study sought to examine the relationship between individual doctoral student characteristics and doctoral program characteristics and doctoral degree completion. A survey, developed by the researcher, based primarily on the previous work of Vincent Tinto and his survey designed for the National Science Foundation (NSF) called the Doctoral Studies Questionnaire along with a nationally vetted instrument called the Survey of Earned Doctorates was administered to all doctoral students enrolled from 1997-2003 at the University of Kentucky and the University of Louisville.

Pearson Correlations found that age, full-time employment, satisfaction with clarity and understanding academic program procedures/requirements, satisfaction with dissertation chair, department satisfaction, material satisfaction, social involvement, 
doctoral student support group, dissertation preparation courses, dissertation preparation seminars have positive correlations with doctoral degree completion The researcher found that not working and employment status change after comprehensive exams produced a negative correlation with doctoral degree completion.

Results from the logistic regression analysis suggested that $36.8 \%$ of variance in doctoral degree completion can be explained with the regression model. Analyses found that enrollment status of the doctoral student and the increase of age of the respondent may have a positive influence on doctoral degree completion. Conversely employment status change after comprehensive exams and increased satisfaction with academic involvement indicated a negative relationship with doctoral degree completion. Finally, the variables of increased satisfaction with the dissertation chair and full-time employment of the respondents produced significant positive relationships with doctoral degree completion.

Further research is suggested to expand on the results of this study. University officials at the University of Kentucky and the University of Louisville should consider the implications of providing the structure within doctoral programs that will accommodate individual doctoral student characteristics that lead to successful doctoral degree completion. 


\section{REFERENCES}

Abedi, J., \& Benkin, E. (1987). The effects of students' academic, financial, and demographic variables on time to the doctorate. Research in Higher Education, 27, 3-14.

Astin, A. (1997). How "good" is your institution's retention rate? Research in Higher Education, 38, 647-658.

Austin, A. E. (2002). Preparing the next generation of faculty: Graduate school as socialization to the academic career. Journal of Higher Education, 73, 94-122.

Bair, C. R., \& Haworth, J. G. (1999, November). Doctoral student attrition and persistence: A meta-synthesis of research. Paper presented at the annual meeting of the Association for the Study of Higher Education, San Antonio, TX.

Baker, H. K. (1992). Service needs of traditional age and adult graduate students. NASPA Journal, 30, 20-29.

Barker, S., Felstehausen, G., Couch, S., \& Henry, J. (1997). Orientation programs for older and delayed-entry graduate students. NASPA Journal, 35, 57-68.

Bauer, E.R. (2004). An examination of the effect of departmental factors on student completion of doctoral requirements. Unpublished doctoral dissertation, University of Massachusetts Boston. MA.

Berg, H. M., \& Ferber, M. A. (1983). Men and women graduate students: Who succeeds and why? Journal of Higher Education, 54, 629-648.

Berry, M. D. (1993). Perceptions of educational administration professors about factors which affect doctoral attrition. Unpublished doctoral dissertation, New Mexico State University, Las Cruces.

Boyle, P., \& Boice, B. (1998). Best practices for enculturation: Collegiality, mentoring, and structure. New Directions for Higher Education, 101, 87-94.

Bowen, W. G., \& Rudenstine, N. L. (1992). In pursuit of the Ph.D. Princeton, NJ: Princeton University Press. 
Brown-Wright, D. A., Dubick, R. A., \& Newman, I. (1997). Graduate assistant expectation and faculty perception: Implications for mentoring and training. Journal of College Student Development, 38, 410-416.

Campbell, R. (1992). A study of the completion and non-completion of the doctor of education degree in educational leadership at the University of Delaware. Unpublished doctoral dissertation, University of Delaware, Newark.

Cesari, J. P. (1990). Thesis and dissertation support groups: A unique service for graduate students. Journal of College Student Development, 31, 375-378.

Cheatham, T. R., Edwards, J. R., \& Erickson, K. V. (1982). The doctoral dissertation in Speech Communication: An inventory of attitudes and experiences. Communication Education, 31, 315-323.

Cook, M. M., \& Swanson, A. (1978). The interaction of student and program variables for the purpose of developing a model for predicting graduation from graduate programs over a 10-year period. Research in Higher Education, 8, 83-91.

Cooke, D. K., Sims, R. L., \& Peyrefitte, J. (1995). The relationship between graduate student attitudes and attrition. Journal of Psychology, 129, 677-688.

Corcoran, M., \& Clark, S. M. (1984). Professional socialization and contemporary career attitudes of three faculty generations. Research in Higher Education, 20, 131-153.

Costello, A. B., \& Osborne, J. W. (2005, July). Best practices in exploratory factor analysis: Four recommendations for getting the most from your analysis. Practical Assessment, Research \& Evaluation, 10(7), 1-9.

Coulter, F. W., Goin, R. P., \& Gerard, J. M. (2004). Assessing graduate students' needs: The role of graduate student organizations. Educational Research Quarterly, $28(1), 15-26$.

Cuetara, J., \& LeCapitaine, J. (1991). The relationship between dissertation writing experiences and doctoral training environments. Education, 112, 233-241.

Cusworth, S. (2001, August). Orientation and retention of counseling PhD students: A qualitative study. Paper presented at the 109th Annual Conference of the American Psychological Association, San Francisco.

de Valero, Y. F. (2001). Departmental factors affecting time-to-degree and completion rates of doctoral students at one land-grant research institution. Journal of Higher Education, 72, 341-367.

Dillman, D. A. (2000). Mail and internet surveys: The tailored design method (2nd ed.). New York: John Wiley \& Sons, Inc. 
Dillman, D. A., Smyth, J. D., \& Christian, L. M. (2009). Internet, mail, and mixed-mode surveys: The tailored design method (3rd ed.). Hoboken, NJ: John Wiley \& Sons, Inc.

Dorn, S. M., \& Papalewis, R. (1995). Educators earning their doctorates: Doctoral student perceptions regarding cohesiveness and persistence. Education, 116, 305314.

Dorn, S. M., \& Papalewis, R. (1997, March). Improving doctoral student retention. Paper presented at the annual meeting of the American Educational Research Association, Chicago, IL.

Ehrenberg, R. G., \& Mavros, P. G. (1995). Do doctoral students' financial support patterns affect their times-to-degree and completion probabilities? Journal of Human Resources, 30, 581-609.

Emerson, J. (1998). An investigation of the characteristics that facilitate or impede completion of inquiry, a nontraditionally organized doctoral program in Educational Administration. Unpublished doctoral dissertation, Columbia University, New York.

Ethington, C. A., \& Smart, J. C. (1986). Persistence to graduate education. Research in Higher Education, 24, 287-303.

Forney, D. S., \& Davis, T. L. (2002). Ongoing transition sessions for student affairs master's students. Journal of College Student Development, 43, 288-293.

Germeroth, D. (1991). Lonely days and lonely nights: Completing the doctoral dissertation. ACA Bulletin, 76, 60-89.

Gilliam, J. C., \& Kritsonis, W. A. (2006). National implications: The hidden nature of doctoral student attrition. National Journal for Publishing and Mentoring Doctoral Student Research, 3(1), 1-7.

Gillingham, L., Seneca, J. J., \& Taussig, M. K. (1991). The determinants of progress to the doctoral degree. Research in Higher Education, 32, 449-468.

Glatthorn, A. A., \& Joyner, R. L. (2005). Writing the winning thesis of dissertation: A step-by-step guide (2nd ed.). Thousand Oaks, CA: Corwin Press.

Globetti, E., Globetti, G., \& Smith, R. E. (1991). An assessment of goals and perceived needs of graduate students: Some implications. College Student Affairs Journal, $10(3), 41-53$. 
Golde, C. M. (1994, November). Student descriptions of the doctoral student attrition process. Paper presented at the annual meeting of the Association for the Study of Higher Education, Tucson, AZ.

Golde, C. M. (1996). How departmental contextual factors shape doctoral student attrition. Unpublished doctoral dissertation, Stanford University, Palo Alto, CA.

Golde, C. M. (1998). Beginning graduate school: Explaining first-year doctoral attrition. New Directions for Higher Education, 101, 55-64.

Golde, C. M. (2000). Should I stay or should I go? Student descriptions of the doctoral attrition process. Review of Higher Education, 23, 199-227.

Golde, C. M. (2005). The role of the department and discipline on doctoral student attrition: Lessons from four departments. Journal of Higher Education, 76, 669700 .

Golde, C. M., \& Dore, T. M. (2001). At cross purposes: What the experiences of today's doctoral students reveal about doctoral education. Philadelphia: Pew Charitable Trusts.

Goplerud, E. N. (1980). Social support and stress during the first year of graduate school. Professional Psychology, 11, 283-289.

Gottlieb, D. (1961). Process of socialization in American graduate schools. Social Forces, 40, 124-131.

Green, K. E., \& Kluever, R. C. (1997, March). The dissertation barriers scale. Paper presented at the annual meeting of the American Educational Association, Chicago.

Hahs, D. L. (1998, November). Creating "good” graduate students: A model for success. Paper presented at the meeting of the Mid-South Educational Research Association, New Orleans.

Hatley, R. V., \& Fiene, J. R. (1995, April). Enhancing doctoral student progress and improving dissertation quality: A success scenario. Paper presented at the annual meeting of the American Educational Research Association, San Francisco.

Heiss, A. M. (1967). Berkeley doctoral students appraise their academic programs. Educational Record, 30-44.

Hodgson, C. S., \& Simoni, J. M. (1995). Graduate student academic and psychological functioning. Journal of College Student Development, 36, 244-253. 
Huck, S. W. (2008). Reading statistics and research (5th ed.). Boston: Pearson Education, Inc.

Huguley, S. (1988). An investigation of obstacles to completion of the dissertation and of doctoral student attitudes toward the dissertation experience. Unpublished doctoral dissertation, Pepperdine University, Malibu, CA.

Isaac, P. D., Quinlan, S. V., \& Walker, M. M. (1992). Faculty perceptions of the doctoral dissertation. Journal of Higher Education, 63, 241-268.

Jacks, P., Chubin, D. E., Porter, A. L., \& Connolly, T. (1983). The ABCs of ABDs: A study of incomplete doctorates. Improving College and University Teaching, 31(2), 74-83.

Kelly, S., \& Schweitzer, J.H. (1999). Mentoring within a graduate school setting. College Student Journal, 33, 130-149.

Kezar, A. J. (Ed.). (2001). Socialization of graduate and professional students in higher education: A perilous passage. 28(3), San Francisco: Jossey-Bass.

King, S. E., \& Chepyator-Thompson, J. R. (1996). Factors affecting the enrollment and persistence of African-American doctoral students. Physical Educator, 53, 170180.

Kluever, R. C. (1997). Students' attitudes toward the responsibilities and barriers in doctoral study. New Directions in Higher Education, 99, 47-56.

Kluever, R. C., \& Green, K. E. (1998). The responsibility scale: A research note on dissertation completion. Educational and Psychological Management, 58, 520531.

Kluever, R. C., Green, K. E., \& Katz, E. (1997, March). Dissertation completers and non-completers: An analysis of psycho-social variables. Paper presented at the annual meeting of the American Research Association, Chicago.

Kuh, G. D., \& Thomas, M. L. (1983). The use of adult development theory with graduate students. Journal of College Student Personnel, 24, 12-19.

Lampley, J. (2001). Service quality in higher education: Expectations versus experiences of doctoral students. College and University, 77(2), 9-14.

Lawson, T. J., \& Fuehrer, A. (1989). The role of social support in moderating the stress that first-year graduate students experience. Education, 110, 186-193. 
Leadabrand, J. A. (1985). Doctoral candidate persistence in community and human resources: A replication of the Pascarella and Terenzini studies based on Tinto's concept. Unpublished doctoral dissertation, The University of Nebraska-Lincoln, Lincoln.

Lee, B. (2003). Factors affecting non-completion of doctoral degrees as evidenced by students labeled all but the dissertation $(A B D)$. Unpublished doctoral dissertation, Tennessee State University, Nashville.

Leppel, K. (2002). Similarities and differences in the college persistence of men and women. Review of Higher Education, 25, 433-450.

Lovitts, B. E. (2004). Research on the structure and process of graduate education. In D. H. Wulff \& A. E. Austin (Eds.), Paths to the professoriate: Strategies for entering the preparation of future faculty (pp. 115-136). San Francisco: Jossey-Bass.

Lovitts, B. E., \& Nelson, C. (2000). The hidden crisis in graduate education: Attrition from Ph.D. programs. Academe, 86(6), 44-51.

Lunneborg, C. E., \& Lunneborg, P. W. (1973). Doctoral study attrition in Psychology. Research in Higher Education, 1, 379-383.

Malmberg, E. (2000). Retention and attrition of doctoral candidates in higher education. Unpublished doctoral dissertation, University of North Texas, Denton.

McDavis, R. J., Molden, I. T., \& Wilson, S. R. (1989). Summer programs: A method for retaining black graduate students. Journal of College Student Development, 30, 272-274.

McGuinness, Jr., Aims, C. (Ed.). (2002, October). An assessment of postsecondary education reform in Kentucky (Submitted to The Prichard Committee for Academic Excellence). (Available from the National Center for Higher Education Management Systems, P.O. Box 9752, Boulder, Colorado 80301-9752). Retrieved October 10, 2009, from Kentucky Council on Postsecondary Education website: http://cpe.ky.gov/planning/legislation/

Mertler, C. A., \& Charles, C. M. (2005). Introduction to educational research (5th ed.). Boston: Pearson Education, Inc.

Mertler, C. A., \& Vannatta, R. A. (2005). Advanced and multivariate statistical methods: Practical application and interpretation (3rd ed.). Glendale, CA: Pyrczak Publishing. 
Morris, M. (2007). Sisters in the struggle: Individual and institutional factors affecting the persistence of black, female, doctoral students at U.S. predominantly white institutions. Unpublished doctoral dissertation, University of Massachusetts, Amherst.

Myers, L. H. (1999). Barriers to completion of the doctoral degree in educational administration. Unpublished doctoral dissertation, Virginia Polytechnic Institute and State University, Blacksburg.

Nerad, M., \& Miller, D. S. (1996). Increasing student retention in graduate and professional programs. New Directions for Institutional Research, 92, 61-76.

Nyquist, J. D., Manning, L., Wulff, D. H., Austin, A. E., Sprague, J., Fraser, P. K., et al. (1999). On the road to becoming a professor: The graduate student experience. Change, 31(3), 18-27.

Ott, M. D., \& Markewich, T. S. (1985, April). Logit analysis of graduate student retention and graduation. Paper presented at the annual forum of the Association for Institutional Research, Portland, OR.

Pascarella, E. T. (1986, March). A program for research and policy development on student persistence at the institutional level. Journal of College Student Personnel, , 100-107.

Pascarella, E. T., \& Terenzini, P. T. (1979). Interaction effects in Spady's and Tinto's conceptual models of college dropout. Sociology of Education, 52, 197-210.

Pattison, S. A. (2003-2004). The effect of an orientation on distance-program satisfaction. Journal of College Student Retention, 5, 205-233.

Patton, P. E. (1997, March). An Agenda for the $21^{\text {st }}$ Century: A plan for postsecondary education. Retrieved October 10, 2009, from Kentucky Council on Postsecondary Education website: http://cpe.ky.gov/planning/legislation/

Pauley, R. (1998). A study of factors relating to the attrition from West Virginia University-Marshall University-West Virginia Graduate College Cooperative Doctoral Program administered by the West Virginia Board of Trustees. Unpublished doctoral dissertation, West Virginia University, Morgantown.

Polson, C. J. (2003). Adult graduate students challenge institutions to change. New Directions for Student Services, 102, 59-68.

Pontius, J. L., \& Harper, S. R. (2006). Principles for good practice in graduate and professional student engagement. New Directions for Student Services, 115, 4758. 
Poock, M. (2001). A model for integrating professional development in graduate education. The College Student Journal, 35, 345-355.

Poock, M. C. (2002). Graduate student orientation: Assessing needs and methods of delivery. Journal of College Student Development, 43, 231-245.

Poock, M. C. (2004). Graduate student orientation practices: Results from a national survey. NASPA Journal, 41, 470-486.

Poock, M. C., \& Love, P. G. (2001). Factors influencing the program choice of doctoral students in higher education administration. NASPA Journal, 39, 203-223.

Rimmer, S. M., Lammert, M., \& McClain, P. (1982). An assessment of graduate student needs. College Student Journal, 16, 187-192.

Rosenblatt, H. S., \& Christensen, C. (1993). "Welcome to the whole family": A graduate student orientation. College Student Journal, 27, 502-505.

Seagram, B. C., Gould, J., \& Pyke, S. W. (1998). An investigation of gender and other variables on time to completion of doctoral degrees. Research in Higher Education, 39, 319-335.

Sheridan, P. M., \& Pyke, S. W. (1994). Predictors of time to completion of graduate degrees. Canadian Journal of Higher Education, 24(2), 68-88.

Sigafus, B. (1998, April). The creation of ABDs: A turning point in educational doctoral programs? Paper presented at the annual meeting of the American Educational Research Association, San Diego.

Stallone, M. N. (2003). Factors associated with student attrition and retention in an educational leadership doctoral program. Unpublished doctoral dissertation, Texas A\&M University-Kingsville and Texas A\&M University-Corpus Christi, Kingsville.

State of Kentucky Task Force on Postsecondary Education. (1997, March).

Postsecondary education: An assessment report to the task force on postsecondary education of 1997. Retrieved October 10, 2009, from Kentucky Council on Postsecondary Education website: http://cpe.ky.gov/planning/legislation/assessmentrep1997.htm

Tabachnick, B. G., \& Fidell, L. S. (2007). Using multivariate statistics (5th ed.). Boston: Allyn \& Bacon.

Taub, D., \& Komives, S. R. (1998). A comprehensive graduate orientation program: Practicing what we preach. Journal of College Student Development, 39, 394-398. 
Tinto, V. (1975). Dropout from higher education: A theoretical synthesis of recent research. Review of Educational Research, 46, 89-125.

Tinto, V. (1993). Leaving college: Rethinking the causes and cures of student attrition (2nd ed.). Chicago: University of Chicago Press.

Tinto, V. (1997). Classrooms as communities: Exploring the educational character of student persistence. Journal of Higher Education, 68, 599-623.

Titley, B. S. (1985). Orientation programs. In U. Delworth \& G. R. Hanson (Eds.), Increasing student retention (pp. 221-243). San Francisco: Jossey-Bass.

Upton, G., \& Cook, I. (2006). A dictionary of statistics (2nd ed.). New York: Oxford University Press.

Vlisides, D., \& Eddy, L. (1993). Graduate student orientation models. College Student Journal, 27, 96-98.

Vogt, W. P. (2005). Dictionary of statistics \& methodology: A nontechnical guide for the social sciences (3rd ed.). Thousand Oaks, CA: Sage.

Wagner, D. V. (1986). Selected personality characteristics and situational factors as correlates of completion and non-completion of the doctoral dissertation. Unpublished doctoral dissertation, University of Michigan, Ann Arbor.

Webb, M. S., Njoku, B. P., \& Allen, L. C. (1996). Doctoral students' perceptions of institutional and program quality. College and University, 71(3), 11-17.

Weidman, J. C., \& Stein, E. L. (2003). Socialization of doctoral students to academic norms. Research in Higher Education, 44, 641-652.

Weidman, J. C., Twale, D. J., \& Stein, E. L. (2001). Socialization of graduate and professional students in higher education: A perilous passage? ASHE-ERIC Higher Education Report, 28. Jossey-Bass, San Francisco.

White, L. L., Jr. (1986). A descriptive analysis of student attrition in the Florida State University and the University of West Florida Cooperative Doctoral External Degree Program. Unpublished doctoral dissertation, Florida State University, Tallahassee.

Winston, R. B. (1976). Graduate school environments: Expectations and perceptions. Journal of College Student Personnel, 17, 43-49.

Wood, D. J. (1978). Internal and external indicators of attrition in the college of education doctoral program at the University of Toledo from 1962 through 1976. Unpublished doctoral dissertation, University of Toledo, Toledo, $\mathrm{OH}$. 
Wright, L. M. (1991). Full-time teaching and the ABD phenomenon. ACA Bulletin, 76, 49-55.

Wynn, R. E. (2003). Derailment in doctoral students in educational leadership programs: A study of high-risk doctoral dissertation pitfalls. Unpublished doctoral dissertation, University of North Carolina at Greensboro, Greensboro. 


\section{APPENDIX A}

\section{DOCTORAL STUDENT EXPERIENCES QUESTIONNAIRE}

Dear Student,

You are being invited to participate in a research study by answering the attached survey about your experiences throughout your doctoral studies. There are no known risks for your participation in this research study. The information collected may not benefit you directly. The information learned in this study may be helpful to others. The information you provide will enable faculty and administrators to better understand aspects of the doctoral experience that both assist and prevent doctoral degree completion from the student perspective. Your completed survey will be stored in a password-protected file on a DVD. The survey will take approximately 15-20 minutes to complete.

Individuals from the Department of Education Leadership, Foundations, and Human Resource Development at U of L, Department of Educational Administration, Leadership, and Research at WKU, the Institutional Review Board (IRB), the Human Subjects Protection Program Office (HSPPO), the WKU Human Subjects Review Board (HSRB), and other regulatory agencies may inspect these records. In all other respects, however, the data will be held in confidence to the extent permitted by law. Should the data be published, your identity will not be disclosed.

Taking part in this study is voluntary. By completing this survey you agree to take part in this research study. You do not have to answer any questions that make you uncomfortable. You may choose not to take part at all. If you decide to be in this study you may stop taking part at any time. If you decide not to be in this study or if you stop taking part at any time, you will not lose any benefits for which you may qualify.

If you have any questions about your rights as a research subject, you may call the Human Subjects Protection Program Office at (502) 852-5188 or the WKU Compliance Manager at (270) 745-2129. You can discuss any questions about your rights as a research subject, in private, with a member of the Louisville Institutional Review Board (IRB) or WKU Human Subjects Review Board (HSRB). You may also call these numbers if you have other questions about the research, and you cannot reach the research staff, or want to talk to someone else. The IRB is an independent committee made up of people from the University community, staff of the institutions, as well as people from the community not connected with these institutions.

The IRB and HSRB has reviewed this research study. If you have concerns or complaints about the research or research staff and you do not wish to give your name, you may call 1-877-8521167. This is a 24 hour hot line answered by people who do not work at the University of Louisville or Western Kentucky University.

If you have any questions, concerns, or complaints about the research study, please contact: Dr. J. R. Fiene at 270-745-2942.

Sincerely,

J. R. Fiene

Glenn A.Gittings 


\section{Section A - BACKGROUND INFORMATION}

What is your current age?

Age (in years):

What is your gender? (check appropriate category)

$\square$ Male

$\square$ Female

How do you describe your primary ethnicity? (check all that apply)

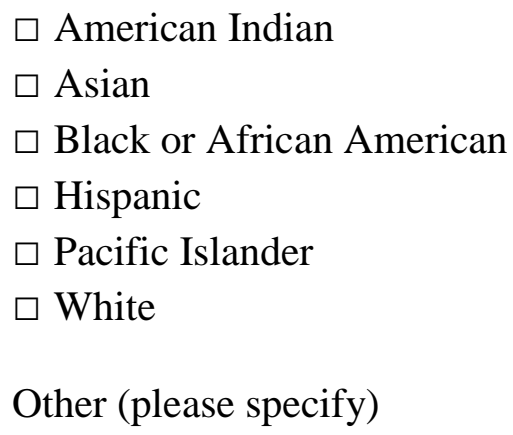

$\square$ Hispanic

$\square$ Pacific Islander

Other (please specify)

$\square$ White

When you began study at your university, were you? (check one):

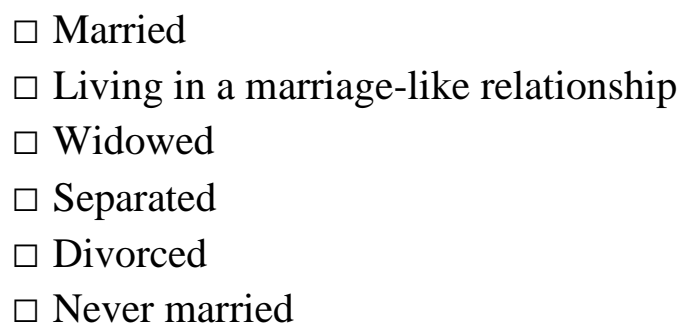

Not including yourself or spouse/partner, how many dependents (children or adults) do you have - that is, how many others receive at least one half of their financial support from you?

Type number of dependents: 
What is your current employment status? (Check all that apply)

$\square$ Not in labor force

$\square$ Employed (full-time)

$\square$ Employed (part-time)

$\square$ Pursuing further studies (i.e. postdoctoral research, other degree)

Other (please specify) 


\section{Section B - EDUCATION INFORMATION}

When did you begin your doctoral studies at your university?

Month (MM)

Year (YYYY)

At what university did you begin your doctoral studies?

Please select one:

$\square$ University of Kentucky

$\square$ University of Louisville

Please name the department (or interdisciplinary committee, center, institute, etc.) of the university that supervised your doctoral studies.

Have you received your doctoral degree?

$\square$ Yes

$\square$ No 


\section{Section B - IF DEGREE YES}

If you have completed your doctoral degree, when was the degree granted?

Month (MM)

Year (YYYY) 


\section{Section B - IF DEGREE NO}

If you have not completed your doctoral degree, how far have you progressed toward the completion of your doctoral degree at your university? (check one)

$\square$ Still pursuing doctoral degree

$\square$ Left doctoral studies during coursework

$\square$ Left doctoral studies after finishing comps but before completing proposal

$\square$ Finished comps, but not yet defended dissertation proposal

$\square$ Defended proposal and still working toward doctoral degree

If you discontinued your doctoral program, why did you leave doctoral studies at your university? Please rate each of the following statements:

\begin{tabular}{|c|c|c|c|}
\hline $\begin{array}{l}\text { Not at all } \\
\text { Important } \\
\text { important }\end{array}$ & $\begin{array}{l}\text { Of little } \\
\text { importance }\end{array}$ & Neutral & Important \\
\hline
\end{tabular}

Could not afford

to continue studies

Found doctoral studies

too difficult

Demands on my family

Demands on my job

Program not to my liking

Disappointed with

quality of program

Could not get approval

for dissertation topic

Could not find the resources to complete

my dissertation

Program did not fit my career goals

Change in career 


\section{Section B - CONTINUED}

During your doctoral studies, how would you primarily classify your enrollment?

$\square$ Mostly part-time (below 9 hours)

$\square$ Mostly full-time (9 hours or more)

$\square$ All part-time (below 9 hours)

$\square$ All full-time (9 hours or more)

Did you attend orientation programs sponsored by the university/department/program?

$\square$ Yes

$\square$ Orientation not available

$\square$ No 


\section{Section B - IF ORIENTATION YES}

If yes, were the orientation programs effective in helping you to adjust to your doctoral studies

$\square$ Not at all Effective

$\square$ Somewhat Not Effective

$\square$ Neutral

$\square$ Effective

$\square$ Very Effective 


\section{Section B - CONTINUED}

If you received full or partial tuition remission (waiver) for your doctoral studies, was it: (check one)

I did not receive any tuition remission

$\square$ For less than $1 / 3$ of tuition

$\square$ Between $1 / 3$ and $2 / 3$ of tuition

$\square$ More than $2 / 3$ tuition, but less than full

$\square$ Full tuition remission

Which of the following were sources of financial support received during the pursuit of your doctoral degree? Check all that apply:

$\square$ Fellowship, scholarship

$\square$ Grant

$\square$ Teaching assistantship

$\square$ Research assistantship

$\square$ Other assistantship

$\square$ Traineeship

$\square$ Internship, clinical residency

$\square$ Loans (from any source)

$\square$ Personal savings

$\square$ Personal earning during grad school(other than sources listed above)

$\square$ Spouse's, partner's, or family's earnings or savings

$\square$ Employer reimbursement/assistance

When you receive your doctoral degree, how much money will you owe, that is directly related to your doctoral education?

$\square$ None

$\square \$ 10,000$ or less

$\square \$ 10,001-\$ 20,000$

$\square \$ 20,001-\$ 30,000$

$\square \$ 30,001-\$ 40,000$

$\square \$ 40,001-\$ 50,000$

$\square \$ 50,001-\$ 60,000$

$\square \$ 60,001$ - $\$ 70,000$

$\$ 70,001$ or more (please specify): 
During the majority of your doctoral program, approximately how far (in miles) did you commute to your university?

Miles to the university

After you completed the qualifying and comprehensive examinations for your doctorate, did your employment status change?

$\square$ Yes

$\square$ No

$\square$ Not yet completed qualifying and comprehensive examinations

Were you employed during your doctoral studies?

$\square$ Yes

$\square$ No 


\section{Section B - IF WORK YES}

\section{How did working affect your doctoral studies?}

$\square$ It made progress very difficult

$\square$ It made progress somewhat difficult

$\square$ It made no difference in progress

$\square$ It made progress somewhat easy

$\square$ It made progress very easy 


\section{Section C - DOCTORAL STUDENT EXPERIENCES}

As you look back over your doctoral studies, how satisfied have you been with each of the following statements concerning departmental assistance? Please rate each of the following statements:

$\begin{array}{lllll}\text { Very } & \text { Dissatisfied } & \text { Neutral } & \text { Satisfied } & \text { Very } \\ \text { dissatisfied } & & & \\ \text { satisfied } & & & \end{array}$

Faculty availability

in your program

Access to research

materials

Quality of research material

Departmental advising

Support from staff

of department

Support from faculty

of department 
Indicate your level of agreement or disagreement with each of the following statements on social involvement during your doctoral studies.

Please rate each of the following statements:

$\begin{array}{llll}\begin{array}{l}\text { Strongly } \\ \text { disagree }\end{array} & \text { Disagree } & \text { Neutral Agree } & \begin{array}{l}\text { Strongly } \\ \text { disagree }\end{array}\end{array}$

It was/has been

easy for me to

make friends with

other students

It was/is easy to

develop personal

relationships with

faculty members

on this campus

There was/is a lot of

contact between

faculty and students

outside of the classroom

There was/is a strong

sense of community

among students in

my program

It was/has been easy

to maintain

relationships with

peers

There was/is

opportunity for

involvement in

graduate campus

organizations

There was/is

opportunity for

involvement in

recreational

campus activities

or organizations 
Overall how satisfied have you been with the clarity and understanding of your academic program components in each of the areas noted below?

Please rate each of the following statements:

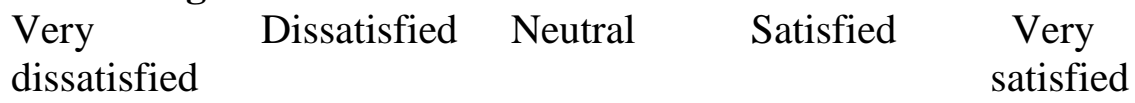

Availability of

courses

Information about

program requirements

Departmental advising

Preparation for

comprehensives

Information about

financial aid

Overall how satisfied have you been with the interaction you have had with your dissertation chair in the areas noted below?

Please rate each of the following statements:

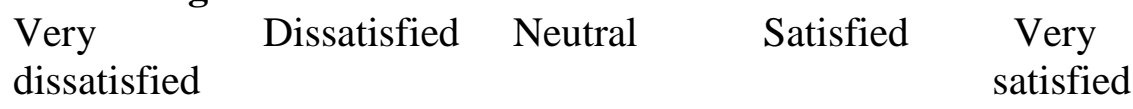

Selection of

dissertation topic

Selection of

dissertation committee

Preparation of

proposal

Dissertation research

Dissertation writing

Accessibility of

dissertation chair

Mark X here if you do not yet have a dissertation committee: 
Overall how satisfied have you been with the opportunity you have had for academic involvement within your doctoral program in the areas noted below? Please rate each of the following statements:

$\begin{array}{lllll}\begin{array}{l}\text { Very } \\ \text { dissatisfied }\end{array} & \text { Dissatisfied } & \text { Neutral } & \text { Satisfied } & \begin{array}{c}\text { Very } \\ \text { satisfied }\end{array}\end{array}$

Presentation of research at department seminars or colloquium

Opportunity to attend national scholarly meetings or conferences

Opportunity to deliver papers or present at national scholarly meetings or conferences

Opportunity to publish articles or notes in professional publications 


\section{Section D - SUPPORT RECEIVED}

Do you have a mentor? (A mentor is defined as a guide or counselor who provides personal support)

$\square$ Yes

$\square$ Yes, but not at the University

$\square$ No 


\section{Section D - IF MENTOR YES}

\section{How long did it take you to locate the mentor? (Check one)}

$\square$ I located someone before entering the program

$\square$ I located someone within the first term of my doctoral study

$\square$ I located someone within my first year of my doctoral study

$\square$ I located someone within the first two years of my doctoral study

$\square$ It took me longer than two years to locate a mentor

\section{Is that person? (check one)}

$\square$ My faculty advisor

$\square$ My dissertation chair

$\square$ A faculty member other than my advisor or chair

$\square$ A staff member or administrator

$\square$ A person outside of the university 


\section{Section D - CONTINUED}

Do you participate in a doctoral student support group?

$\square$ Yes

$\square$ No 


\section{Section D - IF SUPPORT GROUPS YES}

Is that support group made up of? (check all that apply)

$\square$ Peers in my program

$\square$ Peers of the same gender

$\square$ Peers of the same ethnicity

$\square$ Other (please specify):

How important has that support group been to your doctoral studies?

$\square$ Not at all Important

$\square$ Somewhat Not Important

$\square$ Neutral

$\square$ Somewhat Important

$\square$ Very important 


\section{Section D - CONTINUED}

Did you attend department seminars or workshops focused on dissertation preparation assistance as part of your doctoral studies?

$\square$ Yes

$\square$ No

Did you enroll in coursework focused on dissertation preparation assistance as part of your doctoral studies?

$\square$ Yes

$\square$ No

You are finished with the survey. THANK YOU! 


\title{
UK KENTUCKY
}

July 31,2009

\author{
Official Records Custodian \\ 301 Main Building \\ Lexington, KY 40506-0032 \\ $859257-6366$ \\ fax $859323-1062$ \\ www.uky.edu
}

Glenn A. Gittings

Coordinator of Admissions \& Alumni Outreach

University of Louisville

Via email: glenn.gittings@louisville.edu

Dear Mr. Gittings:

This is a follow-up to my letter to you of July 20,2009. Please find attached hereto a spreadsheet generated by Data Administration that includes any and all possible addresses in our files for doctoral students from 1993 to 2005 . The address information includes permanent and current (or local) addresses at the time these individuals were students here. Be advised that this address information is not updated and may not be current.

There is no charge to you for the attached database.

Sincerely yours,

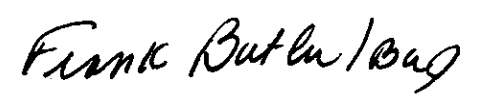

Frank Butler

Official Records Custodian

$\mathrm{km}$ 


\begin{abstract}
APPENDIX C
-Original message-

Subject: Doctoral Students Names and Addresses 1997-2003 (6033)20090806.xls

Date: 8/27/2009 9:02 AM

From: "Jonathan P Borden" <jpbord01@ louisville.edu>

To: <glenn.gittings@louisville.edu>
\end{abstract}

Hi Glenn,

I'm an institutional analyst in the Department of Institutional Research \& Planning at the University of Louisville. I have prepared an excel spreadsheet that answer your request for doctoral student names and address from 1997-2003. I have included students who I do not have addresses for in the system of which there are a little over 100. Since it is my understanding that you will be coordinating with the alumni office I thought you might want these. Most of the 100 are foreign students. In addition, this report does not represent the total population of doctoral students. I had to remove about 500 names due to the students request that their information not be given out under the terms of the Federal Education Rights Privacy Act (FERPA). Furthermore, there are occasional duplicate names such as line 911 and 912 in the spreadsheet. While these are rare, if we have duplicate student id's for a student I couldn't cull them out.

Please let me know if you have any questions.

Thanks,

Jonathan P. Borden

Institutional Research Analyst

Institutional Research \& Planning

Office of Academic Planning and Accountability

University of Louisville

MITC 305

Louisville, Kentucky 40292

Phone: (502) 852-2363

Fax: (502) 852-2344

http://louisville.edu/institutionalresearch

Please submit all data requests at: http://louisville.edu/institutionalresearch/datainformation-request-form

The information contained in this message, and in any accompanying documents, constitutes confidential information which belongs to Institutional Research and Planning in the Office of Academic Planning and Accountability at the University of Louisville. This information is intended only for the use of the individual or entity named above. If you are not the intended recipient of this information, you are hereby notified that any disclosure, copying, distribution, or the taking of action in reliance on this information, is strictly prohibited. If you have received this message in error, please immediately notify us by telephone, at the number listed above. Thank you. 
APPENDIX D
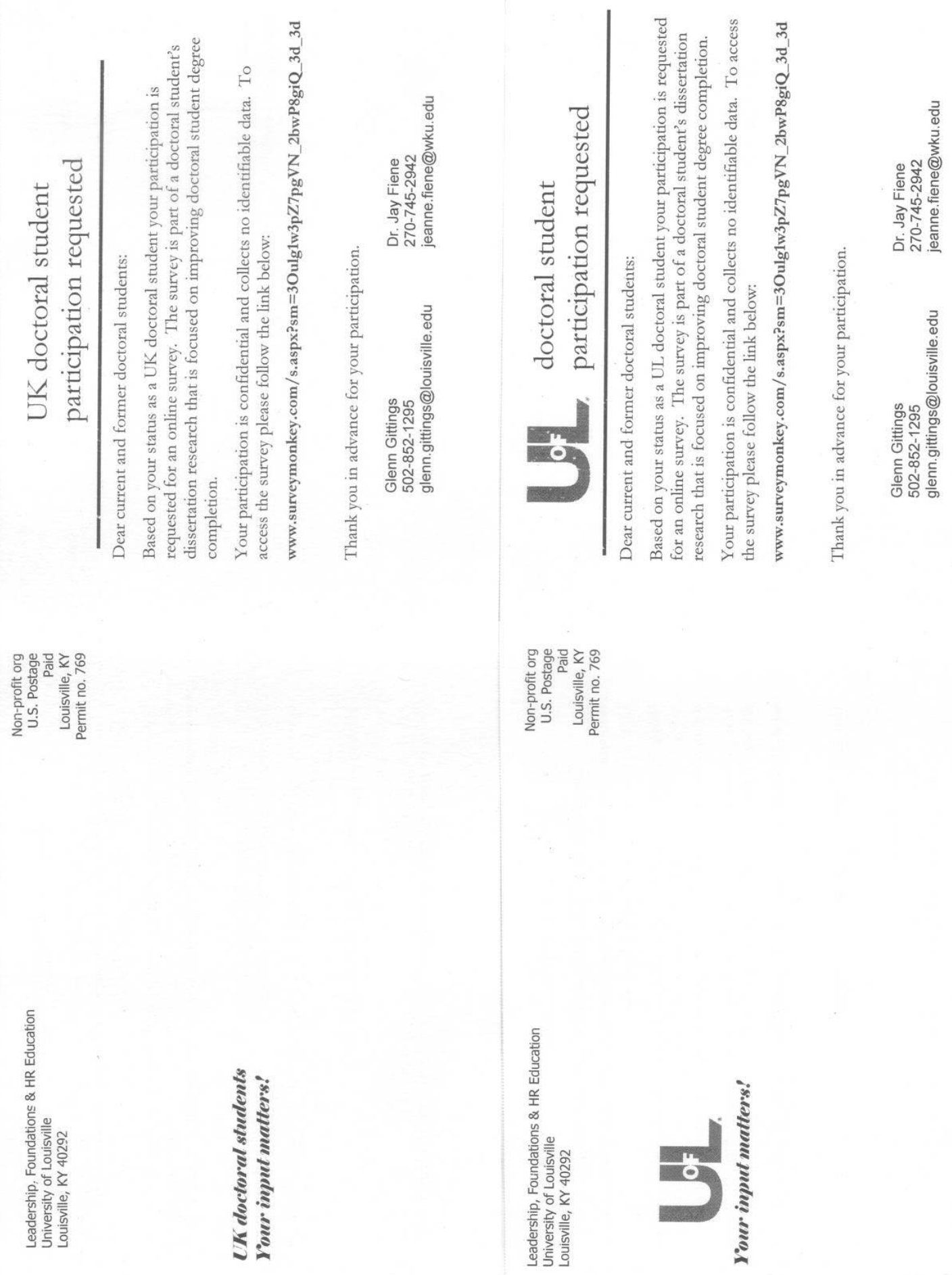

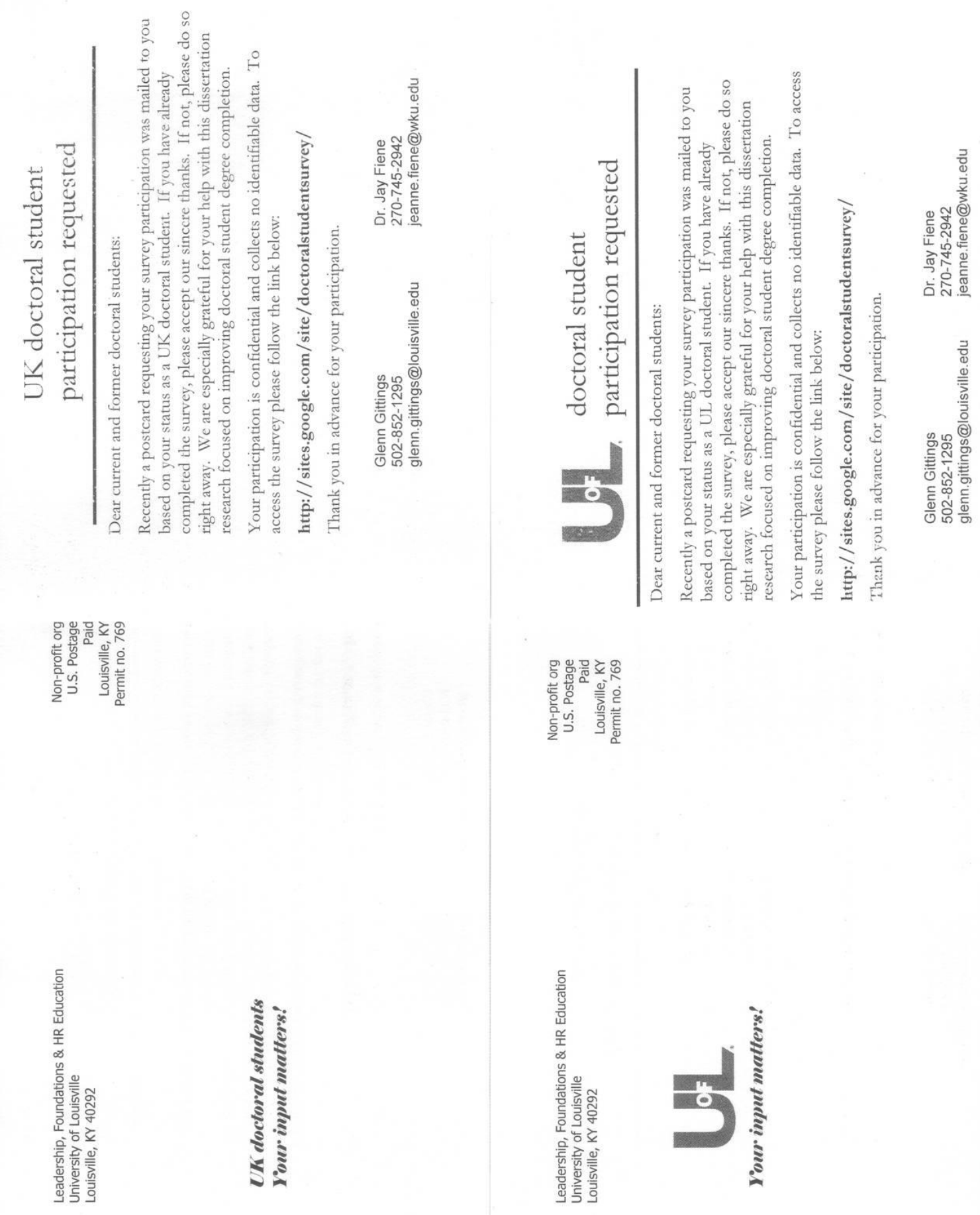


\section{APPENDIX E}

\section{角 \\ WKU。}

A LEADING AMERICAN UNIVERSITY WITH INTERNATIONAL REACH HUMAN SUBJECTS REVIEW BOARD

In future correspondence, please refer to HS10-004, July 6, 2009

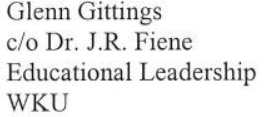

Glenn Gittings

\& Dr. J.R. Fiene:

Your revision to the research project, Doctoral Student Experiences Questionnaire, was reviewed by the HSRB and it has been determined that risks to subjects are: (1) minimized and reasonable; and that (2) research procedures are consistent with a sound research design and do not expose the subjects to unnecessary risk. Reviewers determined that: (1) benefits to subjects are considered along with the importance of the topic and that outcomes are reasonable; (2) selection of subjects is equitable; and (3) the purposes of the research and the research setting is amenable to subjects' welfare and producing desired outcomes; that indications of coercion or prejudice are absent, and that participation is clearly voluntary.

1. In addition, the IRB found that you need to orient participants as follows: (1) signed informed consent is not required; (2) Provision is made for collecting, using and storing data in a manner that protects the safety and privacy of the subjects and the confidentiality of the data. (3) Appropriate safeguards are included to protect the rights and welfare of the subjects.

\section{This project is therefore approved at the Exempt Review Level.}

2. Please note that the institution is not responsible for any actions regarding this protocol before approval. If you expand the project at a later date to use other instruments please re-apply. Copies of your request for human subjects review, your application, and this approval, are maintained in the Office of Sponsored Programs at the above address. Please report any changes to this approved protocol to this office. A Continuing Review protocol will be sent to you in the future to determine the status of the project. Also, please use the stamped approval forms to assure participants of compliance with The Office of Human Research Protections regulations.
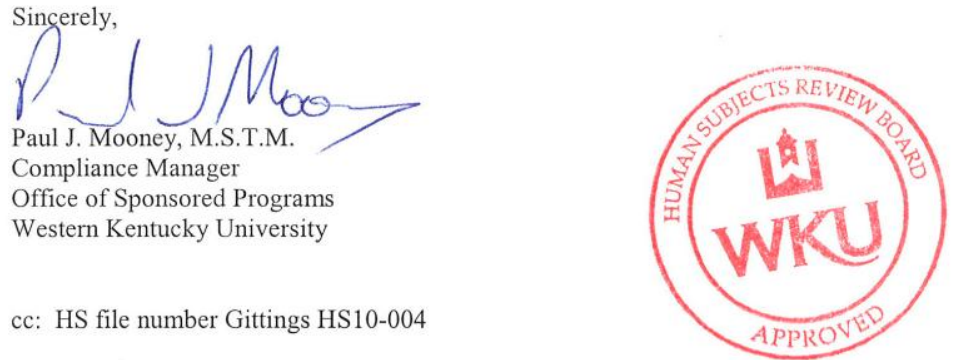

The Spirit Makes the Master:

Office of Sponsored Programs | Western Kentucky University | 1906 College Heights Blvd. \#11026 | Bowling Green, KY 42101-1026 phone: 270.745.4652 | fax: 270.745.4211 | e-mail: paul.mooney@wku.edu | web: http://ored.wku.edu/Research_Compliance/Human_Subjects/

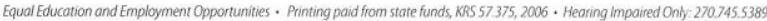




\section{APPENDIX F}

Original message

Subject: BRAAN2: IRB Protocol Marked as Exempt

Date: 6/23/2009 11:51 AM

From: <InstitutionalReviewBoard@louisville.edu>

To: <glenn.gittings@louisville.edu>, <jeanne.fiene@wku.edu >

The following IRB Protocol has been marked as Exempt.

Tracking \#: 09.0307

PI: Fiene, Jeanne

Title: DOCTORAL STUDENT EXPERIENCES QUESTIONAIRRE

Link to BRAAN2 Login 〈https://braanprod.louisville.edu/>

Help is available at the BRAAN2 Help Site

<http://louisville.edu/research/braan2>

For additional assistance please call the Human Subjects Protection

Program at 502-852-5188. 


\section{CURRICULUM VITAE}

\section{Glenn Allen Gittings \\ 8705 Lantern Lite Parkway \\ Louisville, KY 40220 \\ (502) 415-2767}

glenngittings@gmail.com

\section{EDUCATION}

SKILLS

$\begin{array}{ll}\text { University of Louisville } & \text { Louisville, KY } \\ \text { Ph.D. Educational Leadership and } & \text { May 2010 } \\ \text { Organizational Development } & \end{array}$

Western Kentucky University

Bowling Green, KY

M.A.E. Student Affairs in Higher Education

May 2002

University of Louisville

Louisville, KY

B.A. Liberal Studies concentration in

May 2000

Sociology, Psychology, \& Engineering

Interpersonal: Strong initiative, task oriented, mission driven, excellent verbal and written communication

Computer: $\quad$ PeopleSoft, SCT Banner, Raiser's Edge 7.0, Adobe PageMaker, Microsoft Office, Adobe Photoshop, MS

Publisher, PageBuilder 2.6

\section{WORK EXPERIENCE}

7/08-Present

Coordinator of Admissions \& Alumni Outreach

University of Louisville

Louisville, KY

- Advised and counseled prospective students and parents.

- Coordinated and facilitated 15 outreach events throughout Fall and Spring semesters for prospective students designed to expand the base of students interested in UofL.

- Supervised professional Admissions Staff.

- Served as liaison with the Alumni Office for Alumni Scholarship Programs and worked to integrate UofL alumni into recruitment events and recruitment efforts throughout the state of KY.

- Reviewed and adjudicated undergraduate applications for admissions, managed student records, and ran queries within the university database (PeopleSoft). 
Admissions Counselor

Western Kentucky University

Bowling Green, KY

- Developed and implemented recruitment and retention strategies for all markets, including high school seniors, transfer students, GED graduates, and adult learners.

- Integral part of a staff that grew enrollment by more than $20 \%$ over the 5 years of employment as WKU has become the fastest growing public university in Kentucky.

- Coordinated and facilitated Bowling Green Regional College Fair which invited more than 1,000 high school students and nearly 100 colleges, universities, and organizations.

- Organized and managed WKU prospective student open house in Louisville.

- Assisted with editing, proofing, and layout of recruitment publication materials.

- Managed and updated student records within the university database (SCT Banner).

University Experience Instructor - Fall 2004 - Spring 2006

Western Kentucky University

Bowling Green, KY

- Taught University Experience course, which assisted in the freshman year transition and acclimation to college for new students.

- Instructed and incorporated lectures, speakers, and assignments to promote stronger student social and academic integration into the

6/02-9/03 university and the community.

Development Manager

Junior Achievement of Kentuckiana

Louisville, KY

- Coordinated annual fundraising campaign, which included: donor solicitation and cultivation, donor research, donor identification, new donor prospecting, grant writing.

- Integral component of a staff that identified, cultivated, solicited, and stewarded philanthropic gifts for a successful \$5.5 million Capital Campaign.

- Identified, cultivated, solicited, stewarded philanthropic gifts $(\$ 1,000$ $\$ 10,000$ level).

- Developed and standardized a systematic Direct Mail \& Telemarketing Campaign.

- Re-designed company website utilizing MS Windows based website editing software.

- Assisted in planning and facilitation of multiple special events, which included: event planning, solicitation of sponsorships, event management, and post event evaluation. 
Alumni Relations and Annual Giving Intern

Western Kentucky University, Office of Alumni Relations, Annual Giving Bowling Green, KY

- Integral part of a staff of 9 that raised \$3.2 million and conducted 225 alumni events.

- Managed Affinity Merchandise which included: product marketing, sales and accounting, giveaway items, and corporate partnerships.

- Attended and participated in Alumni Club and Chapter events which included: Event planning, volunteer recruitment, event management, and post event evaluation.

\section{PROFESSIONAL DEVELOPMENT}

- Phi Kappa Phi Honors Society.

- Omicron Delta Kappa Honors Society.

- Committee Member, KASCAC Annual Calendar Committee - Kentucky Association of Secondary and College Admissions Counselors (KASCAC).

- Committee Chair, 2007 New Admissions Professionals Workshop Committee- Kentucky Association of College Registrars and Admissions Officers (KACRAO).

\section{PRESENTATIONS/PUBLICATIONS}

- Gittings, G. A. (2006, May). The Leader in You. KASA Hotline, 36(8), 2.

- Higher Education and the Business Model, Co-Presented with Dr. Aaron Hughey at the Conference of the College Professionals of Kentucky, Louisville, KY, 2001.

\section{AWARDS}

- Brooke McElwain Scholarship, 2001-2002 WKU.

- Outstanding Graduate Student in Student Affairs, 2001-2002 WKU.

- Council for Advancement and Support of Education (CASE) District III Student Delegate Scholarship, 2002 WKU. 